\title{
Digital Retaliation? Denial-of-Service Attacks After
}

\section{Sanction Events}

\author{
Philipp M. Lutscher* \\ University of Oslo \& University of Konstanz \\ Conditionally accepted in the Journal of Global Security Studies \\ January 7, 2021
}

\begin{abstract}
Conventional wisdom expects to see a rise in cyber activities around aggressive foreign policy events. In this article, I test this claim by investigating whether sanctions lead to an increase in DoS attacks using new data on Denial-of-Service (DoS) attacks measured from Internet traffic. Exploring the development of DoS attacks around sanctions imposed against Russia in 2014 indeed shows an increase of DoS attacks against several sanction sender states. Extending this case study to a systematic analysis, including all sanction threats and impositions made by the United States and the European Union between 2008 and 2016, shows no apparent patterns. When I exclusively consider sanctions against technologically advanced countries, however, the frequency of attacks rises systematically against the United States. It thus appears that states do not always have to expect a digital retaliation after aggressive foreign policies. Nevertheless, sanctioning countries may have to anticipate an increase in DoS attacks when their governments impose sanctions against technologically advanced countries.
\end{abstract}

*Postdoctoral Fellow. Department of Political Science, University of Oslo, Postboks 1097 Blindern, 0317 Oslo, Norway; philipp.lutscher@stv.uio.no. 


\section{Introduction}

On November 5, 2018, CNN reported that United States (U.S.) banks prepared themselves for anticipated cyber attacks when the U.S. government reinstated sanctions against Iran (Pagliery, 2018).1 Many news outlets, security pundits, and the public indeed expect a rise in cyber attacks after aggressive foreign policy events such as sanctions. This appears to be especially true for low-cost cyber actions, of which so-called Denial-of-Service (DoS) attacks are the most frequent type. This brute-force and technically simple cyber action overloads a server by flooding it with high levels of data traffic and rendering it temporally not reachable. Despite the simplicity of these attacks, they are a threat to international security as they can cause high economic costs, especially when they target industry and financial services (Matthews, 2014).

There are several examples of DoS attacks related to international disputes. DoS attacks rose against news, government, and industry websites during the 2008 RussoGeorgian War (Deibert, Rohozinski and Crete-Nishihata, 2012), or were supposedly launched to retaliate sanctions against Iran (Perlroth and Hardy, 2013). Previous empirical work illustrates that DoS attacks are one of the most commonly used types of cyber attacks between adversary states (Valeriano and Maness, 2014). Nevertheless, there has yet not been a systematic investigation of whether aggressive foreign policy events increase the frequency of DoS attacks.

In this paper, I investigate whether DoS attacks against sanction sending countries rise when they threaten or impose sanctions. My investigation advances previous research in two ways. First, I systematically explore international political drivers of DoS attacks focusing on sanctions as one of the likeliest cases for which one should expect such attacks.2 Second, instead of collecting data on DoS attacks from media sources, I rely on

\footnotetext{
${ }^{1}$ In this paper, I use the terms cyber attack, action and operation interchangeably. In defining these terms, I follow Hathaway et al. (2012) who state that "[a] cyber attack consists of any action taken to undermine the function of a computer network for a political or national security purposes."

${ }^{2}$ Although I focus on sanctions in this paper, the results may likely be comparable to other aggressive foreign policies, e.g., trade wars or kinetic conflict.
} 
a dataset of DoS attacks measured from Internet traffic to gain a more comprehensive picture of the development and intensity of DoS attacks on countries worldwide (CAIDA, 2016).

I start exploring this relationship by focusing on sanctions against Russia in 2014 as a most likely case to expect a digital retaliation. This investigation shows compelling evidence for an increase in DoS attacks against the main sanctioning entities, the U.S. and European Union (E.U.), as well as other sanctioning countries. To explore how systematic this relationship is, I run time series models considering all sanction threats and impositions made by the U.S. and the E.U. from 2008 until the beginning of 2016 on a daily level. The results show no apparent patterns. However, when I restrict the analysis to sanctions against technologically advanced countries - which can be assumed to have higher cyber capabilities - I find a significant positive correlation between sanction impositions and DoS attacks against the U.S. This research innovation thus illustrates that not every aggressive foreign policy leads to a digital retaliation. The study's results nevertheless suggest that the number of DoS attacks may increase against sanctioning sending countries when they target technologically advanced states - additional costs governments need to consider when imposing sanctions against foreign countries.

This article proceeds as follows. First, building on literature on emotions in international relations (Sasley, 2011) and previous works on politically motivated DoS attacks (e.g., Asal et al., 2016; Deibert, Rohozinski and Crete-Nishihata, 2012; Kostyuk and Zhukov, 2019; Valeriano, Jensen and Maness, 2018), I discuss why the frequency of DoS attacks should increase against countries when they threaten or impose sanctions. Afterward, I introduce the data on DoS attacks and sanctions. I then present micro evidence for an increase of DoS attacks after the imposition of sanctions against Russia in 2014, before I discuss the method and results of the macro analysis. 


\section{Emotions, Sanctions and Denial-of-Service Attacks}

Following studies from social identity theory (Tajfel, 1978) and their application to international relations (e.g., Larson and Shevchenko, 2014; Sasley, 2011), aggressive foreign policy events can influence the political behavior and emotions of states, various group within the country, and society at large. Foreign policies such as sanctions may be perceived as humiliating, trigger anger, and increase hostility against the foreign aggressor (see Sasley, 2011).

The Internet has provided new disruptive ways for states and individuals to show this anger and displeasure. DoS attacks have some useful properties as a retaliation tool in this regard. First, they are hard to trace back, making it a relatively low risk to use them. Second, DoS attacks are brute-force and easy to conduct. Perpetrators do not have to rely on sophisticated tools and infrastructure to launch these attacks. ${ }^{3}$ Nonetheless, if DoS attacks are successful in disabling the targeted servers, they are still visible and can lead to considerable economic costs. Cybersecurity firms speak of around 40000 U.S. Dollars per hour when business websites are taken offline (Matthews, 2014).

On the one hand, governments or government-related entities targeted by sanctions may use DoS attacks to retaliate and display displeasure. Governments can either rent botnets themselves or "order" own cyber groups to launch these attacks. Since the ultimate attribution of DoS attacks remains difficult, their use comes with minimal costs, i.e., a physical or digital retaliation to these attacks is unlikely (Valeriano, Jensen and Maness, 2018).

On the other hand, the simplicity of DoS attacks enables not only governments but also citizens and patriotic hacker groups to respond in this fashion. Sanctions reinforce nationalist sentiments and make citizens more susceptible to government propaganda (Galtung, 1967). These nationalist sentiments likely increase hostility against the sender country (Grossman, Manekin and Margalit, 2018), and may even encourage citizens to engage in collective action in favor of the government (Hellmeier, 2020), including the

\footnotetext{
${ }^{3}$ This is different for so-called Advanced Persistent Threats (APTs), state-sponsored groups that launch custom-tailored cyber attacks and that require highly sophisticated infrastructure (Geers et al. 2014).
} 
use of politically motivated cyber attacks to do so (Holt et al., 2017).

In their analysis of the use of DoS attacks during the Russo-Georgian war in 2008, Deibert, Rohozinski and Crete-Nishihata (2012) show that it was very plausibly Russian citizens, groups, and hackers that were responsible for the large-scale DoS attacks during the conflict. A similar conclusion is made by $\operatorname{Rid}(2012)$ who investigates the 2007 DoS attacks against the Estonian government, news, and industry websites. These large-scale attacks happened after the Estonian government relocated a Soviet Union memorial site in disagreement with the Russian government. Although many pundits describe this incident as a government-planned act of cyber warfare, there is evidence that many citizens and pro-government hacking groups just wanted to show disapproval (Ottis, 2008). Likewise, Kostyuk and Zhukov (2019) do not find strong support for a strategic use and interaction between DoS attacks and battlefield events during the ongoing civil conflicts in Ukraine and Syria.

As it nevertheless remains difficult to attribute cyber operations, governments may have been actively involved during these incidents as well. Besides, governments likely facilitate the use of DoS attacks by citizens and non-state groups due to their use of propaganda to take action against foreign aggression, as well as their sponsoring of patriotic hacking groups. Finally, since one can start DoS attacks globally, not only domestic citizens may use these attacks, but activists worldwide who disagree with a government's policy (see Lutscher et al., 2020).

To summarize, when states, groups, or individuals indeed use DoS attacks to retaliate digitally, we should expect that aggressive foreign policies increase the frequency of DoS attacks against the sender state. Related to sanction events that means, first, that:

Hypothesis 1 The frequency of DoS attacks rises against the sender state when it threatens sanctions.

Second, this increase should be stronger when states impose sanctions as this policy is more salient and should fuel negative sentiments towards the sender state more strongly (Galtung, 1967). We should thus expect that: 
Hypothesis 2 The frequency of DoS attacks rises against the sender state when it imposes sanctions and this increase is stronger compared to sanction threats.

An alternative explanation would be that states use DoS attacks strategically in response to sanction events in order to gain concessions, i.e., the lifting or non-imposition of sanctions. Previous theoretical (e.g., Gartzke, 2013) and empirical (e.g., Valeriano, Jensen and Maness, 2018) studies find little evidence for such a coercive use of cyber operations. In particular for DoS attacks, it is questionable how these actions should influence foreign policy decisions and be perceived as a credible threat. As described above, DoS attacks are hard to attribute, and-compared to other more advanced cyber operations - they only come with limited costs, which makes it difficult to perceive them as a costly signal.

\section{Data}

Data on DoS attacks The main data for this study comes from the Center for Advanced Internet Studies (CAIDA) at the University of California, San Diego from 2008 2016 (CAIDA, 2016). CAIDA measures DoS attacks from Internet traffic and captures so-called "randomly spoofed" DoS attacks, where attackers craft their flood of requests to the target such that it appears to originate from one or several fake Internet addresses, i.e., not corresponding to the machine(s) executing the attack. CAIDA can measure these attacks because attacked servers still respond to requests made by the fake IP address of the attacker and this response may end up within a large address space of unassigned IPv4 addresses monitored by CAIDA (see Moore et al., 2006, for more technical details) 4

Compared to previous media-based approaches, this measurement approach is by construction not prone to media biases, neither media attention nor underreporting of DoS attacks. Concerning the former, my approach avoids measurement errors because sanctions may increase not only DoS attacks but also the reporting of them. Regarding the latter, media outlets likely miss to report a large share of cyber incidents, either

\footnotetext{
${ }^{4}$ The monitored space is approximately $1 / 256$ th of all unassigned $\mathrm{IPv} 4$ Internet addresses.
} 
because they are not observed (Poznansky and Perkoski, 2018) or simply not newsworthy (Earl et al., 2004). The data by CAIDA can get a more comprehensive picture of DoS attacks worldwide. The data include information about attack strength and duration, the timing of the attack, and the targeted IP address. In this paper, I use this information to retrieve the number of spoofed DoS attacks per country and day from March 2008 until December 2015. More precisely, I rely mainly on attack data against servers hosted in the U.S. and the E.U., summing up DoS attacks against each member state.

Despite these advantages, the data come with some limitations (Moore et al., 2006). First, CAIDA captures a subset of DoS attacks. The measurement is thus an approximation for the overall level of DoS attacks. Even so, recent studies show that spoofed DoS attacks are comparable to other popular DoS attack vectors (Jonker et al., 2017). Second, since attackers use fake addresses, I cannot infer the identity of the attacker or even the attack's country of origin but have information on the targeted country only. However, even if newspapers may report on potential perpetrators, this information is often not reliable because attackers use botnets, spoofing methods, and other techniques to hide their true identities.

Data on sanction events The EUSANCT dataset is the second main data source I use in this paper (Weber and Schneider, 2020). The dataset extents and merges previous sanction datasets (e.g., Morgan, Bapat and Kobayashi, 2014), and contains information on sanction episodes from 1989 until the end of 2015 for the three most important sanction senders, the U.S., the E.U., and the United Nations (U.N.).

In defining sanction episodes, threats, and impositions, Weber and Schneider (2020) closely follow the TIES dataset (Morgan, Bapat and Kobayashi, 2014). A sanction episode normally starts with a sanction threat, which is defined as a verbal statement of government officials, drafting of legislation against a target state, or conditional laws, stating that sanctions are a possibility against a target state if certain target behaviors do not change. Sanction impositions are then the formal realizations of these threats.

From March 2008 until December 2015, the data record 29 or 20 sanction threats and 28 or 23 impositions by the U.S. or E.U., respectively. I do not focus on U.N. sanctions 
because it would be difficult to determine where to expect an increase in DoS attacks.$^{5}$

\section{Case Evidence: The Crimean Crisis in 2014}

In a first step, I use both data sources to investigate one of the likeliest cases for which one should expect to find evidence: sanctions against Russia in 2014 $\sqrt[6]{6}$ After the Russian invasion of the Crimean Peninsula on February 27, 2014, Western states condemned this action as illegal and threatened with consequences if Russia would not withdraw their troops. Because the Russian authorities did not comply, the U.S. imposed the first set of sanctions on March 6, which included travel bans and the freezing of U.S. assets for several Russian officials. Again, instead of complying, the Russian authorities announced an "independence" referendum of the Crimean Peninsula on March 16 and the RussoUkraine conflict escalated. On March 15, the U.S. started an initiative in the Security Council that should condemn the Russian aggression as well as reinforced sanctions on March 17 after the referendum took place. The E.U. undertook similar actions and imposed visa restrictions and froze assets. On March 18, Russia annexed the Crimean Peninsula. Around the same dates, the governments of Canada, Australia, New Zealand, and Japan imposed sanctions against Russia as well.

Figure 1 shows the number of DoS attacks against servers hosted in the U.S. and the E.U. The top panel reveals that attacks against the U.S. peaked eleven days after the U.S. imposed their first set of sanctions. It appears that the spike is related to the reinforcement of sanctions and the increased tension during the referendum weekend (March 15 - 17). Similarly, the data record an increase in DoS attacks against the E.U. with the highest number of DoS attacks on the imposition date (bottom panel). Looking at the other sanctioning countries supports this finding (see Figure 2p. In particular, the number of DoS attacks against Canada spiked when the country imposed sanctions

\footnotetext{
${ }^{5}$ For the later macro analysis the variable remains binary for the few imposition or threat dates on which several sanctions were imposed or threatened. In five cases for the U.S., and two cases for the E.U., sanction impositions and threats overlap on the same day.

${ }^{6}$ In the supplementary online appendix A, I explore two other high-profile cases, sanctions against Iran in 2010 and Syria in 2011, similarly finding an increase of DoS attacks after sanction impositions, in particular against servers hosted in the U.S.
} 

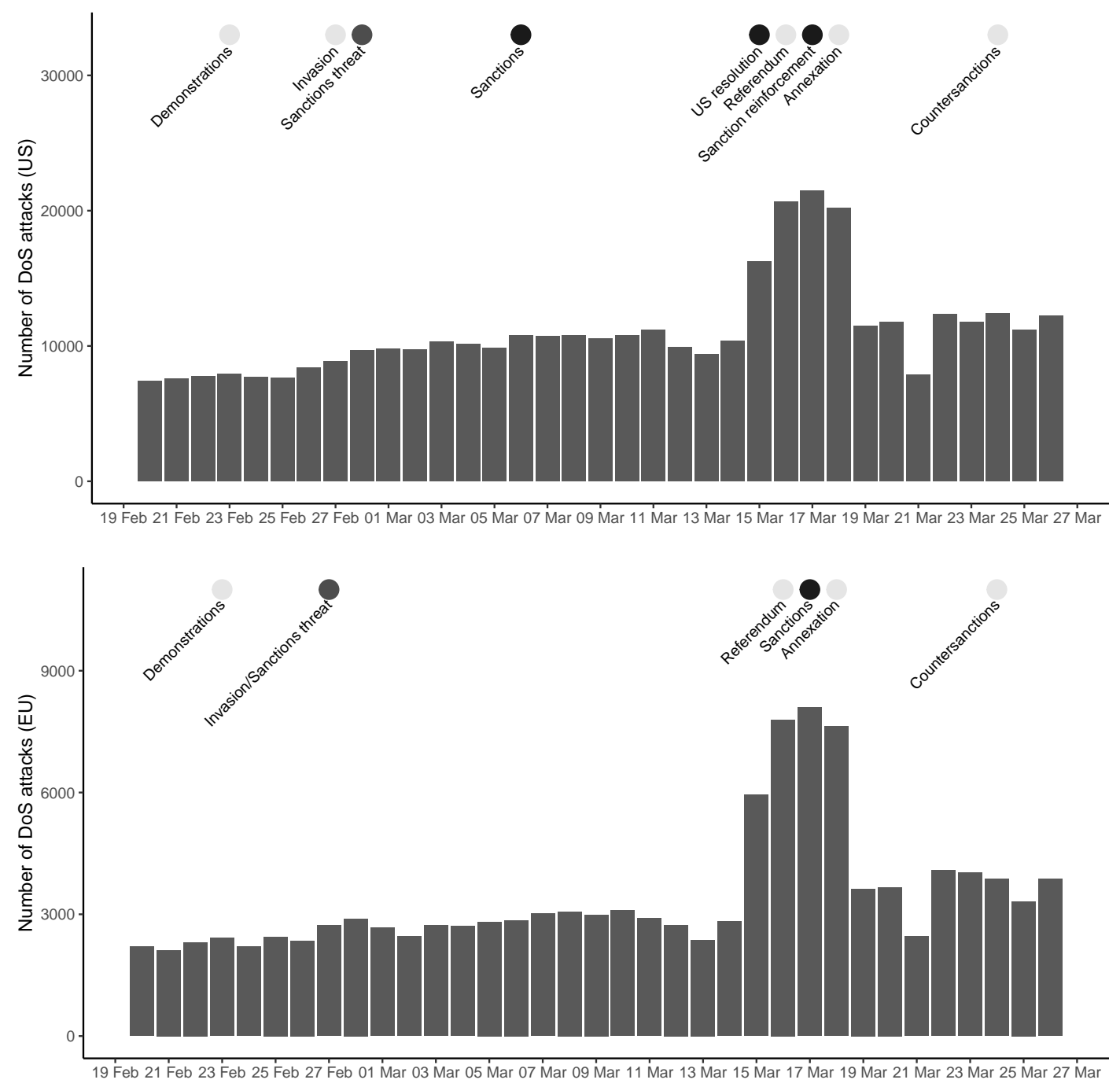

Figure 1: Number of DoS attacks in the U.S. \& the E.U. (February/March 2014). Note: Development of DoS Attacks (vertical bars), sanction related events (black dots), threats (dark grey dots) and other events (grey dots). 
and for Australia when the country supported the Security Council resolution by the U.S. Moreover, Figure A.1 in the supplementary online appendix A illustrates that DoS attacks against servers hosted in Russia and Ukraine increased during the same period, suggesting a kind "digital clash" between both countries.

What can be said about the motivation and potential perpetrators in this case? First, botnet activities originating from Russia and Ukraine increased during this period, suggesting that Russian botnets were used to launch DoS attacks (Gilbert, 2019). Second, news outlets reported about DoS attacks against several NATO websites on March 16 by a group named Cyber Berkut. This group emerged in 2014 as a Ukrainian pro-Russian hacktivist group (Cherney, 2014). Third, an own Google trend investigation of the term "Denial-of-Service attack" shows a remarkable increase in interest in the technique in Russia. The trend measures the interest for a search term, where interest is defined as the share of the search term to the absolute search volume for a given day, relative to the highest search volume for the period of study. Figure 3 shows that the trend gained momentum after the imposition of the U.S. sanction, especially just before the referendum weekend, and displays overall high correlations to the development of DoS attacks against the U.S. and E.U. in Figure 1 ( $r=0.56$ and $r=0.51$, respectively). Besides, the Russian Google trend for "Low Orbit Ion Cannon," which is an easy to use tool for activists to conduct DoS attacks, highlights similar patterns.7 Although this does not allow to make any causal claims as media coverage on DoS attacks or some other factor may influence search queries as well, it is worthwhile mentioning that interest spiked before the rise in DoS attacks. Finally, Frye (2019) shows in survey experiments that the annexation of Crimea increased citizens' support for the Russian government.

It appears therefore overall plausible that some citizens displayed their increased anger against the U.S. and E.U. by using DoS attacks. Nevertheless, while the presented evidence rather supports the use of DoS attacks as a mean to show discontent by patriotic hacking groups and citizens (cf., Deibert, Rohozinski and Crete-Nishihata, 2012), it may

\footnotetext{
${ }^{7}$ As this term is more volatile; a systematic investigation remains challenging. Moreover, although Google is not the main search engine in Russia, I believe that this should not alter its use as a proxy for public interest.
} 

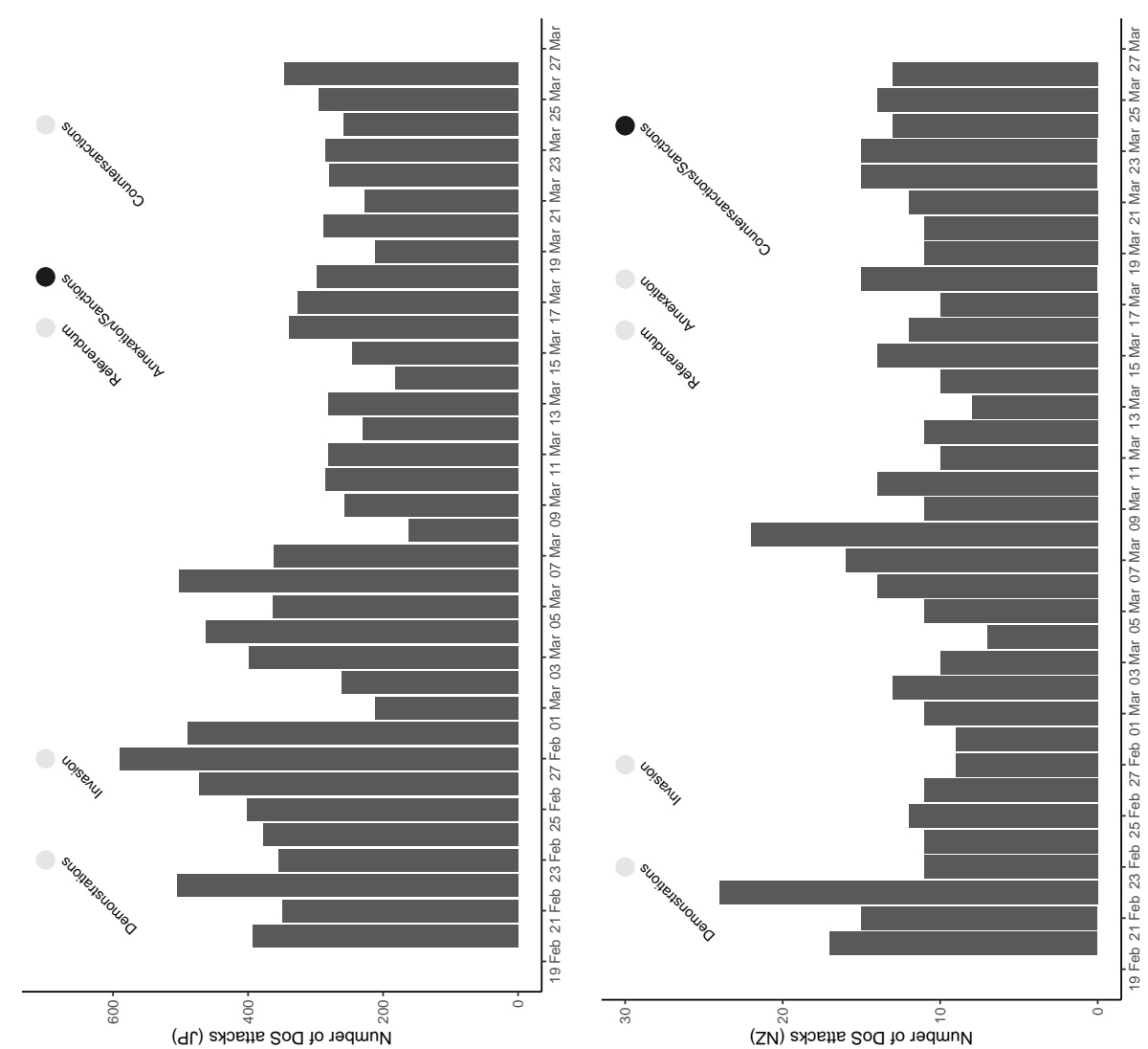

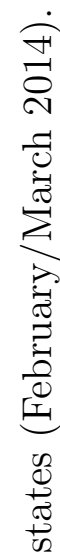
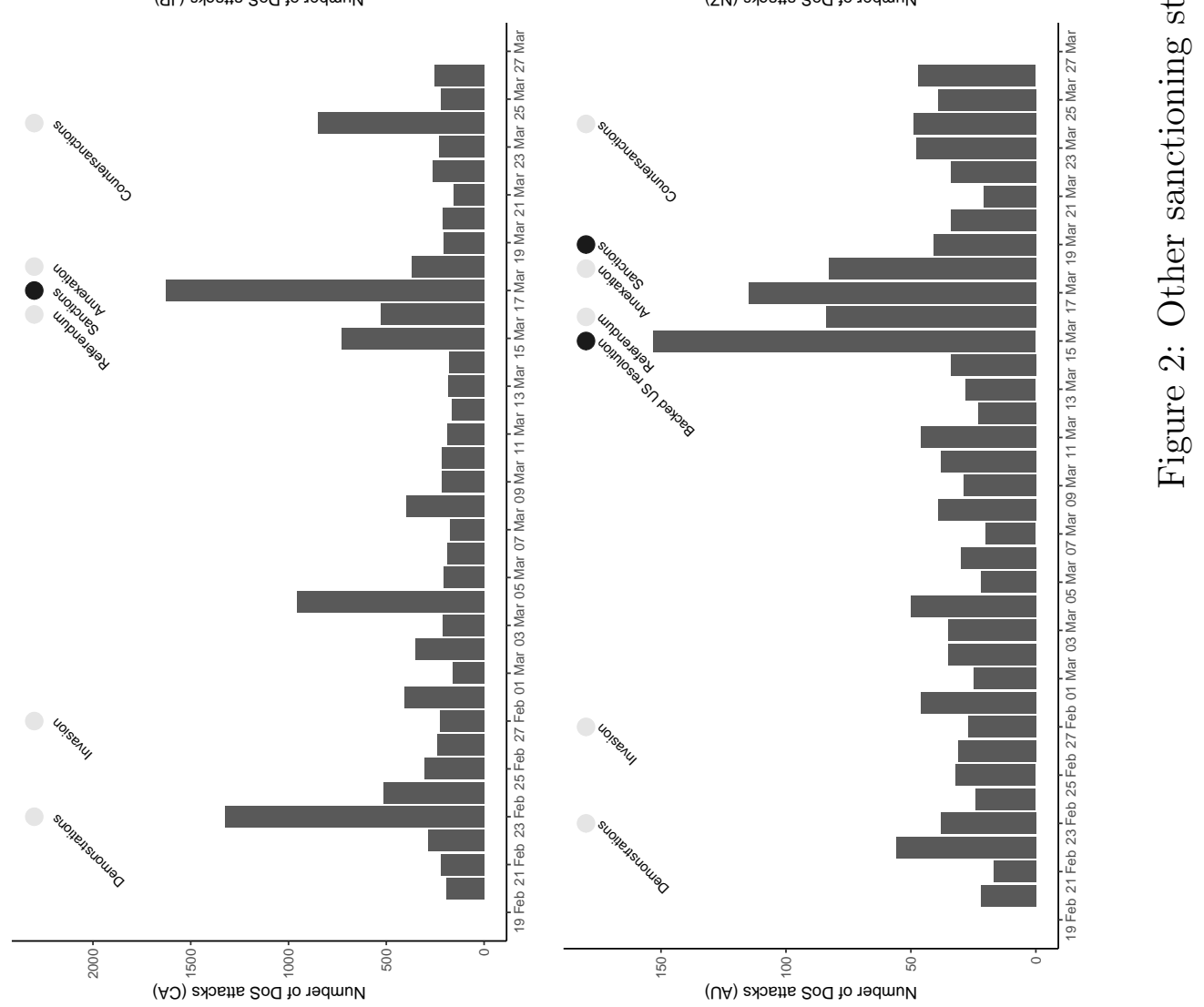
still be that government entities used DoS attacks to retaliate in this fashion as well

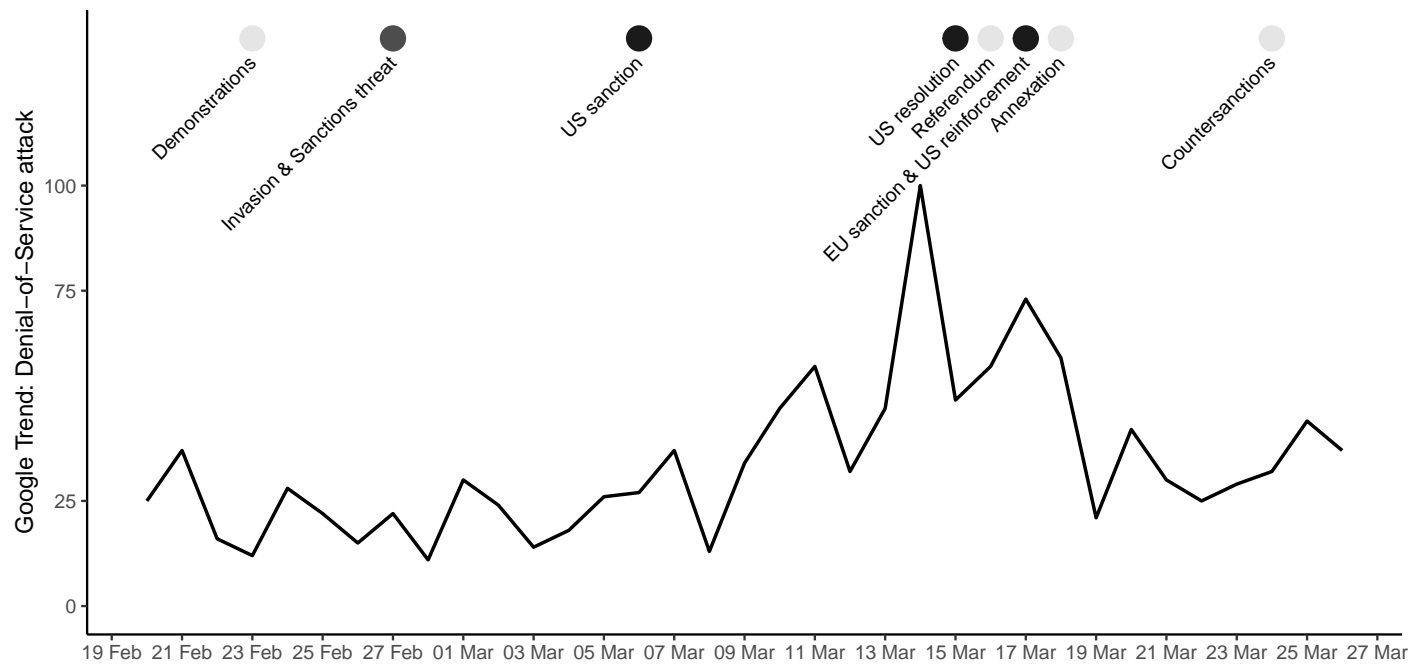

Figure 3: Russian Google Trend for DoS attack (February/March 2014).

An alternative explanation for the increase in DoS attacks against the U.S. and the E.U. could be that perpetrators launched DoS attacks against servers that host Ukrainian websites in the U.S. or E.U. (see Lutscher et al., 2020). Although this was also likely the case, the increasing number of DoS attacks on other sanctioning countries and the presented anecdotal evidence supports the conclusion that U.S.- and E.U.-related servers suffered from DoS attacks as well.

\section{Macro Evidence: U.S. and E.U. Sanctions}

To investigate whether the findings from the case study hold more broadly, I combined the DoS and sanction data for the most important sanction senders - the U.S. and the E.U. Figure 4 illustrates the created daily time series from 2008 until the beginning of 2016 . Afterward, I run so-called autoregressive distributed lag (ARDL) models that can model short- and long-term temporal relationships between variables Hendry, 1995; Philips, 2018). These linear regression models allow to include a sufficient number of lags for

\footnotetext{
${ }^{8}$ To be clear, I do not argue that the Russian government is not conducting cyber actions. In fact, there is evidence that the Russian intelligence services are responsible for many cyber operations that involve espionage and infiltration campaigns worldwide. However, in contrast to DoS attacks, these operations require much more resources and planning ahead of time.
} 
both the independent, sanction threats and impositions, and the dependent variables, the number of DoS attacks against the U.S. and E.U.
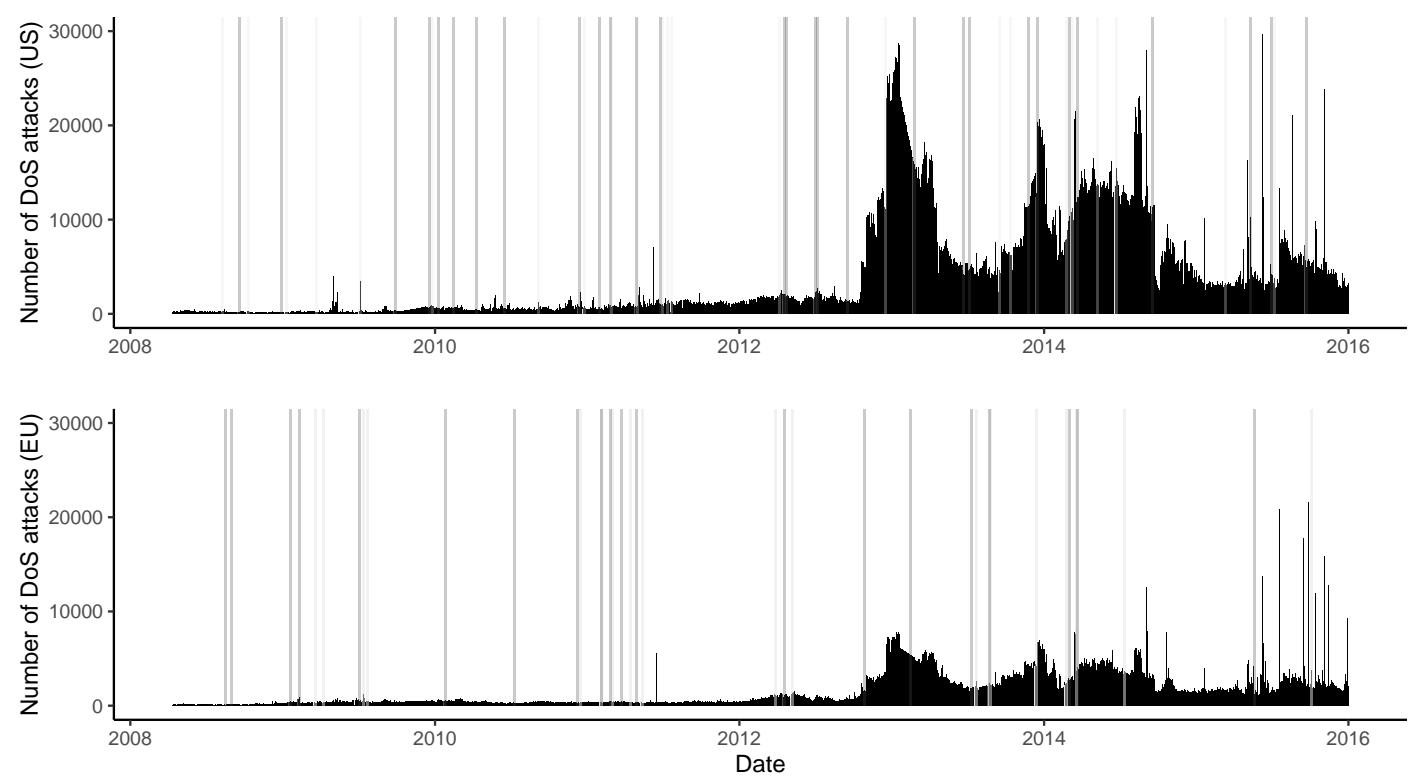

Figure 4: Number of DoS attacks against the U.S. and E.U., sanction threats (light grey), and sanction impositions (dark grey)

To run these models reliably, I had to pre-process and transform the data. More precisely, I analyze changes in the normalized number of DoS attacks for two distinct periods that last from March 2008 until February 2012 and again from February 2012 until December 2015. Finally, I followed the literature and used the Akaike Information Criterion (AIC) to determine the best fitting number of lags to include in the models (Burnham and Anderson, 2004). The pre-processing steps and method are explained in detail in the supplementary online appendix B,

In the presentation of the results, I follow recent approaches and simulate counterfactual scenarios for variables of interest (Philips, 2018).9 For the in Figure 5 displayed simulation of the development of DoS attacks I set a hypothetical sanction imposition to the point in time "5" (dashed vertical line) and assume that there is no sanction threat. The dashed horizontal line shows the null effect that is the value for which the non-normalized change in the number of DoS attacks is zero.

The figure shows that in all simulations the $90 \%$ and $95 \%$ confidence intervals cross

\footnotetext{
${ }^{9}$ In the supplementary online appendix C, I report the full regression models and long-run multiplier coefficients.
} 
U.S. sanctions (03/2008-02/2012)

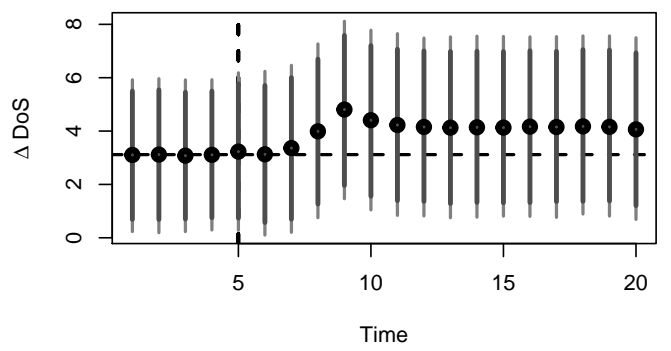

E.U. sanctions (03/2008-02/2012)

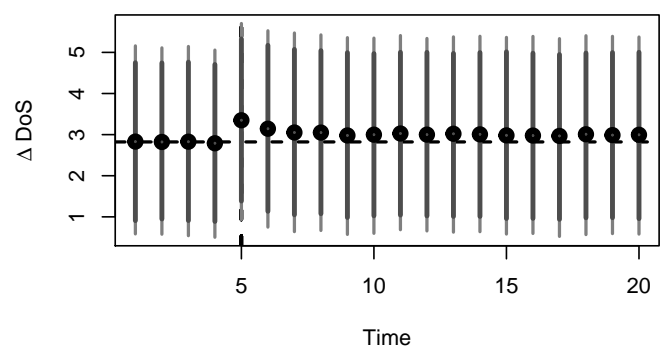

U.S. sanctions (02/2012-12/2015)

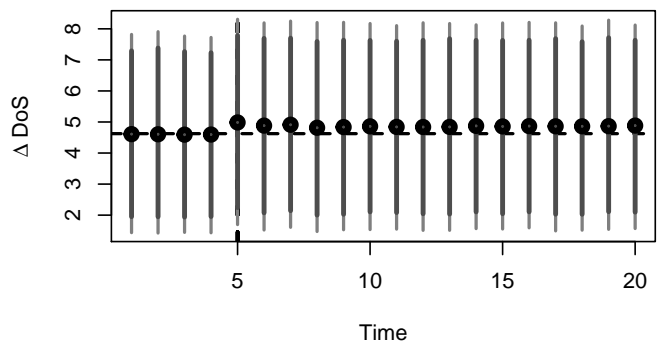

E.U. sanctions (02/2012-12/2015)

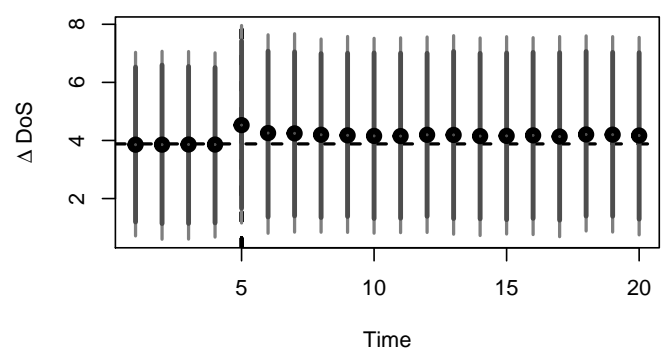

Figure 5: Simulations of DoS attacks. Note: Based on 10000 draws. $95 \%$ and 90\% confidence intervals are displayed. The intervention is marked with a dashed vertical line, the horizontal line shows the null effect. The U.S. and E.U. time series are split at their respective breaking points.

the horizontal line (null effect) for all points in time. The results thus do not suggest any significant increase in DoS attacks after the imposition of sanctions. As shown in the supplementary online appendix C, simulations for sanction threats also display a null and even no temporal effects 10 Does this mean that the case study from above is an exception? Or does Russia have specific properties that make a digital retaliation more likely?

It is well known that Russia is an active player in cyberspace, possesses sufficient cyber capabilities, and has active patriotic hacking groups. Although DoS attacks are relatively simple to conduct, using them at large requires a certain level of technological advancement; making it worthwhile to investigate the impact of sanctions conditional on this factor. To measure technological advancement comparatively, I rely on a proxy

\footnotetext{
${ }^{10} \mathrm{~A}$ caveat may be that within sanction periods the sender state(s) reinforce threats and the severity of the sanction gradually that could influence the decision to retaliate digitally. Unfortunately, this information is not available in Weber and Schneider (2020). Nevertheless, it is fair to assume that if states and/or groups within states use DoS attacks to retaliate, we should already expect this happening after the first serious threat and/or imposition.
} 
variable and use the Communication Technology (ICT) Development Index (IDI) by the International Telecommunication Union (ITU). This variable measures the access to, use of, and skills regarding modern ICTs for countries worldwide (ITU, 2017).11

Figure 6 illustrates the results when I exclusively consider sanctions against countries that score $25 \%$ or above in the IDI compared to the yearly worldwide average $\sqrt{12}$ The results indeed change. In particular for the U.S. time series for the time period later than February 2012, the simulation displays a steady increase of DoS attacks, with a peak at day eleven after the imposition date, where the $90 \%$ confidence intervals of the simulated change in the number of DoS attacks is clearly distinguishable from the horizontal dashed line (null effect). Since the substantial predictions of the normalized models are hard to interpret, I run non-normalized models that are reported in the supplementary online appendix $\mathrm{D}$. These models illustrate similar patterns and predict a maximal increase of approximately 5,000 DoS attacks against U.S. servers after the imposition of sanctions $\sqrt{13}$ Furthermore, as detailed in the same supplementary material, I show that this increase becomes even stronger when using $50 \%$ or $75 \%$ as thresholds to define technological advanced countries. Moreover, the results remain similar when using another index proposed by Valeriano, Jensen and Maness $(2018)$ to measure cyber capabilities. For sanction threats, in contrast, the simulations still suggest a null finding regardless of the targeted country's technological advancement (see the supplementary online appendix $\mathrm{C}$ for details).

To further explore how valid these findings are, I conduct additional sensitivity and robustness tests that are reported in the supplementary online appendix D. These tests include Granger tests, placebo tests, different operationalizations for the dependent and independent variables, as well as different model specifications. In sum, most of the additional models support the finding of a positive correlation between sanction impositions

\footnotetext{
${ }^{11}$ Since the ITU does not publish the IDI every year, I fill values for years in between using linear imputation.

${ }^{12}$ When using this threshold, the number of considered sanction impositions decreases to 11 and 10 for the U.S. and the E.U., respectively.

${ }^{13}$ Another solution would be to transform the predictions of the, statistically more appropriate, normalized models. However, while these models allow drawing robust inference, such back-transformed predictions are imprecise suggesting a maximal increase of approximately 37,000 DoS attacks.
} 
U.S. sanctions (techno.) (03/2008-02/2012)

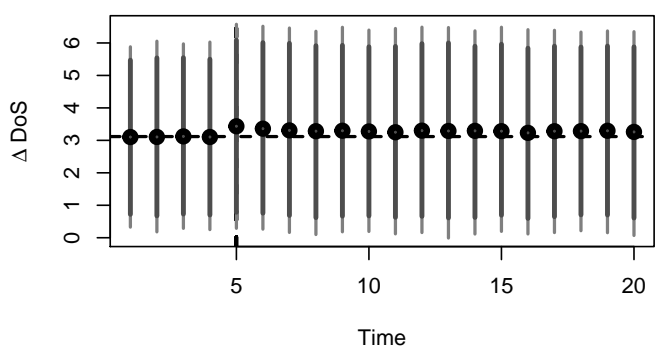

E.U. sanctions (techno.) (03/2008-02/2012)

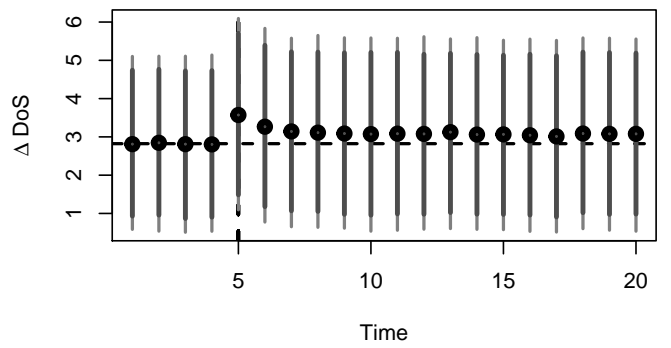

U.S. sanctions (techno.) (03/2008-02/2012)

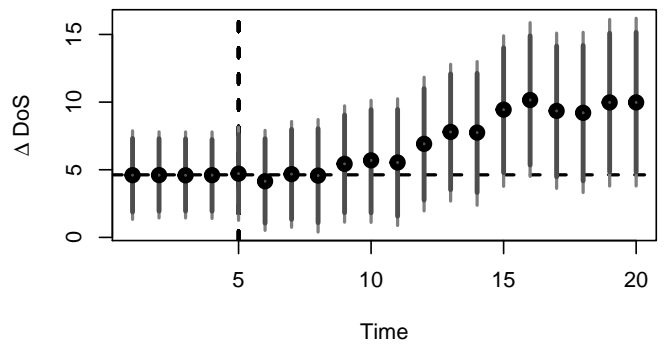

E.U. sanctions (techno.) (03/2008-02/2012)

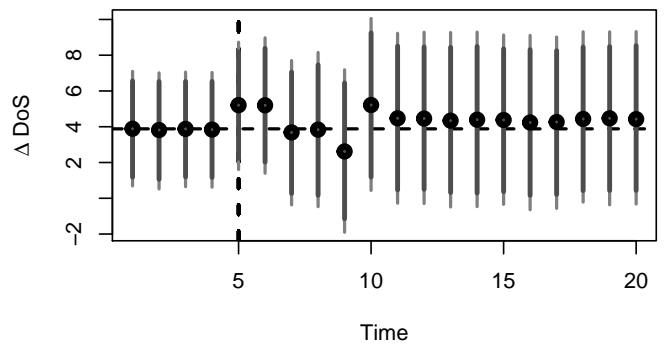

Figure 6: Simulations of DoS attacks exclusively considering sanctions on technologically advanced countries.

and the number of DoS attacks against the U.S. when the targeted country is sufficiently technologically advanced. However, two caveats remain. First, placebo tests using GDP p.c. to measure technological advancement show similar results; suggesting that not necessarily a country's technological advancement but general economic development is important in increasing the number of DoS attacks. However, since both variables highly correlate $(r=0.9)$, it is difficult to distinguish both concepts. Second, some of the additional models indicate that specific sanctioning cases, foremost the Russian one, can be seen as an influential observation in the statistical analysis. Leaving out the Russian case still show similar patterns, yet, with slightly higher levels of uncertainty.

\section{Conclusion}

Using data on DoS attacks inferred from Internet data traffic, this study investigated the use of DoS attacks against sanction sender states. While my study could find no evidence for an increase of DoS attacks when countries threaten sanctions, my results point to a digital retaliation when countries impose sanctions. Nevertheless, such an use seems to 
be conditional on one factor: the sanctioned country needs a certain level of technological advancement or development.

One main problem in studying cyber attacks remains their attribution. I thus cannot make definite claims about the perpetrators and motivation of the measured DoS attacks. My case study on Russia suggests that it had been likely patriotic groups and individuals launching DoS attacks against servers in the U.S. and the E.U. to signal displeasure. While some cyber conflict studies argue that states use cyber attacks also as a strategic tool to gain concessions (e.g., Sharp, 2017), my study shows that for DoS attacks this seems rather unlikely the case. The frequency of attacks spiked for a short period only, and their effects and overall costs appear to be still limited (cf. Rid, 2012; Gartzke, 2013).

Finally, this research innovation advances the empirical cyber conflict literature (e.g., Asal et al., 2016; Valeriano and Maness, 2014; Valeriano, Jensen and Maness, 2018). Whereas previous work likely suffered from media biases, either under- or overreporting, the data used in this paper enables researchers and the public to get a more comprehensive picture of cyber activities worldwide. Future research may use these data to investigate similar questions such as cyber conflict dynamics (e.g., Kostyuk and Zhukov, 2019) or how domestic events influence DoS attacks (e.g., Lutscher et al., 2020). 


\section{Funding}

Work for this project was supported by the DFG grant 402127652 and by the National Science Foundation grant CNS-1730661. This material is based on research sponsored by the Air Force Research Laboratory under agreement number FA8750-18-2-0049. The U.S. Government is authorized to reproduce and distribute reprints for governmental purposes notwithstanding any copyright notation thereon. The views and conclusions contained herein are those of the authors and should not be interpreted as necessarily representing the official policies or endorsements, either expressed or implied, of Air Force Research Laboratory or the U.S. Government. This work used the Extreme Science and Engineering Discovery Environment (XSEDE), which is supported by the National Science Foundation grant number ACI-1053575.

\section{Acknowledgments}

I would like to thank Nils Weidmann, Molly Roberts and Karsten Donnay for their support and valuable comments from early stages of this project. Furthermore, I thank Sebastian Hellmeier, Anita Gohdes, Lukas Kawerau, Patrick Weber, Eda Keremoglu, Julian Schüssler and Max Heermann who helped a lot in improving this paper. Finally, I thank the two anonymous reviewers and the editors of the JOGSS, whose comments led to major improvements of this paper. All remaining errors are my own. 


\section{References}

Asal, Victor, Jacob Mauslein, Amanda Murdie, Joseph Young, Ken Cousins and Chris Bronk. 2016. "Repression, Education, and Politically Motivated Cyberattacks." Journal of Global Security Studies 1(3):235-247.

Burnham, Kenneth P and David R Anderson. 2004. "Multimodel Inference: Understanding AIC and BIC in Model Selection." Sociological Methods $\&$ Research 33(2):261-304.

CAIDA, UC San Diego. 2016. "The CAIDA UCSD Near-Real-Time Network Telescope - 2008-2016.". http://www.caida.org/data/passive/telescope-near-realtime_dataset.xml.

Cherney, Max. 2014. "Pro-Russian Hackers Took Down Three NATO Websites. The work of Russian cyber-agent provocateurs?" Motherboard, March 16. https://motherboard.vice.com/en_us/article/jp5mxd/pro-russia-ukranianshack-nato-websites (accessed 07-29-2019).

Deibert, Ronald J, Rafal Rohozinski and Masashi Crete-Nishihata. 2012. "Cyclones in Cyberspace: Information Shaping and Denial in the 2008 Russia-Georgia War." Security Dialogue 43(1):3-24.

Earl, Jennifer, Andrew Martin, John D McCarthy and Sarah A Soule. 2004. "The Use of Newspaper Data in the Study of Collective Action." Annual Review of Sociology 30:65-80.

Frye, Timothy. 2019. "Economic Sanctions and Public Opinion: Survey Experiments from Russia." Comparative Political Studies 52(7):967-994.

Galtung, Johan. 1967. "On the Effects of International Economic Sanctions, with Examples from the Case of Rhodesia." World Politics 19(3):378-416.

Gartzke, Erik. 2013. "The Myth of Cyberwar: Bringing War in Cyberspace Back Down to Earth." International Security 38(2):41-73.

Geers, Kenneth, Darien Kindlund, Ned Moran and Rob Rachwald. 2014. "WORLD WAR C: Understanding Nation-State Motives Behind Today's Advanced Cyber Attacks." FireEye. https://www.fireeye.com/content/dam/fireeye-www/global/en/ current-threats/pdfs/fireeye-wwc-report.pdf (accessed 06-28-2019).

Gilbert, David. 2019. "Inside the Massive Cyber War Between Russia and Ukraine." Vice, March 29. https://news.vice.com/en_us/article/bjqe8m/inside-the-massivecyber-war-between-russia-and-ukraine (accessed 07-29-2019). 
Grossman, Guy, Devorah Manekin and Yotam Margalit. 2018. "How Sanctions Affect Public Opinion in Target Countries: Experimental Evidence from Israel." Comparative Political Studies 51(14):1823-1857.

Hathaway, Oona A, Rebecca Crootof, Philip Levitz, Haley Nix, Aileen Nowlan, William Perdue and Julia Spiegel. 2012. "The Law of Cyber-attack." California Law Review pp. $817-885$.

Hellmeier, Sebastian. 2020. "How Foreign Pressure Affects Mass Mobilization in Favor of Authoritarian Regimes." European Journal of International Relations Online First:128.

Hendry, David F. 1995. Dynamic Econometrics. Oxford: Oxford University Press.

Holt, Thomas J, Max Kilger, Lichun Chiang and Chu-Sing Yang. 2017. "Exploring the Correlates of Individual Willingness to Engage in Ideologically Motivated Cyberattacks." Deviant Behavior 38(3):356-373.

ITU, International Communication Union. 2017. "The ICT Development Index (IDI): Conceptual Framework and Methodology." . https://www.itu.int/en/ITU-D/ Statistics/Pages/publications/mis2017/methodology.aspx.

Jonker, Mattijs, Alistair King, Johannes Krupp, Christian Rossow, Anna Sperotto and Alberto Dainotti. 2017. Millions of Targets Under Attack: A Macroscopic Characterization of the DoS Ecosystem. In Proceedings of the 2017 Internet Measurement Conference. IMC '17 New York, NY, USA: ACM pp. 100-113.

Kostyuk, Nadiya and Yuri M Zhukov. 2019. "Invisible Digital Front: Can Cyber Attacks Shape Battlefield Events?" Journal of Conflict Resolution 63(2):317-347.

Larson, Deborah Welch and Alexei Shevchenko. 2014. "Russia Says No: Power, Status, and Emotions in Foreign Policy." Communist and Post-communist Studies 47(3-4):269279 .

Lutscher, Philipp M., Nils B. Weidmann, Margaret E. Roberts, Mattijs Jonker, Alistair King and Alberto Dainotti. 2020. "At Home and Abroad: The Use of Denial-of-service Attacks During Elections in Nondemocratic Regimes." Journal of Conflict Resolution 64(1-2):1-29.

Matthews, Tim. 2014. "Incapsula Survey : What DDoS Attacks Really Cost Businesses." Incapsula. https://lp.incapsula.com/rs/incapsulainc/images/eBook2020DDoS20Impac20Survey.pdf (accessed 29-07-2019). 
Moore, David, Colleen Shannon, Douglas J Brown, Geoffrey M Voelker and Stefan Savage. 2006. "Inferring Internet Denial-of-Service Activity." ACM Transactions on Computer Systems (TOCS) 24(2):115-139.

Morgan, T Clifton, Navin Bapat and Yoshiharu Kobayashi. 2014. "Threat and Imposition of Economic Sanctions 1945-2005: Updating the TIES dataset." Conflict Management and Peace Science 31(5):541-558.

Ottis, Rain. 2008. Analysis of the 2007 cyber attacks against estonia from the information warfare perspective. In Proceedings of the 7th European Conference on Information Warfare. pp. 163-169.

Pagliery, Jose. 2018. "U.S. banks Prepare for Iranian Cyberattacks as Retaliation for Sanctions.". https://edition.cnn.com/2018/11/09/tech/iran-sanctions-usbanks-cyber-hack-invs/index.html (accessed 07-30-2019).

Perlroth, Nicole and Quentin Hardy. 2013. "Bank Hacking Was the Work of Iranians, Officials Say." . https://www.nytimes.com/2013/01/09/technology/online-bankingattacks-were-work-of-iran-us-officials-say.html (accessed 07-30-2019).

Philips, Andrew Q. 2018. "Have Your Cake and Eat It Too? Cointegration and Dynamic Inference from Autoregressive Distributed Lag Models." American Journal of Political Science 62(1):230-244.

Poznansky, Michael and Evan Perkoski. 2018. "Rethinking Secrecy in Cyberspace: The Politics of Voluntary Attribution." Journal of Global Security Studies 3(4):402-416.

Rid, Thomas. 2012. "Cyber War Will Not Take Place." Journal of Strategic Studies $35(1): 5-32$.

Sasley, Brent E. 2011. "Theorizing States Emotions." International Studies Review $13(3): 452-476$.

Sharp, Travis. 2017. "Theorizing Cyber Coercion: The 2014 North Korean Operation against Sony." Journal of Strategic Studies 40(7):898-926.

Tajfel, Henri Ed. 1978. Differentiation Between Social Groups: Studies in the Social Psychology of Intergroup Relations. Academic Press.

Valeriano, Brandon, Benjamin M Jensen and Ryan C Maness. 2018. Cyber Strategy: The Evolving Character of Power and Coercion. Oxford: Oxford University Press.

Valeriano, Brandon and Ryan C Maness. 2014. "The Dynamics of Cyber Conflict Between Rival Antagonists, 2001-11." Journal of Peace Research 51(3):347-360. 
Weber, Patrick M and Gerald Schneider. 2020. "Post-Cold War Sanctioning by the EU, the UN, and the US: Introducing the EUSANCT Dataset." Conflict Management and Peace Science Online First:1-18. 


\section{Online Appendix}

Philipp M. Lutscher, Digital Retaliation? Denial-of-Service Attacks After Sanction Events, Forthcoming in the Journal of Global Security Studies

\section{Table of Contents}

A Additional Case Study Material

\begin{tabular}{|lll}
\hline P & Pre-processing Steps \& Method & 5
\end{tabular}

\begin{tabular}{|ll}
\hline C Regression Results \& Additional Simulations & 10
\end{tabular}

\begin{tabular}{|l|l|}
\hline D Robustness and Sensitivity Tests & 15
\end{tabular} 


\section{A Additional Case Study Material}

In this appendix, I report the additional material for the in the main text discussed case study, as well as illustrate the development of DoS attacks during two other high-profile sanction events: sanctions against Iran in 2010 and Syria in 2011.

Figure A.1 shows the development of DoS attacks against Ukrainian and Russian servers during the Crimean crisis in 2014. The figure shows that these developments have been likely influenced by political events as well. In particular during the annexation weekend, servers in both countries were targeted by a high number of DoS attacks.

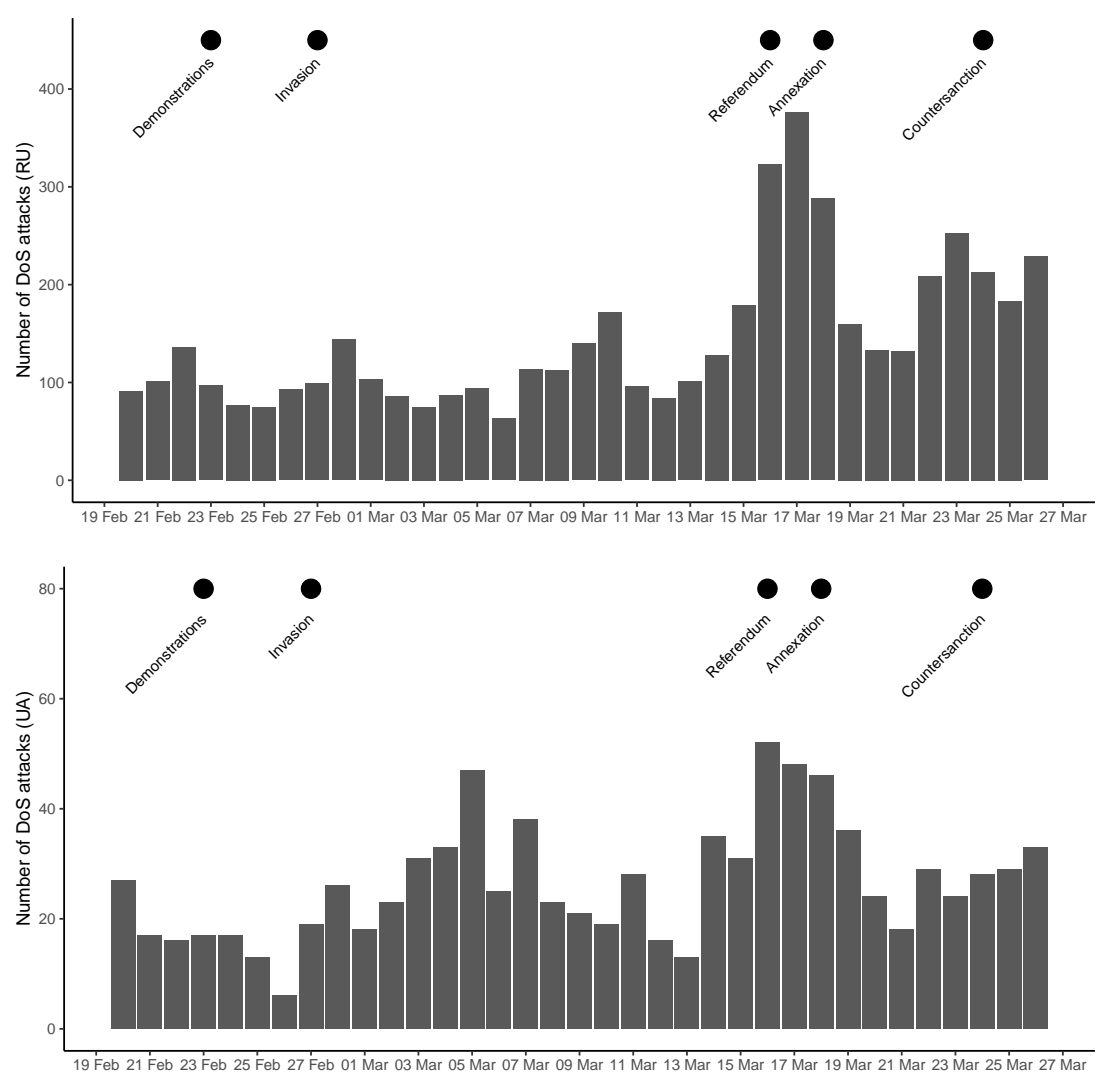

Figure A.1: Development of DoS attacks in Russia \& Ukraine in March 2014.

Figure A.2 illustrates the development of DoS attacks against U.S. and E.U. servers after the U.S. and E.U. imposed sanctions against Iran in 2010 and 2011, respectively. The figure clearly shows an increase in DoS attacks against U.S. servers after the imposition of sanctions on September 3, 2010, whereas there appears to be no obvious pattern related to the development of DoS attacks against European server ${ }^{14}$ Although I could not

\footnotetext{
${ }^{14}$ Moreover, I did not find any patterns when investigating the development of DoS attacks after the
} 
find anecdotal evidence on the potential perpetrators for DoS attacks in September 2010, tentative evidence from other incidents show that Iran-based groups or actors use DoS attacks for political purposes (HP Security Research, 2014).

Figure A.3 displays the development of DoS attacks around sanction threats and impositions against Syria in 2011. The figure shows a clear increase of DoS attacks against U.S. servers after the U.S. imposed sanction against Syria in April 2011. Moreover, there appears to be also an increase of attacks against E.U. servers, although this is not as clear-cut. Finally, anecdotal evidence suggest that in this case the patriotic hacker group "Syrian Electronic Army" was likely involved in launching disruptive cyber actions against the U.S. (Fisher and Keller, 2011), 15
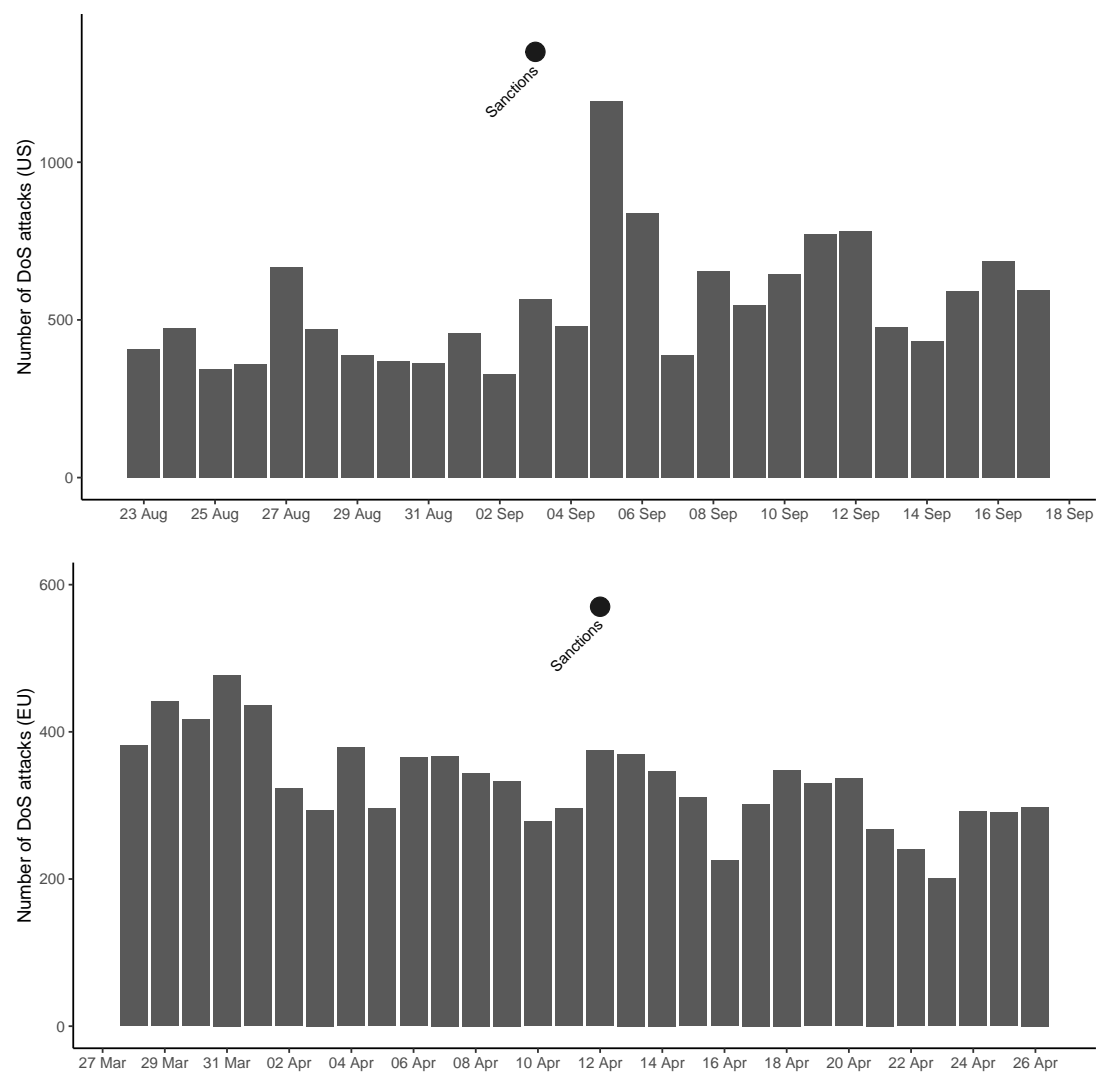

Figure A.2: Development of DoS attacks around sanction impositions against Iran in 2010 (U.S.) and 2011 (E.U.)

U.S. and E.U. threaten sanctions at different points in time (see replication file).

${ }^{15}$ Due to insufficient data it was not possible to investigate the Google Trend in both cases. 

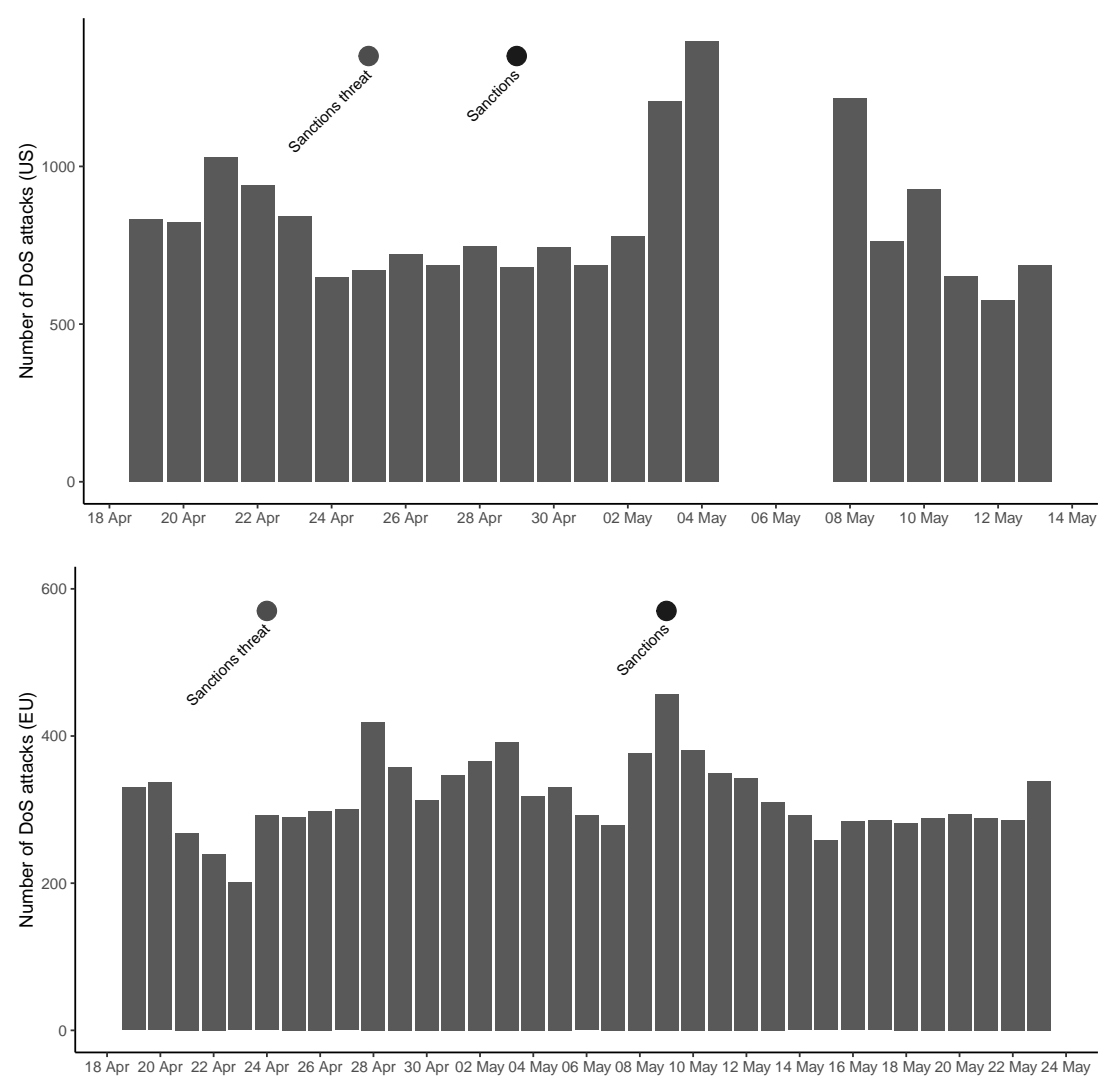

Figure A.3: Development of DoS attacks around sanction impositions against Syria in 2011. Note: Blank periods highlight failed measurements. 


\section{B Pre-processing Steps \& Method}

In this appendix, I describe my pre-processing steps and the used statistical method in more detail. As mentioned in the main text, my dependent variable - the number of DoS attacks - need to fulfill certain criteria in order to allow me to run the autoregressive distributed lag (ARDL) models.

First, I imputed missing values for the development of DoS attacks against the U.S. and the E.U. Due to technical failures in the measurement provided by CAIDA approximately $6.9 \%$ of the observations are not available. More precisely, in these cases, the system did not post-process the internet traffic data to measure randomly spoofed DoS attacks. Nevertheless, in only three times the measurement failed for longer than ten days (with a maximum number of 52 days) and the most common failure lasted two days only. Since statistical models and simulations dealing with time series require complete time series, I imputed these missing values using ARIMA state space representation with Kalman smoothing using the R-package imputeTS (Moritz and Bartz-Beielstein, 2017). The best-chosen values (AR order, differencing and MA order) for the U.S. time series were an $\operatorname{ARIMA}(5,1,3)$ model and for the E.U. time series an $\operatorname{ARIMA}(1,1,1)$ model with drift. Afterward, the predictions were smoothed using a Kalman algorithm (using observations before and after the NAs) due to the high volatility of the data. ${ }^{16}$ Figure B.1 highlights the imputed values in red for the split time series. In general, the missing values rarely overlap with the independent variables of interest and models without the imputed values show similar results as the main models (see Table D.8 in Appendix D).

Second, the time series indicate that there could have been a structural break during the temporal development of DoS attacks. If the time series suffers from such breaks, this leads to unreliable models and estimates. To check whether this is the case, I run Pettitt tests (Pettitt, 1979; Verstraeten et al., 2006). These tests suggest indeed that there are time-breaks in both time series (see Table B.1 and Figures B.2 B.3). Thus, in order to run efficient time series models on the data, I divide the two time series into four with breaking points at 2012-02-13 (U.S. time series) and 2012-01-31 (E.U. time

\footnotetext{
${ }^{16}$ For more details see Gardner, Harvey and Phillips (1980).
} 

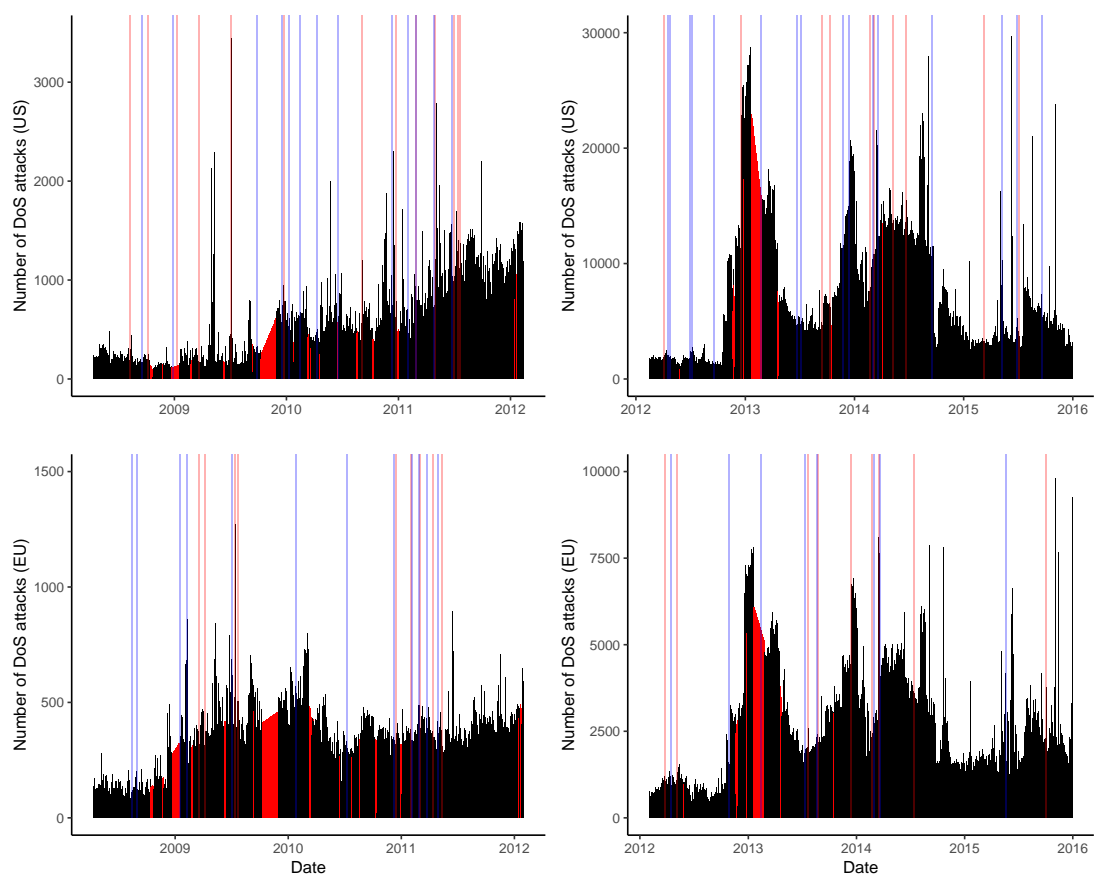

Figure B.1: Imputed predictions and NAs. Note: Time series split at breaking points. Red areas indicate imputed values, while blue and red horizontal lines, the sanction threats or impositions, respectively.

series). Although it is difficult to exactly determine the reasons behind these breaks, this might have something to do with the increased use of content delivery networks, DoS mitigation services, in general more internet-connected devices/servers, or simply more attacks from 2012 onward. As confirmed by CAIDA, this increase is not due to a change in the measurement procedure.

\begin{tabular}{lllc}
\hline & $U^{*}$ & p-value & Probable change point \\
\hline DoS U.S. & 1953000 & $<0.01$ & $2012-02-13$ \\
DoS E.U. & 1957500 & $<0.01$ & $2012-01-31$ \\
\hline
\end{tabular}

Table B.1: Pettitt test for structural breaks. Note: The null hypothesis, no change in the central tendency of a time series, is tested against the alternative hypothesis, change. $U^{*}$ is the maximum of $\mathrm{U}$, the test statistic as calculated in Verstraeten et al. (2006).

Third, it is necessary to check for non-stationary processes within the data. A stationary process describes a stochastic process where the variance and mean of a time series do not change over time, which is a requirement for many statistical tests. KwiatkowskiPhillips-Schmidt-Shin (KPSS) and/or Dickey-Fuller tests emphasize that all four time series suffer from non-stationary (see Table B.2). To solve these problems, I took the first 


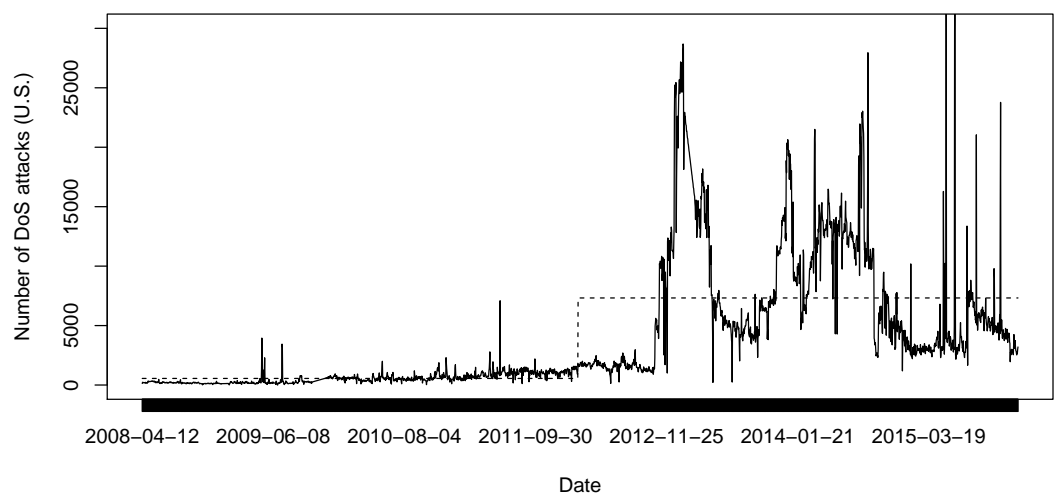

Figure B.2: Pettitt tests for structural breaks (U.S. time series). Note: Outliers above 30,000 DoS attacks per day are cut-off.

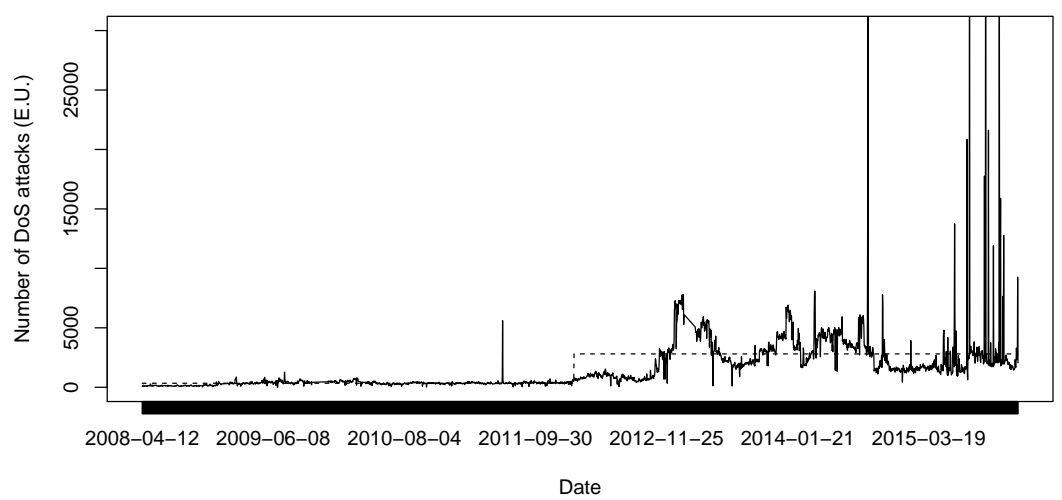

Figure B.3: Pettitt tests for structural breaks (E.U. time series). Note: Outliers above 30,000 DoS attacks per day are cut-off. 
differences of the dependent variable (Wooldridge, 2015) 17

\begin{tabular}{r|rr||rr}
\hline & KPSS test (level) & ADF test (level) & KPSS test $(\Delta)$ & ADF test $(\Delta)$ \\
\hline DoS U.S. $<=2012-02-13$ & $<0.01$ & $<0.01$ & 0.10 & $<0.01$ \\
DoS U.S. $>2012-02-13$ & 0.05 & 0.31 & 0.10 & $<0.01$ \\
DoS E.U. $<=2012-01-31$ & 0.03 & $<0.01$ & 0.10 & $<0.01$ \\
DoS E.U. $>2012-01-31$ & 0.03 & $<0.01$ & 0.10 & $<0.01$ \\
\hline
\end{tabular}

Table B.2: Kwiatkowski-Phillips-Schmidt-Shin (KPSS) and Dickey-Fuller (ADF) tests for non-stationary processes. While for the ADF test the null hypothesis is the existence of a unit-root (that causes non-stationarity), the null hypothesis for the KPSS is stationarity.

Fourth, the dependent variable should be approximately normally distributed. While applied researchers find perfectly normally distributed variables only rarely, quantilequantile plots show that the dependent variables for the U.S. and E.U. and the different periods are not normally distributed and suffer from heavy tails. To counter this, I used a modified box-cox transformation that allows negative values to make the variables normally distributed (Hawkins and Weisberg, 2017). Figures B.4 - B.5 show that these transformations greatly helped in making the outcome variables normally distributed.

U.S. $<=2012-02-13$ (untransformed

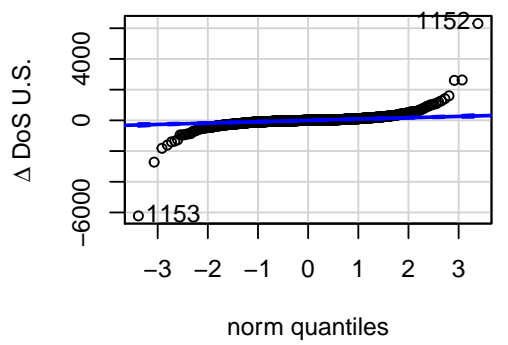

U.S. $<=2012-02-13$ (transformed)

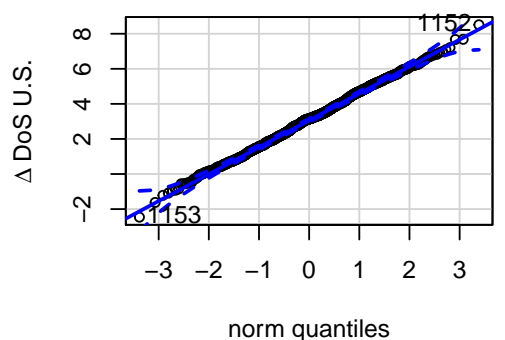

U.S. > 2012-02-13 (untransformed)

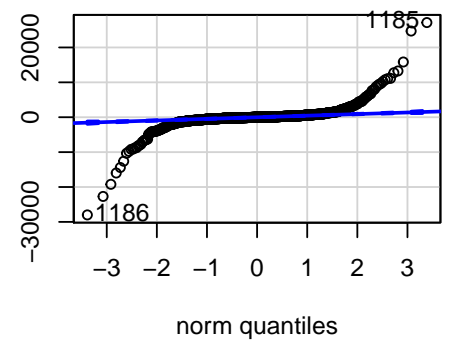

U.S. > 2012-02-13 (transformed)

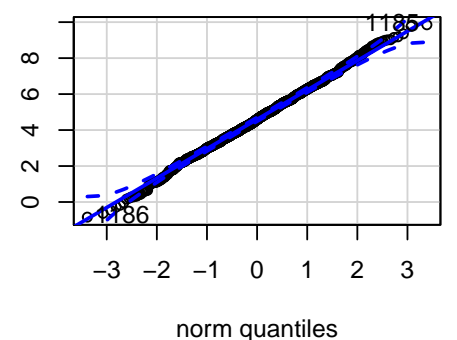

Figure B.4: Box-Cox transformation of $\Delta$ DoS attacks on the U.S.

\footnotetext{
${ }^{17}$ For some time series the KPSS tests revealed no serious problems with non-stationary, nevertheless as the Dickey-Fuller tests suggest an unit-root, I calculated first differences for these time series as well.
} 
E.U. $<=2012-01-31$ (untransformed

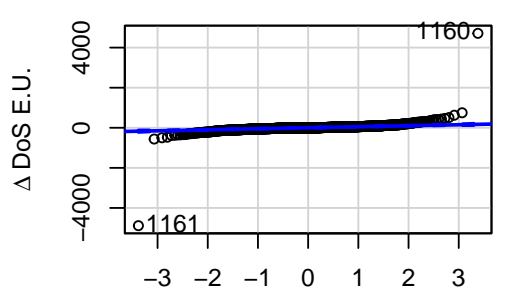

norm quantiles

E.U. $<=2012-01-31$ (transformed)

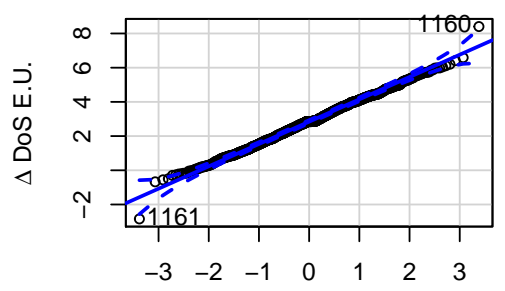

norm quantiles
E.U. > 2012-01-31 (untransformed)

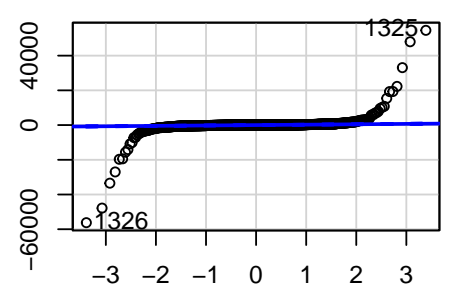

norm quantiles

E.U. > 2012-01-31 (transformed)

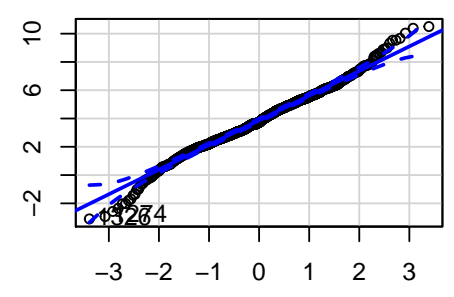

norm quantiles

Figure B.5: Box-Cox transformation of $\Delta$ DoS attacks on the E.U.

In the end, these pre-processing steps had been necessary to reliably and robustly run the ARDLs models. These models can be summarized as follows:

$$
\Delta D o S_{t}=\alpha_{0}+\sum_{i=1}^{p} \alpha_{i} \Delta D o S_{t-i}+\sum_{j=0}^{q} \beta_{j} \text { sanction }_{t-j}+\sum_{k=0}^{r} \beta_{k} \text { threat }_{t-k}+\epsilon_{t}
$$

Where $p$ is the maximal number of lags for the dependent variable, $q$ for the sanction imposition variable, $r$ for the threat variable and $\epsilon_{t}$ the error term.

As described in the main text, I used the Akaike Information Criterion (AIC) to find the models with the best fitting lags (Burnham and Anderson, 2004) and restricted the maximum number of lags the AIC selection algorithm can choose to 14 days because a digital retaliation to sanction threats and impositions should happen relatively soon afterward. Finally, I included more lags of the dependent variable when the model still showed autocorrelation issues 18

\footnotetext{
${ }^{18}$ Using the Bayesian Information Criterion leads to much fewer lags. Since the goal of this study is to determine whether sanctions are at all correlated to DoS attacks, I used the AIC.
} 


\section{Regression Results \& Additional Simulations}

In this appendix, I report the regression tables and additional simulations, I referred to in the main text.

Table C.1 shows the main regression results that allow to evaluate the direction of an estimate and whether a variable has a time effect. At first glance, it appears that the coefficients of the sanction imposition variable are mostly positive, while the opposite is true for sanction threats. Besides, for the sanction imposition variable the models suggest the inclusion of temporal lags, while for the threat variable this is not the case. A concern may be that the inclusion of both variables biases inference for the sanction threat variable because the imposition of sanctions can be considered as a "post-treatment" variable. However, as shown in Table C.3 running analyses with the sanction threat variable alone also suggest a null finding.

One common way for ARDL models to investigate temporal effects of variables is to calculate the so-called long-run multiplier (LRM) coefficient (Wooldridge, 2015). This statistic is the temporally aggregated coefficient of the variable of interest, i.e. the overall effect size, and allows to not only investigate the direction but also the magnitude of a variable's impact. The following equation shows how this multiplier is calculated:

$$
L R M=\frac{\sum_{i=0}^{p} b_{i}}{1-\sum_{j=1}^{q} a_{j}}
$$

Table C.2 reports the LRM coefficient for the sanction imposition variable for all eight models. For the U.S. time series, all coefficients are positive. The time series later than 2012-02-13, which considers sanctions against technologically advanced countries, highlights the largest coefficient. The coefficients for the E.U. are also mostly positive (but considerably smaller) and display higher values when considering sanctions against more technological countries defined as a value above $25 \%$ compared to the global average in the ICT Development Index (ITU, 2017). These results support the finding of a positive association between the imposition of sanctions and a rise in the number of DoS attacks, in particular when the United States imposes sanctions against technologically 


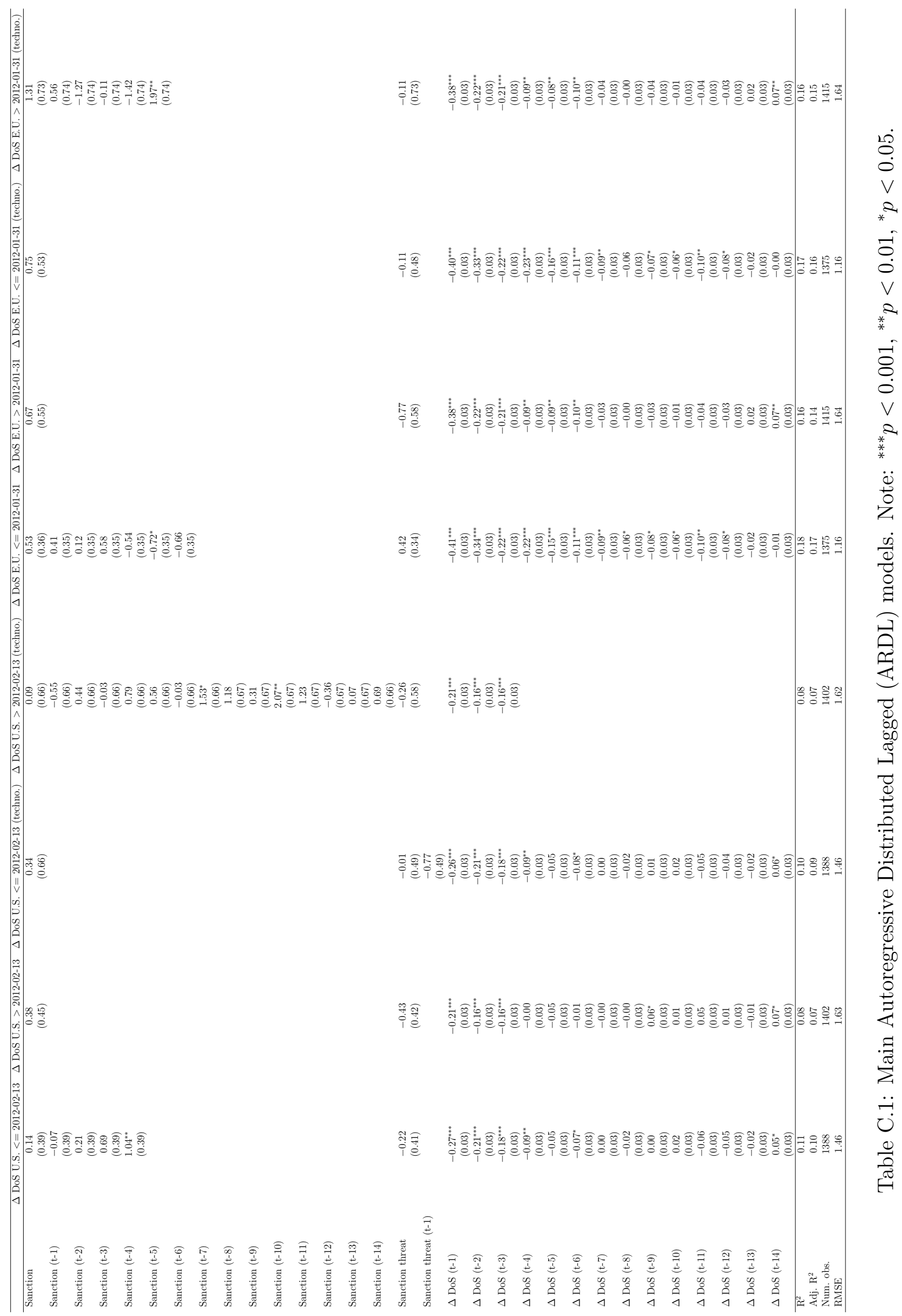


advanced countries. However with the LRM coefficient it is hard to determine the levels of uncertainty for this relationship. This is why I used the simulation approach as proposed by Philips $(2018)$ in the main text.

\begin{tabular}{lc}
\hline Variable & Long-run multiplier coefficient \\
\hline Sanction U.S. $<=2012-02-13$ & 1.04 \\
Sanction U.S. $>$ 2012-02-13 & 0.27 \\
Sanction U.S. (techno.) $<=2012-02-13$ & 0.18 \\
Sanction U.S. (techno.) $>2012-02-13$ & 5.19 \\
Sanction E.U. $<=2012-01-31$ & -0.09 \\
Sanction E.U. $>$ 2012-01-31 & 0.31 \\
Sanction E.U. (techno.) $<=2012-01-31$ & 0.25 \\
Sanction E.U. (techno.) $>2012-01-31$ & 0.49 \\
\hline
\end{tabular}

Table C.2: Long-run multiplier coefficients.
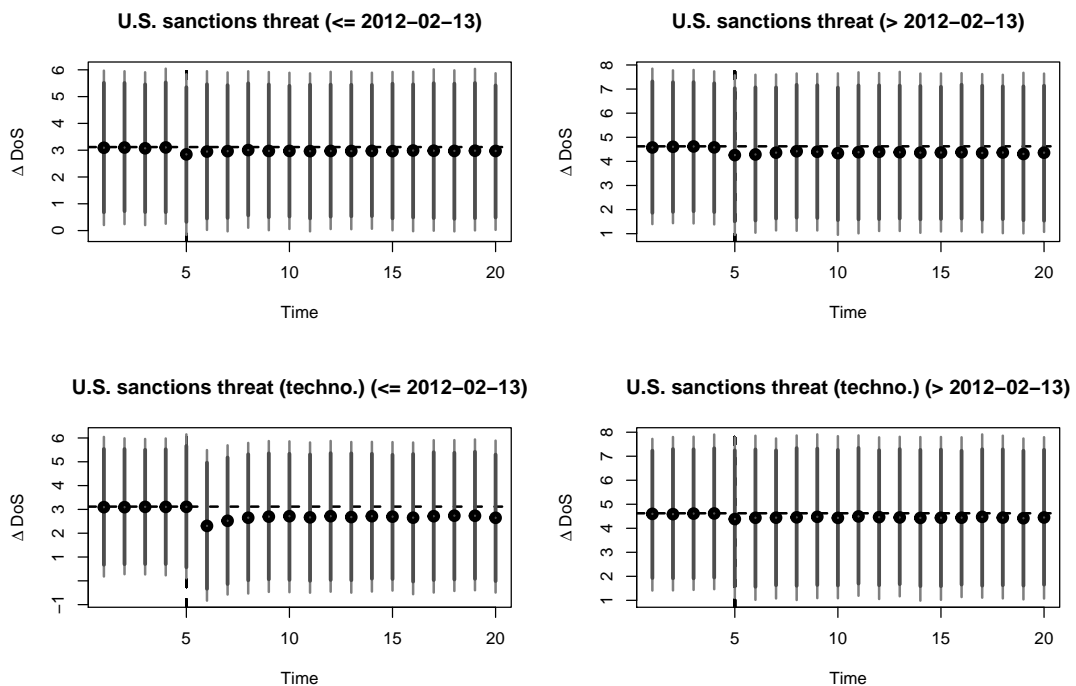

Figure C.1: Simulations of DoS attacks (U.S.) - sanction threats. Note: Based on 10000 draws. $95 \%$ and $90 \%$ confidence intervals are displayed. The intervention is marked with a dashed vertical line, the horizontal line shows the null effect. The simulations suggest a null effect of sanction threats on the development of DoS attacks on the U.S., when running models without the imposition variable. 

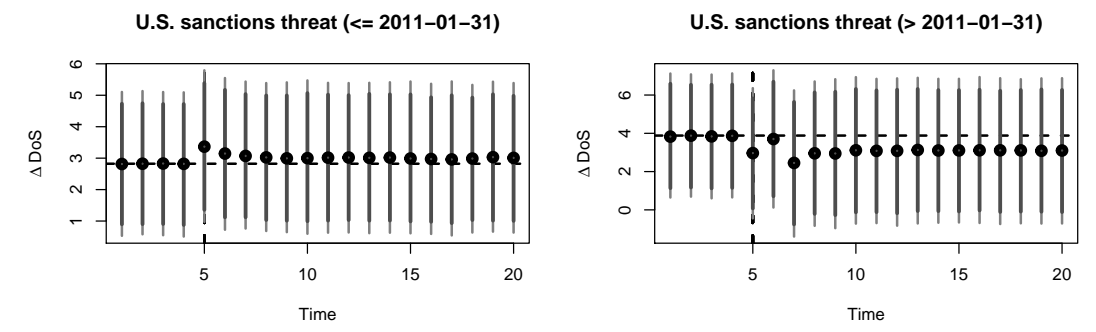

U.S. sanctions threat (techno.) $(<=2011-01-31)$

U.S. sanctions threat (techno.) (> 2011-01-31)
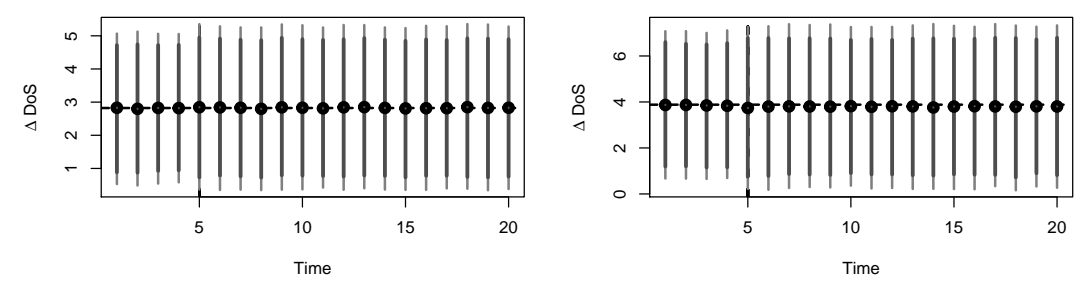

Figure C.2: Simulations of DoS attacks (E.U.) - sanction threats. Note: The simulations suggest a null effect of sanction threats on the development of DoS attacks on the E.U., when running models without the imposition variable. 


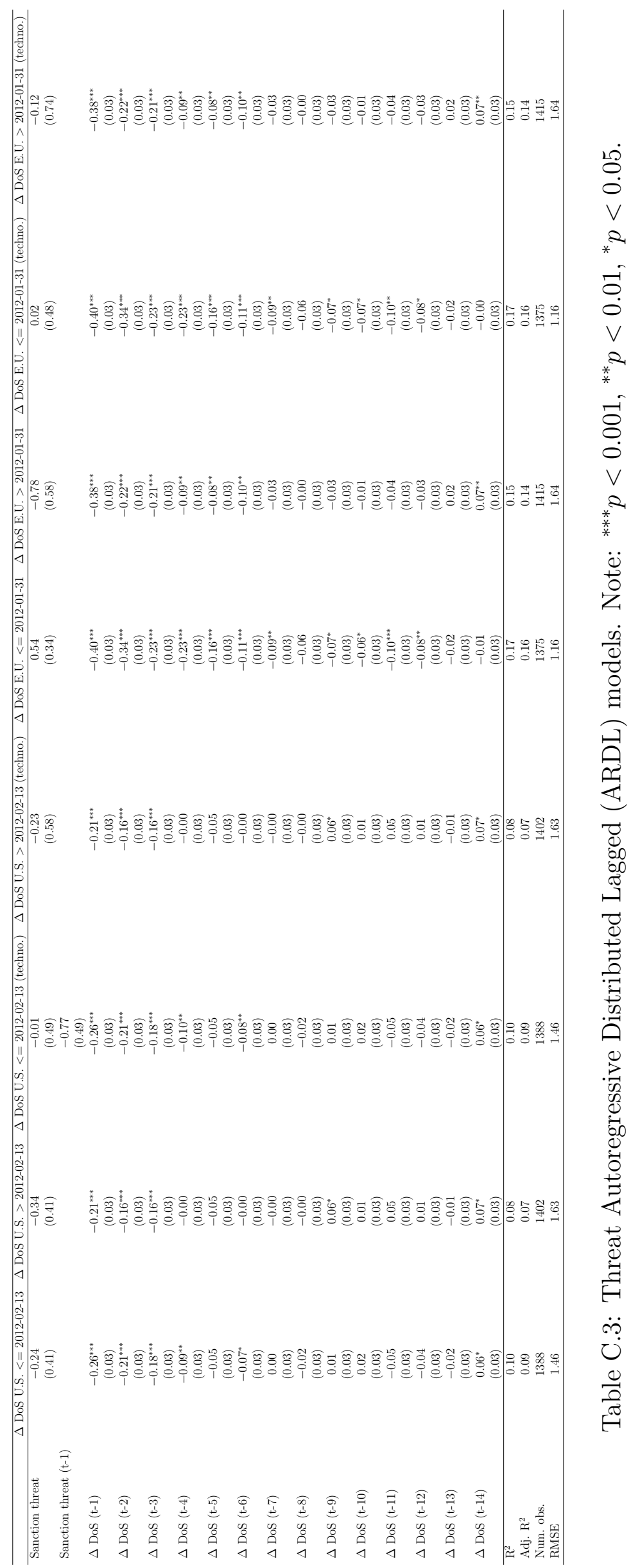




\section{Robustness and Sensitivity Tests}

In this appendix I present the additional robustness and sensitivity tests that are referred to in the main text. While I present these results graphically in the main text, the corresponding tables are reported at the end of this section.

Reverse causality One concern might be that the analysis faces problems of reverse causality. The U.S. indeed imposed sanctions against Iranian citizens recently because they were alleged to be involved in the large-scale DoS attacks against the U.S. between 2011 and 2013 (Volz, 2018). While this example emphasizes that it is rather unlikely that governments impose sanctions directly after a cyberattack hit the sender country, it might be that targeted countries already launch DoS attacks before the imposition date. To test whether this is the case, I run Granger (causality) tests showing whether the inclusion of lags increases the model fit (F statistic) for the respective models, where the dependent variable is either $\triangle D o S$ or sanction. Table D.1 shows that in the case of the U.S. time series, two models with DoS attacks as the dependent variable display a significantly better model fit. This finding supports the previous results and highlights that sanctions do explain some variance in the development of DoS attacks. While for some E.U. time series this is the case as well, here the Granger tests also highlight that DoS attacks correlate to sanctions before their imposition earlier or equal to the 201201-31 time series.

Different proxy variable for technological advancement Another issue may be the validity of the used index for technological development. To check whether this is an issue, I used a different proxy variable to measure technological advancement. I follow Valeriano, Jensen and Maness (2018) who proposes a proxy variable that considers two forms of cyber power: technical infrastructure and knowledge capital. To create this index, Valeriano, Jensen and Maness (2018) rely on six World Bank indicators (number of broadband subscriptions, number of secure servers, percentage of high technology exports, number of internet users, absolute number of scientific and technical journal 


\begin{tabular}{rrllr}
\hline $\mathrm{F}$ & $\operatorname{Pr}(>\mathrm{F})$ & Direction & Country & Time \\
\hline $\mathbf{2 . 5 3}$ & $\mathbf{0 . 0 4}$ & Sanction -> DoS & U.S. & $<=\mathbf{2 0 1 2 - 0 2 - 1 3}$ \\
0.77 & 0.59 & DoS -> Sanction & U.S. & $<=2012-02-13$ \\
No lag & No lag & Sanction -> DoS & U.S. & $>2012-02-13$ \\
0.72 & 0.75 & DoS -> Sanction & U.S. & $>2012-02-13$ \\
No lag & No lag & Sanction (techn.) -> DoS & U.S. & $<=2012-02-13$ \\
0.55 & 0.91 & DoS -> Sanction (techn.) & U.S. & $<=2012-02-13$ \\
$\mathbf{1 . 7 6}$ & $\mathbf{0 . 0 4}$ & Sanction (techn.) - $>$ DoS & U.S. & $>\mathbf{2 0 1 2 - 0 2 - 1 3}$ \\
0.25 & 0.76 & DoS -> Sanction (techn.) & U.S. & $>2012-02-13$ \\
$\mathbf{2 . 4 5}$ & $\mathbf{0 . 0 2}$ & Sanction - $>$ DoS & E.U. & $<=\mathbf{2 0 1 2 - 0 1 - 3 1}$ \\
$\mathbf{1 . 9 7}$ & $\mathbf{0 . 0 2}$ & DoS -> Sanction & E.U. & $<=\mathbf{2 0 1 2 - 0 1 - 3 1}$ \\
No lag & No lag & Sanction - > DoS & E.U. & $>2012-01-31$ \\
0.79 & 0.57 & DoS -> Sanction & E.U. & $>2012-01-31$ \\
No lag & No lag & Sanction (techn.) $>$ DoS & E.U. & $<=2012-01-31$ \\
$\mathbf{2 . 0 1}$ & $\mathbf{0 . 0 1}$ & DoS -> Sanction (techn.) & E.U. & $<=\mathbf{2 0 1 2 - 0 1 - 3 1}$ \\
$\mathbf{3 . 0 4}$ & $\mathbf{0 . 0 1}$ & Sanction (techn.) - $>$ DoS & E.U. & $>\mathbf{2 0 1 2 - 0 1 - 3 1}$ \\
0.44 & 0.96 & DoS -> Sanction (techn.) & E.U. & $>2012-01-31$ \\
\hline
\end{tabular}

Table D.1: Granger tests. Bold highlighted directions are significant at $p<0.05$. The number of lags is the same as in the main models.

articles and the number of patent applications) 19 As shown in Figure D.1, the results remain the same when considering sanctions against countries that score $25 \%$ or higher compared to the yearly average in this index.
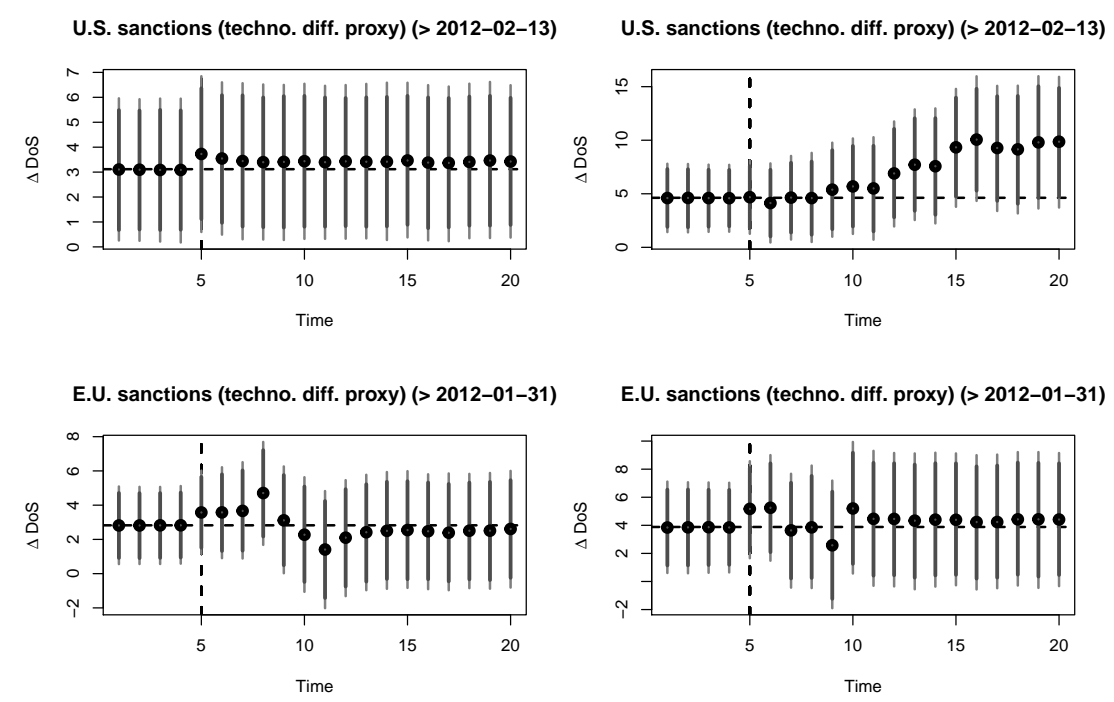

Figure D.1: Simulations of DoS attacks - different proxy for technological advancement

\footnotetext{
${ }^{19}$ These indicators are then normalized into z-scores to have comparable observations per country and year and the average is taken to create an unified cyber power index. When taking the average, I disregarded missing values for some indicators.
} 
Economic development as country-specific factor To test whether it is not the technological capability of the target country that is important but other country features, I conduct placebo tests considering sanctions against countries with a logged GDP p.c. above $25 \%$ of the worldwide year average (World Bank, 2019). The found patterns are very similar, suggesting that not necessarily a country's technological advancement but general economic development is important (see Figure D.2 and Table D.3. However, since the two variables highly correlate with $r=0.9$, it is difficult to distinguish both concepts.
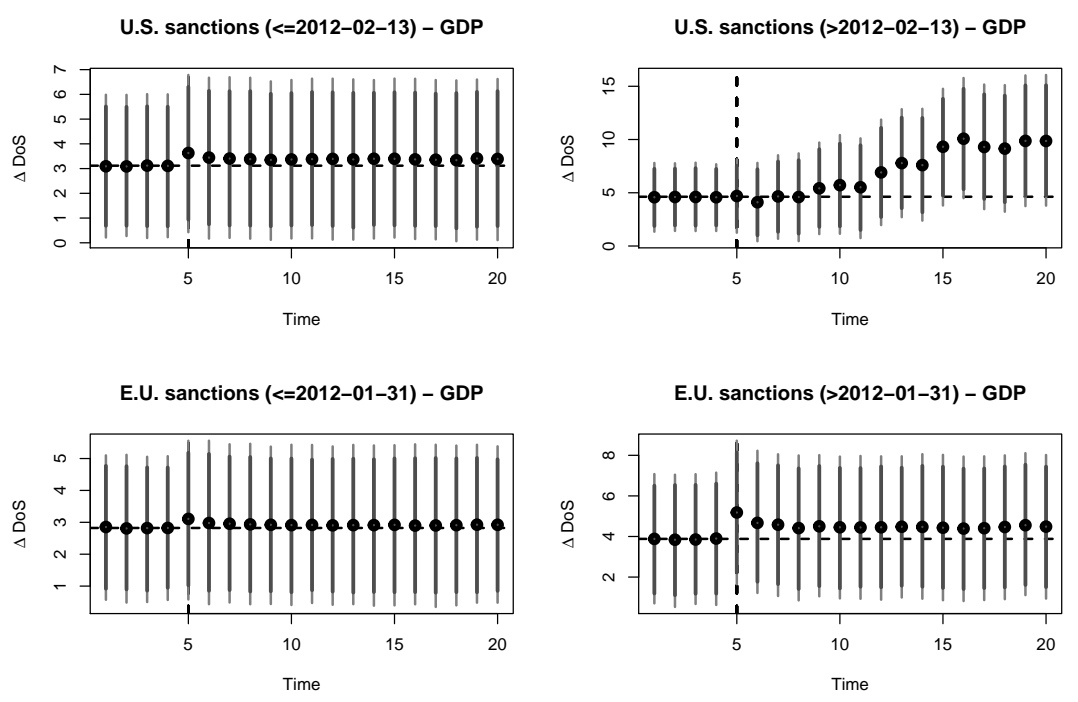

Figure D.2: Simulations of DoS attacks (U.S.) - GDP.

Different thresholds to define technological advancement As mentioned in the main text, I employ different thresholds to define technologically advanced countries and consider sanctions on countries with an IDI score above $50 \%$ or $75 \%$ of the worldwide yearly average. Due to fewer sanction cases, these analyses are restricted to the time series later than 2012-02-13 (U.S.) and 2012-01-31 (E.U.), respectively. The results show a stronger increase, the higher the technological development of sanction-targeted countries (see Figures D.3 and Table D.4.

Global development of DoS attacks It may be that the found relationship is not specific for DoS attacks on the U.S. but captures a global trend. To test this possibility, 
U.S. sanctions (techno. 50\%) (> 2012-02-13)

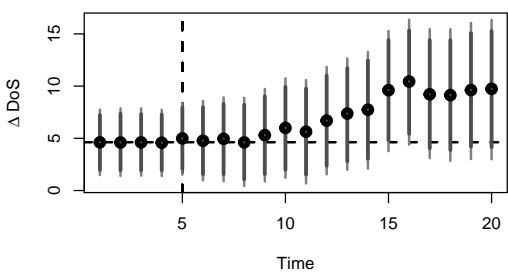

E.U. sanctions (techno. 50\%) (> 2012-01-31)

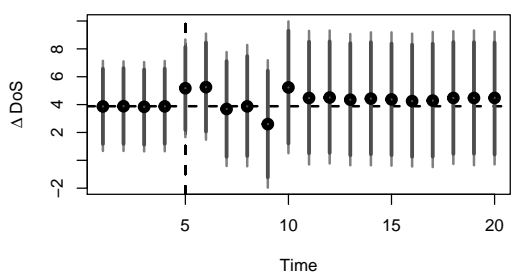

U.S. sanctions (techno. 75\%) (> 2012-02-13)

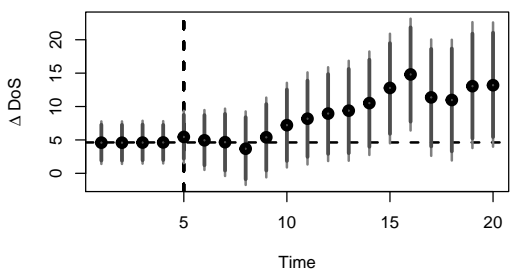

E.U. sanctions (techno. 75\%) (> 2012-01-31)

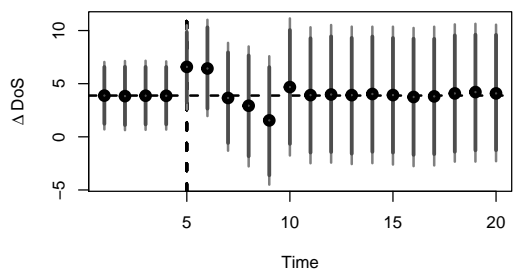

Figure D.3: Simulations of DoS attacks (different thresholds). Note: Based on 10000 draws. $95 \%$ and $90 \%$ confidence intervals are displayed.

I conduct a placebo test using the number of worldwide DoS attacks as the dependent variable. For most time series, the results do not show the same relationships anymore, which supports the notion that the development is U.S.-specific (see Figure D.4 and Table D.5). 20

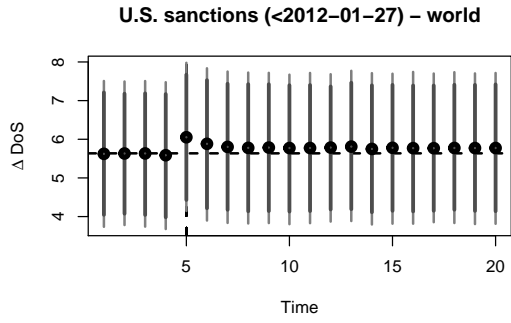

U.S. sanctions (techno.) (<2012-01-27) - world

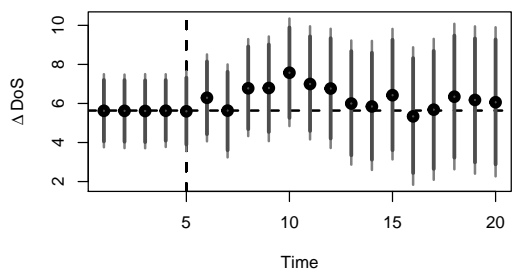

U.S. sanctions (>2012-01-27) - world

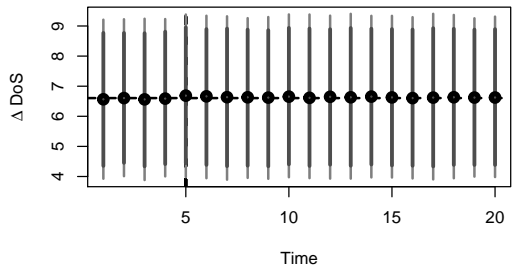

U.S. sanctions (techno.) (>2012-01-27) - world

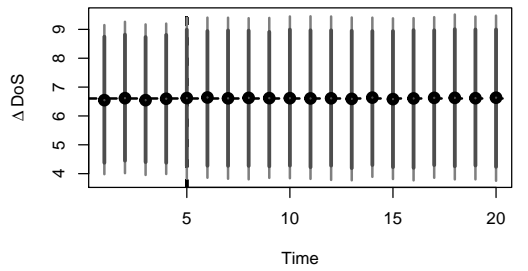

Figure D.4: Simulations of DoS attacks (world).

\footnotetext{
${ }^{20}$ Only for the time series earlier than or equal to 2012-01-27, which focuses on technologically advanced targets, there seems to be some insignificant pattern suggesting that DoS attacks increased worldwide (that may be due to the U.S. sanction or some other event).
} 
Strong DoS attacks only Since the DoS data capture even the smallest attacks that may simply be noise, I only consider large DoS attacks, defined as belonging to the top $30 \%$ of attacks on a country/year as measured by the intensity of the data traffic used in the attack. The patterns remain the same and are additionally near to borderline significance for the first U.S. and second E.U. time series when technologically advanced countries are targeted (see Figure D.5 D.6 and Table D.6.

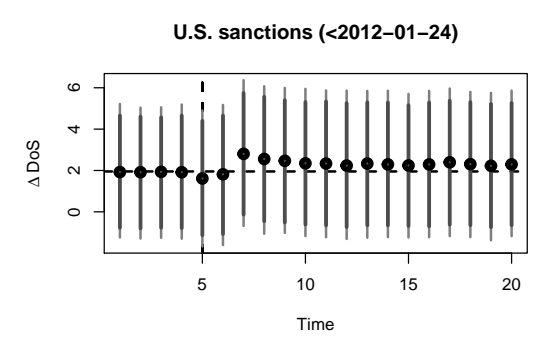

U.S. sanctions (techno.) (<2012-01-24)

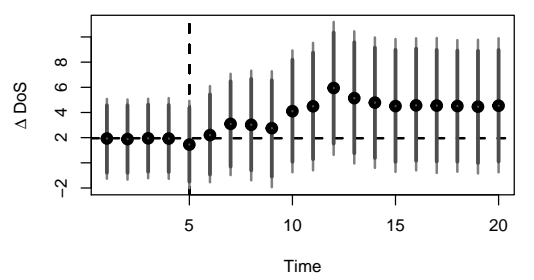

U.S. sanctions (>2012-01-24)

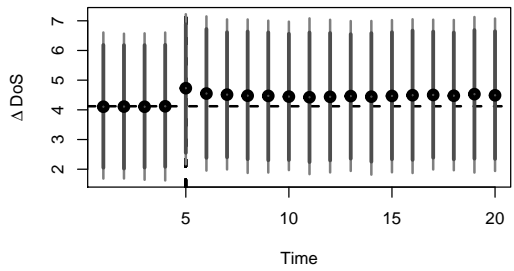

U.S. sanctions (techno.) (>2012-01-24)

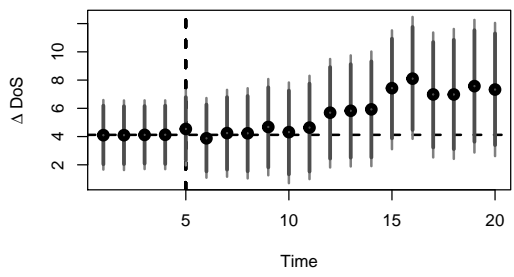

Figure D.5: Simulations of DoS attacks (U.S.) - strong attacks.
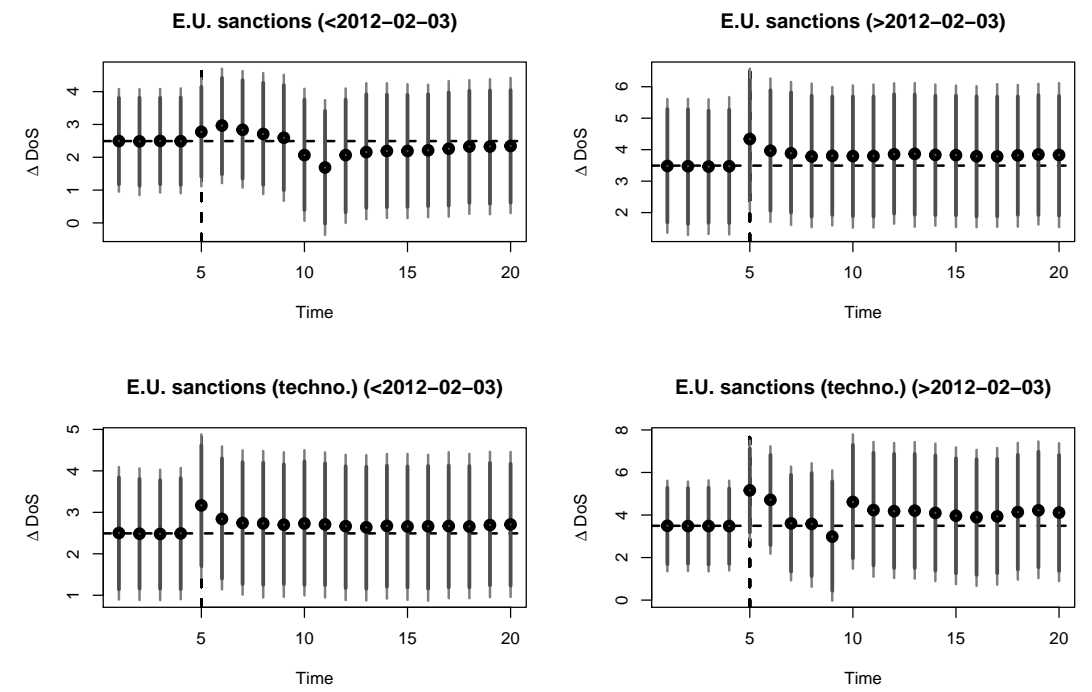

Figure D.6: Simulations of DoS attacks (E.U.) - strong attacks. 
Different lag lengths It may be that the chosen lag length is too short. When I extend the maximal lag length to 21 days, the number of optimal lags remains the same for the independent variables (see Table D.10).

Models without box-cox transformation Running models without using the boxcox transformations highlight similar results and even show clearer patterns for the U.S. time series considering sanctions on technologically advanced countries earlier or equal than 2012-02-13 (see Figures D.7 D.8 and Table D.7).
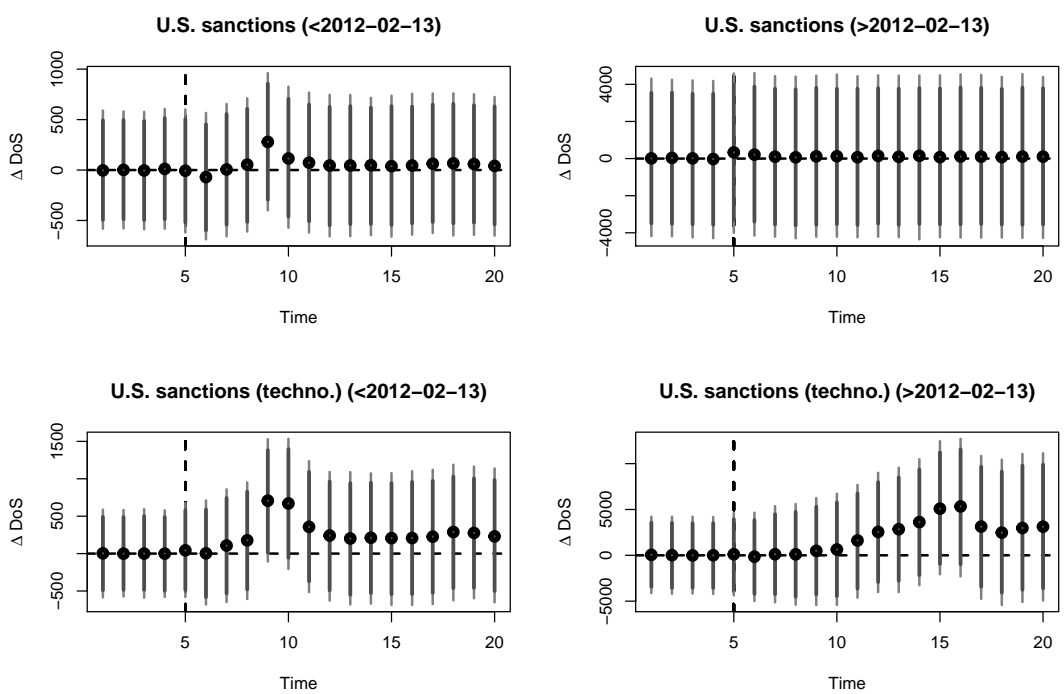

Figure D.7: Simulations of DoS attacks (U.S.) - untransformed.
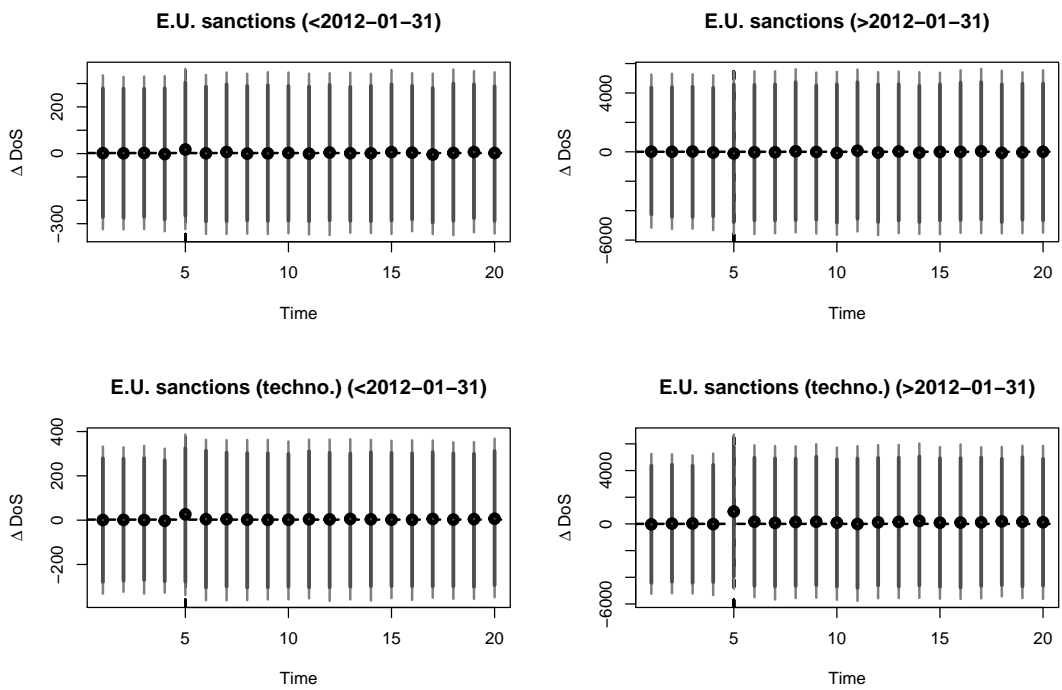

Figure D.8: Simulations of DoS attacks (E.U.) - untransformed. 
Models without filling NAs Comparing the regression tables when I run the models without NA imputations shows the same patterns as in the main models (see Table D.8) ${ }^{21}$

Weekly aggregated models When I aggregate the models to a one-week granularity this leads to higher levels of uncertainty but still similar patterns (see Figures D.9 D.10 and Table D.9.
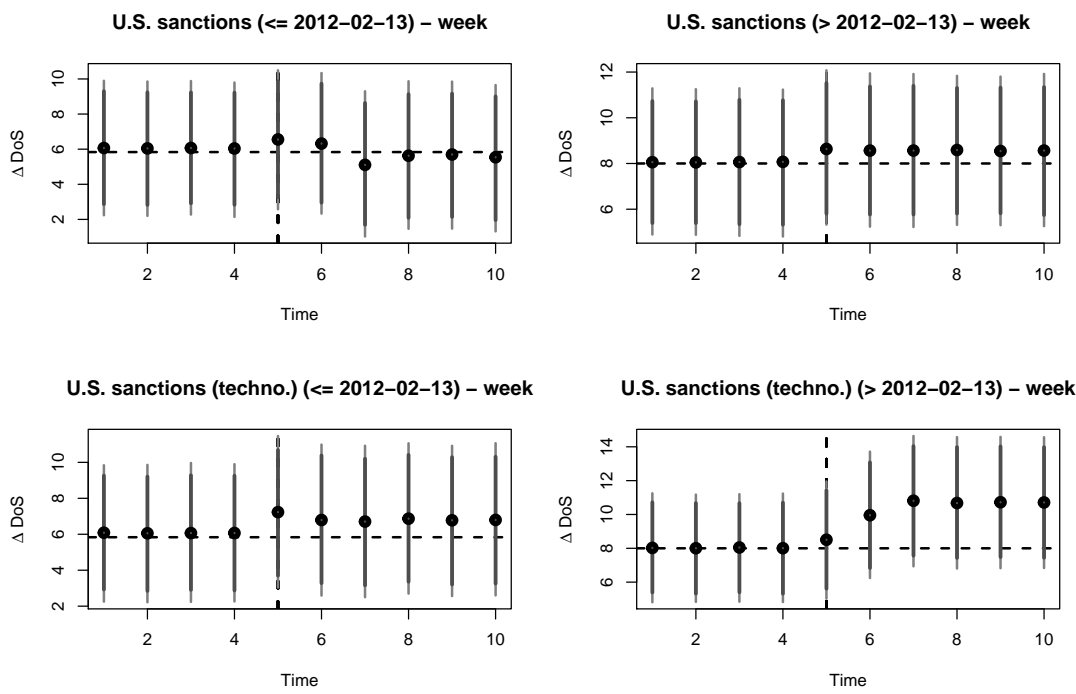

Figure D.9: Simulations of DoS attacks (U.S.) - week level.
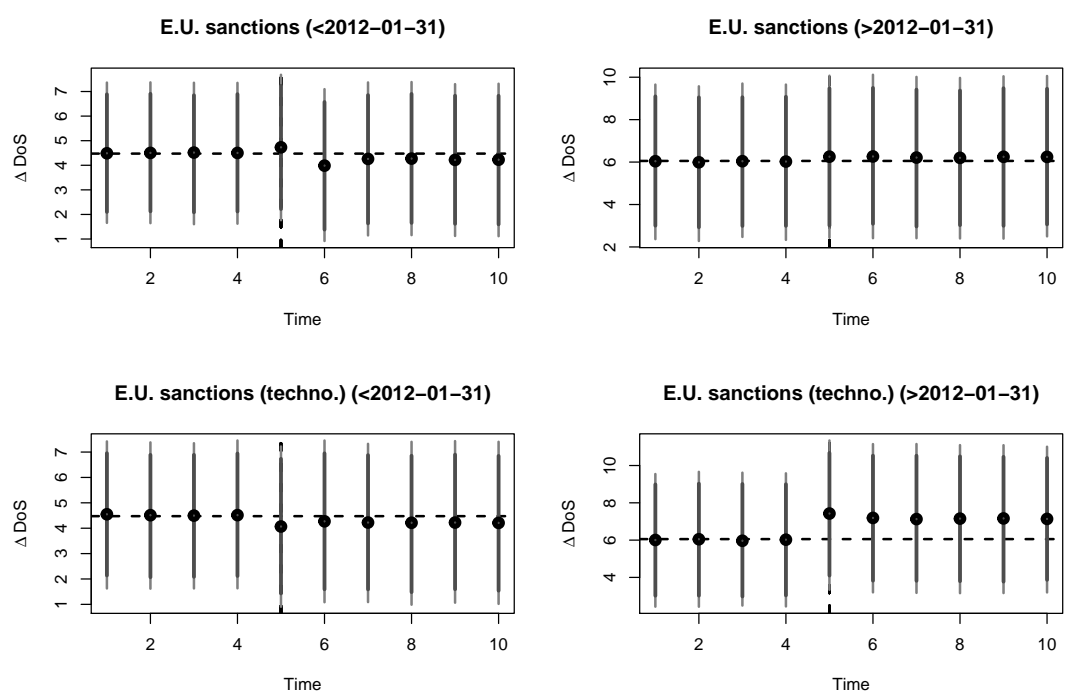

Figure D.10: Simulations of DoS attacks (E.U.) - week level.

\footnotetext{
${ }^{21}$ Due to the NAs simulations were unfortunately not possible.
} 
Sanction types Finally, I investigate whether the type of sanctions matter. To classify sanction types, I follow Hellmeier (2020) and discriminate between targeted (asset freezes, travel bans), low-level (import/export restrictions, termination of foreign aid, suspension of economic agreements, diplomatic sanctions) and high-level sanctions (economic embargoes, blockades, major financial sanctions). Since sanction types are often combined, this categorization is not exclusive. Another caveat is that this information is coded ex-post and aggregated to the whole sanctioning periods.

Inspecting the sanction types reveals that targeted sanctions are related to an increase of DoS attacks for the U.S. time series later than 2012-02-13, again stronger, considering sanctions on technologically advanced countries (see Figure D.11). Figure D.13 highlights that low-level sanctions are positively related to an increase of DoS attacks in the U.S. time series before or equal to 2012-02-13. Figure D.15illustrates a substantially stronger increase when one considers high-level sanctions. However, since in the period of study the data records only the imposition of two high-level sanctions, against Syria in 2011 and Russia in 2014, it is difficult to determine whether the targeted country or the sanction type influences the likelihood of a digital retaliation. However, given that the results show an increase in DoS attacks against servers in the U.S. after the imposition of all different sanction types, it seems that country characteristics matter more.
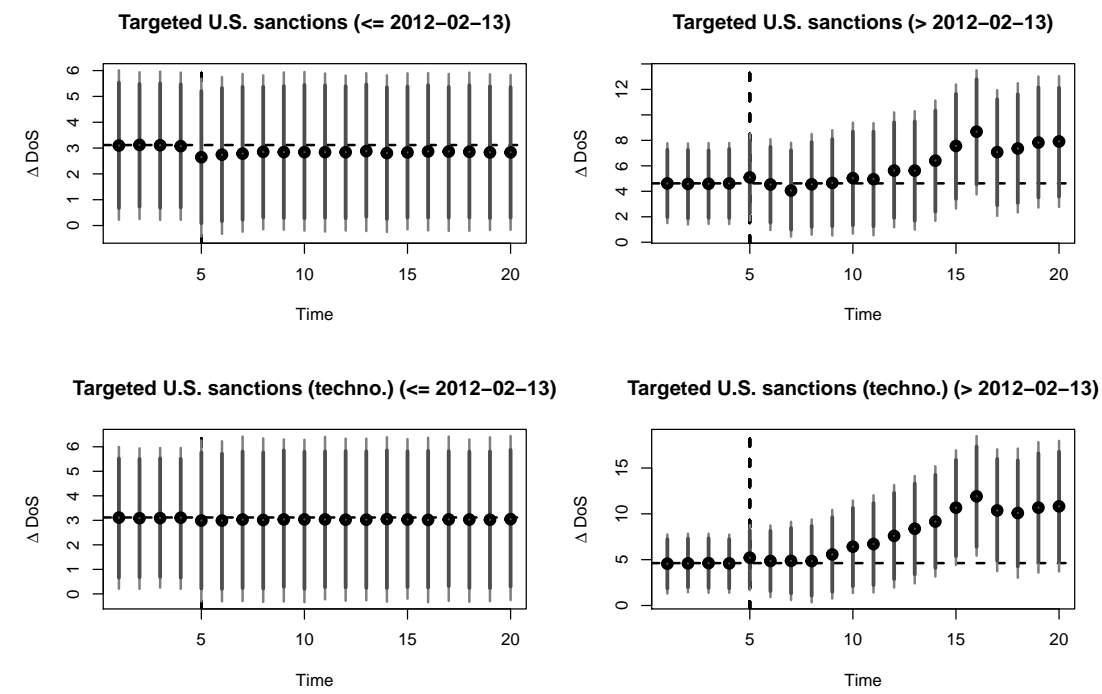

Figure D.11: Simulations of DoS attacks (U.S.) - Targeted sanctions. 

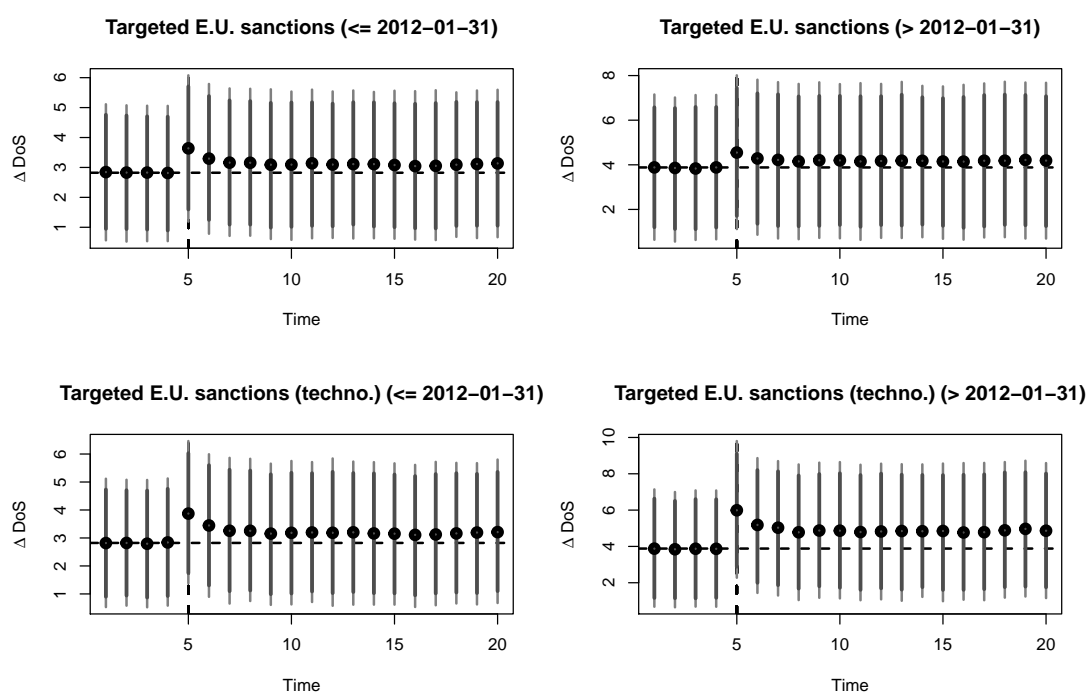

Figure D.12: Simulations of DoS attacks (E.U.) - Targeted sanctions.
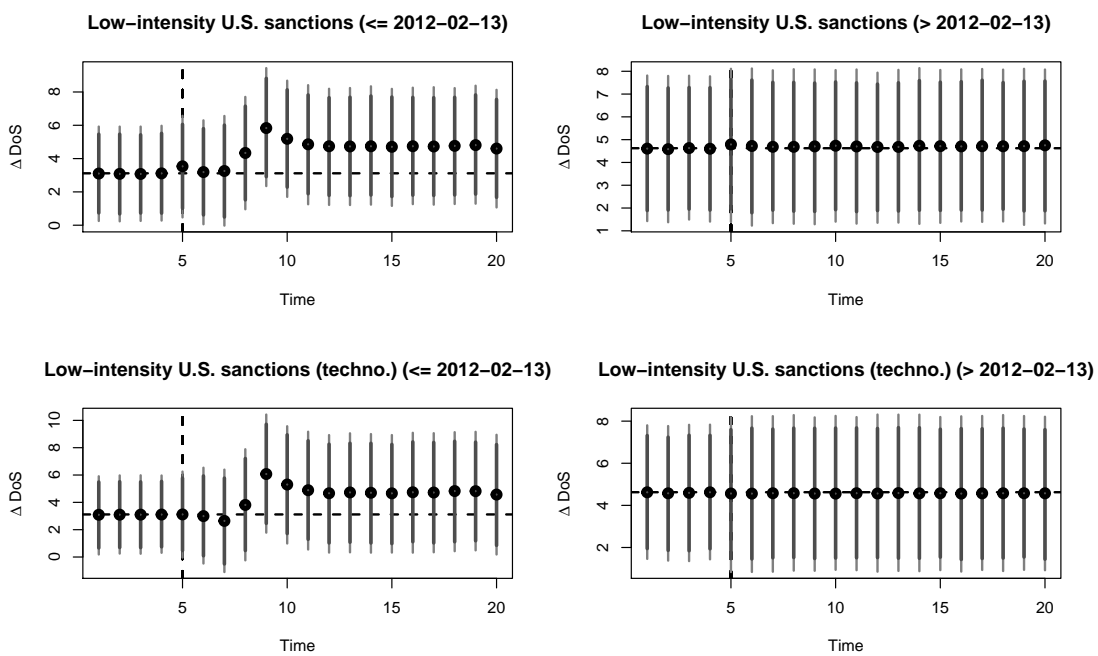

Figure D.13: Simulations of DoS attacks (U.S.) - Low-intensity sanctions. 

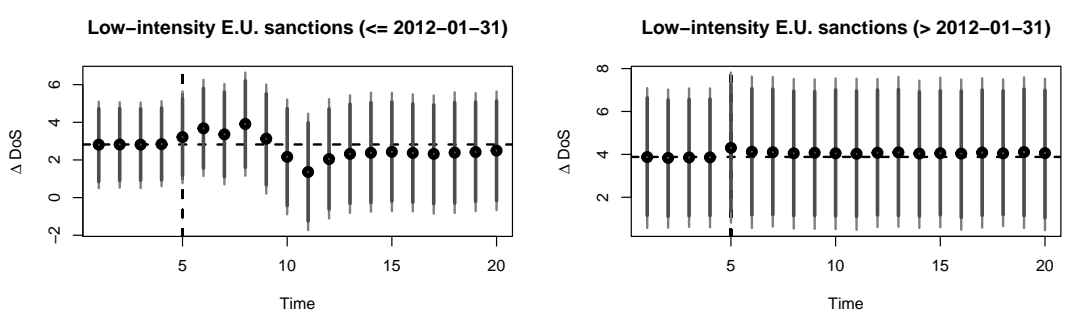

Low-intensity E.U. sanctions (techno.) $(<=2012-01-31)$

Low-intensity E.U. sanctions (techno.) (> 2012-01-31)
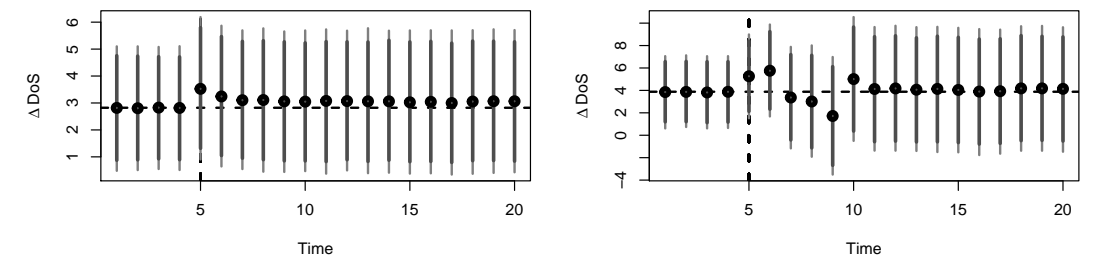

Figure D.14: Simulations of DoS attacks (E.U.) - Low-intensity sanctions.
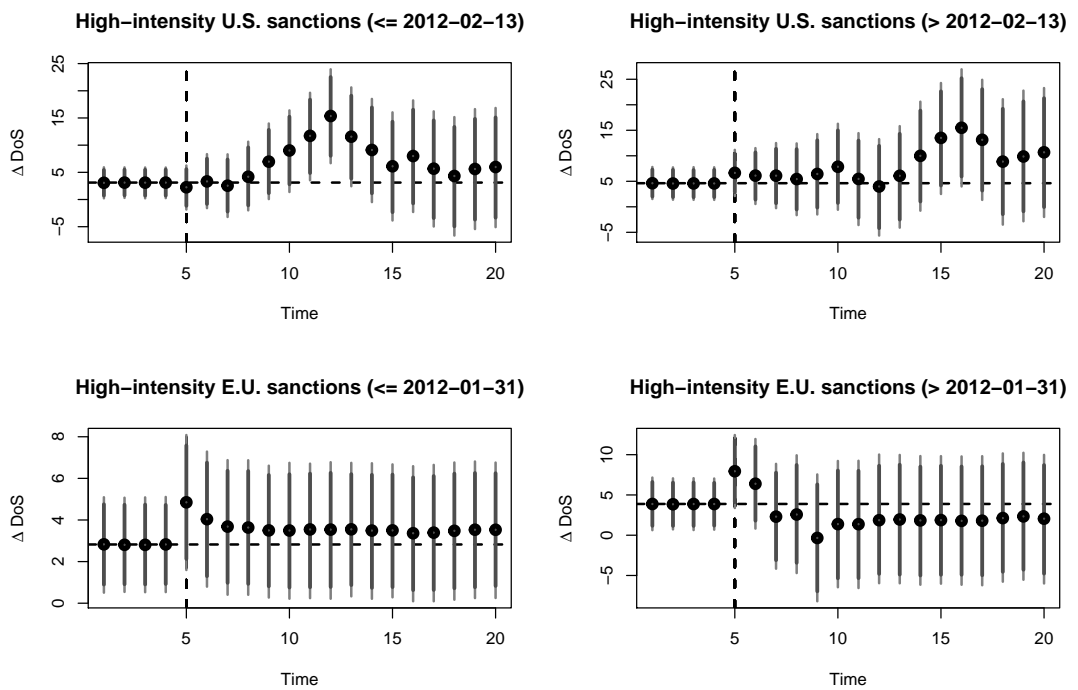

Figure D.15: Simulations of DoS Attacks (U.S. \& E.U.) - High-intensity sanctions. 
Influential observations Some of the robustness tests, in particular the ones displayed in Figure D.3 and Figure D.15, suggest that sanctions against Russia in 2014 may drive the main results. To investigate how valid this concern is, I run models leaving out sanctions against Russia in 2014. Although this increases the level of uncertainty, Figure D.16 still show similar patterns as in the main analysis.

U.S. sanctions (techno., w/o Russia) (> 2012-02-13)

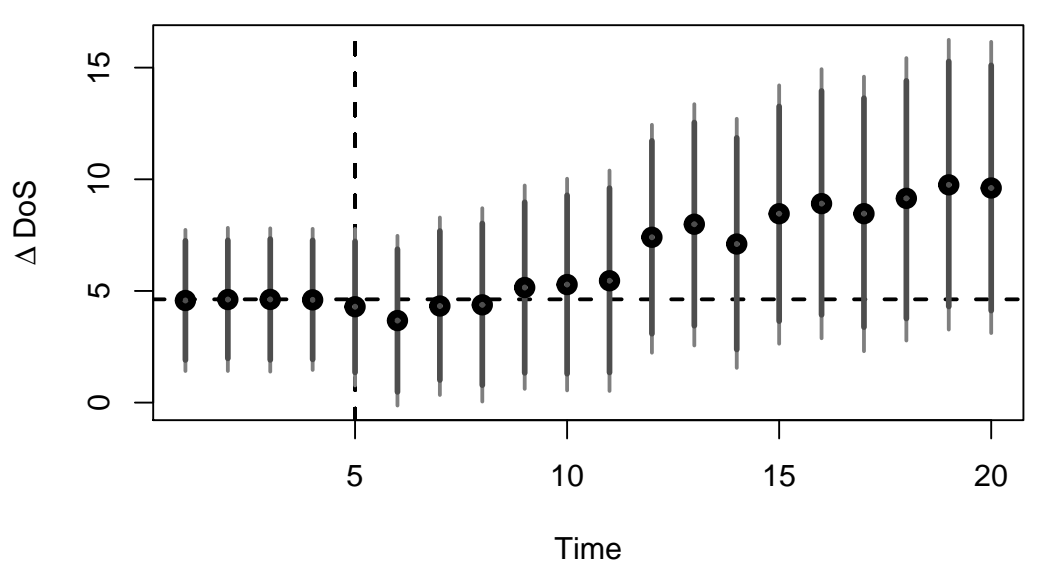

Figure D.16: Simulations of DoS attacks (U.S.) - Sanctions on technologically advanced countries (without Russia). 


\begin{tabular}{|c|c|c|c|c|}
\hline & $\Delta$ DoS U.S. $>2012-02-13$ (techno., different proxy) & $\Delta$ DoS U.S. $>2012-02-13$ (techno, different proxy) & $\Delta$ DoS E.U. $>2012-01-31$ (techno., different proxy) & $\Delta$ DoS E.U. > 2012-01-31 (techno, different proxy) \\
\hline Sanction & 0.61 & 0.09 & 0.76 & 1.31 \\
\hline & $(0.60)$ & $(0.66)$ & $(0.50)$ & $(0.73)$ \\
\hline Sanction $(\mathrm{t}-1)$ & & -0.55 & 0.30 & 0.56 \\
\hline & & $(0.66)$ & $(0.48)$ & $(0.74)$ \\
\hline Sanction (t-2) & & 0.44 & 0.35 & -1.27 \\
\hline & & $(0.66)$ & $(0.48)$ & $(0.74)$ \\
\hline Sanction $(t-3)$ & & -0.03 & $1.22^{*}$ & -0.11 \\
\hline & & $(0.66)$ & $(0.48)$ & $(0.74)$ \\
\hline Sanction $(\mathrm{t}-4)$ & & 0.79 & $-0.97^{*}$ & -1.42 \\
\hline & & $(0.66)$ & $(0.48)$ & $(0.74)$ \\
\hline Sanction (t-5) & & 0.57 & $-1.01^{*}$ & $1.97^{* *}$ \\
\hline & & $(0.66)$ & $(0.48)$ & $(0.74)$ \\
\hline Sanction $(\mathrm{t}-6)$ & & $\begin{array}{r}-0.02 \\
(0.66)\end{array}$ & $\begin{array}{l}-1.40^{* * *} \\
(0.48)\end{array}$ & \\
\hline Sanction (t-7) & & $1.53^{*}$ & & \\
\hline Sanction $(\mathrm{t}-8)$ & & $\begin{array}{l}(0.66) \\
1.18\end{array}$ & & \\
\hline Sanction (t-9) & & $\begin{array}{c}(0.67) \\
0.21\end{array}$ & & \\
\hline Sanction (t-10) & & $(0.69)$ & & \\
\hline & & $(0.67)$ & & \\
\hline Sanction (t-11) & & 1.23 & & \\
\hline Sanction $(\mathrm{t}-12)$ & & -0.35 & & \\
\hline & & $(0.67)$ & & \\
\hline Sanction (t-13) & & 0.07 & & \\
\hline Sanction (t-14) & & & & \\
\hline & & $(0.66)$ & & \\
\hline Sanction threat & 0.05 & 0.19 & 0.26 & -0.11 \\
\hline & $(0.52)$ & $(0.51)$ & $(0.46)$ & $(0.73)$ \\
\hline$\Delta \operatorname{DoS}(\mathrm{t}-1)$ & $-0.26^{* * *}$ & $-0.21^{+* * *}$ & $-0.40^{* *+*}$ & $-0.38^{*+*}$ \\
\hline & $(0.03)$ & $(0.03)$ & $(0.03)$ & $(0.03)$ \\
\hline$\Delta \operatorname{DoS}(\mathrm{t}-2)$ & $-0.21^{* * *}$ & $-0.16^{* * *}$ & $-0.34^{* * *}$ & $-0.22^{+2+t}$ \\
\hline$\Delta \operatorname{DoS}(\mathrm{t}-3)$ & $-0.18^{* * *}$ & $-0.16^{* *+}$ & $\begin{array}{l}(0.03) * 2 \\
-0.22^{* *}\end{array}$ & $\begin{array}{c}(0.03) \\
-0.21^{*+\infty}\end{array}$ \\
\hline & $(0.03)$ & $(0.03)$ & $(0.03)$ & $(0.03)$ \\
\hline$\Delta \operatorname{DoS}(\mathrm{t}-4)$ & $-0.09^{* *}$ & & $-0.22^{* * * *}$ & $-0.09^{* *}$ \\
\hline & $(0.03)$ & & $(0.03)$ & $(0.03)$ \\
\hline$\Delta \operatorname{DoS}(\mathrm{t}-5)$ & -0.05 & & $-0.15^{* *+}$ & $-0.08^{* *}$ \\
\hline & $(0.03)$ & & $(0.03)$ & $(0.03)$ \\
\hline$\Delta \operatorname{DoS}(\mathrm{t}-6)$ & $-0.07^{*}$ & & $-0.10^{* *}$ & $-0.10^{* *}$ \\
\hline & $(0.03)$ & & $(0.03)$ & $(0.03)$ \\
\hline$\Delta \operatorname{DoS}(\mathrm{t}-7)$ & 0.00 & & $-0.09^{* *}$ & -0.04 \\
\hline & $(0.03)$ & & $(0.03)$ & $(0.03)$ \\
\hline$\Delta \operatorname{DoS}(\mathrm{t}-8)$ & -0.02 & & $-0.06^{*}$ & -0.00 \\
\hline & $(0.03)$ & & $(0.03)$ & $(0.03)$ \\
\hline$\Delta \operatorname{DoS}(\mathrm{t}-9)$ & 0.01 & & $-0.08^{*}$ & -0.04 \\
\hline & $(0.03)$ & & $(0.03)$ & $(0.03)$ \\
\hline$\Delta \operatorname{DoS}(\mathrm{t}-10)$ & 0.02 & & $-0.07^{*}$ & -0.01 \\
\hline & $(0.03)$ & & $(0.03)$ & $(0.03)$ \\
\hline$\Delta \operatorname{DoS}(\mathrm{t}-11)$ & -0.05 & & $-0.10^{* *}$ & -0.04 \\
\hline & $(0.03)$ & & $(0.03)$ & $(0.03)$ \\
\hline$\Delta \operatorname{DoS}(\mathrm{t}-12)$ & -0.04 & & $-0.07^{*}$ & -0.03 \\
\hline & $(0.03)$ & & $(0.03)$ & $(0.03)$ \\
\hline$\Delta \operatorname{DoS}(\mathrm{t}-13)$ & -0.02 & & -0.02 & 0.02 \\
\hline & $(0.03)$ & & $(0.03)$ & $(0.03)$ \\
\hline$\Delta \operatorname{DoS}(\mathrm{t}-14)$ & $0.06^{*}$ & & -0.01 & $0.07^{7^{* x}}$ \\
\hline & $(0.03)$ & & $(0.03)$ & $(0.03)$ \\
\hline $\mathrm{R}^{2}$ & 0.10 & 0.08 & 0.19 & 0.16 \\
\hline Adj. $R^{2}$ & 0.09 & 0.07 & 0.17 & 0.15 \\
\hline Num. obs. & 1388 & 1402 & 1375 & 1415 \\
\hline
\end{tabular}

Table D.2: Different Proxy ARDL models. Note: ${ }^{* * *} p<0.001,{ }^{* *} p<0.01,{ }^{*} p<0.05$. 


\begin{tabular}{|c|c|c|c|c|}
\hline & $\Delta$ DoS U.S. $<=2012-01-31$ (GDP) & $\Delta$ DoS U.S. $>2012-01-31$ (GDP) & $\Delta$ DoS E.U. $<=2012-01-31$ (GDP) & $\Delta$ DoS E.U. $>2012-01-31$ (GDP) \\
\hline Sanction & $\begin{array}{c}0.51 \\
(0.75)\end{array}$ & $\begin{array}{c}0.09 \\
(0.66)\end{array}$ & $\begin{array}{c}0.42 \\
(0.60)\end{array}$ & $\begin{array}{c}1.31 \\
(0.73)\end{array}$ \\
\hline \multirow[t]{2}{*}{ Sanction (t-1) } & & -0.55 & & 0.56 \\
\hline & & $(0.66)$ & & $(0.74)$ \\
\hline Sanction (t-2) & & $\begin{array}{c}0.44 \\
(0.66)\end{array}$ & & $\begin{array}{l}-1.27 \\
(0.74)\end{array}$ \\
\hline \multirow[t]{2}{*}{ Sanction (t-3) } & & -0.03 & & -0.11 \\
\hline & & $(0.66)$ & & $(0.74)$ \\
\hline \multirow[t]{2}{*}{ Sanction (t-4) } & & 0.79 & & -1.42 \\
\hline & & $(0.66)$ & & $(0.74)$ \\
\hline \multirow[t]{2}{*}{ Sanction (t-5) } & & 0.57 & & $1.97^{* *}$ \\
\hline & & $(0.66)$ & & $(0.74)$ \\
\hline \multirow[t]{2}{*}{ Sanction (t-6) } & & -0.02 & & \\
\hline & & $(0.66)$ & & \\
\hline \multirow[t]{2}{*}{ Sanction (t-7) } & & $1.53^{*}$ & & \\
\hline & & $(0.66)$ & & \\
\hline Sanction (t-8) & & $\begin{array}{l}1.18 \\
(0.67)\end{array}$ & & \\
\hline \multirow[t]{2}{*}{ Sanction (t-9) } & & 0.21 & & \\
\hline & & $(0.69)$ & & \\
\hline \multirow[t]{2}{*}{ Sanction (t-10) } & & $2.07^{* *}$ & & \\
\hline & & $(0.67)$ & & \\
\hline \multirow[t]{2}{*}{ Sanction (t-11) } & & 1.23 & & \\
\hline & & $(0.67)$ & & \\
\hline \multirow[t]{2}{*}{ Sanction (t-12) } & & -0.35 & & \\
\hline & & $(0.67)$ & & \\
\hline Sanction (t-13) & & $\begin{array}{c}0.07 \\
(0.67)\end{array}$ & & \\
\hline \multirow[t]{2}{*}{ Sanction (t-14) } & & 0.69 & & \\
\hline & & $(0.66)$ & & \\
\hline \multirow{2}{*}{ Sanction threat } & -0.08 & 0.17 & -0.07 & -0.11 \\
\hline & $(0.60)$ & $(0.53)$ & $(0.54)$ & $(0.73)$ \\
\hline$\Delta \operatorname{DoS}(\mathrm{t}-1)$ & $-0.26^{* * *}$ & $-0.21^{* * *}$ & $-0.40^{* * * *}$ & $-0.38^{* * *}$ \\
\hline & $(0.03)$ & $(0.03)$ & $(0.03)$ & $(0.03)$ \\
\hline$\Delta \operatorname{DoS}(\mathrm{t}-2)$ & $-0.21^{* * *}$ & $-0.16^{* * *}$ & $-0.33^{* * *}$ & $-0.22^{* * *}$ \\
\hline & $(0.03)$ & $(0.03)$ & $(0.03)$ & $(0.03)$ \\
\hline$\Delta \operatorname{DoS}(\mathrm{t}-3)$ & $-0.18^{* * *}$ & $-0.16^{* * *}$ & $-0.23^{* * *}$ & $-0.21^{* * *}$ \\
\hline & $(0.03)$ & $(0.03)$ & $(0.03)$ & $(0.03)$ \\
\hline$\Delta \operatorname{DoS}(\mathrm{t}-4)$ & $-0.09^{* *}$ & & $-0.23^{* * *}$ & $-0.09^{* *}$ \\
\hline & $(0.03)$ & & $(0.03)$ & $(0.03)$ \\
\hline$\Delta \operatorname{DoS}(\mathrm{t}-5)$ & -0.05 & & $-0.16^{* * *}$ & $-0.08^{* *}$ \\
\hline & $(0.03)$ & & $(0.03)$ & $(0.03)$ \\
\hline$\Delta \operatorname{DoS}(\mathrm{t}-6)$ & $-0.07^{*}$ & & $-0.11^{* * *}$ & $-0.10^{* *}$ \\
\hline & $(0.03)$ & & $(0.03)$ & $(0.03)$ \\
\hline$\Delta \operatorname{DoS}(\mathrm{t}-7)$ & 0.00 & & $-0.09^{* *}$ & -0.04 \\
\hline & $(0.03)$ & & $(0.03)$ & $(0.03)$ \\
\hline$\Delta \operatorname{DoS}(\mathrm{t}-8)$ & -0.02 & & -0.06 & -0.00 \\
\hline & $(0.03)$ & & $(0.03)$ & $(0.03)$ \\
\hline$\Delta \operatorname{DoS}(\mathrm{t}-9)$ & 0.01 & & $-0.07^{*}$ & -0.04 \\
\hline & $(0.03)$ & & $(0.03)$ & $(0.03)$ \\
\hline$\Delta \operatorname{DoS}(\mathrm{t}-10)$ & 0.03 & & $-0.07^{*}$ & -0.01 \\
\hline & $(0.03)$ & & $(0.03)$ & $(0.03)$ \\
\hline$\Delta \operatorname{DoS}(\mathrm{t}-11)$ & -0.05 & & $-0.10^{* *}$ & -0.04 \\
\hline & $(0.03)$ & & $(0.03)$ & $(0.03)$ \\
\hline$\Delta \operatorname{DoS}(\mathrm{t}-12)$ & -0.04 & & $-0.08^{*}$ & -0.03 \\
\hline & $(0.03)$ & & $(0.03)$ & $(0.03)$ \\
\hline$\Delta \operatorname{DoS}(\mathrm{t}-13)$ & -0.02 & & -0.02 & 0.02 \\
\hline & $(0.03)$ & & $(0.03)$ & $(0.03)$ \\
\hline$\Delta \operatorname{DoS}(\mathrm{t}-14)$ & $0.06^{*}$ & & -0.00 & $0.07^{* *}$ \\
\hline & $(0.03)$ & & $(0.03)$ & $(0.03)$ \\
\hline $\mathrm{R}^{2}$ & 0.10 & 0.08 & 0.17 & 0.16 \\
\hline Adj. $R^{2}$ & 0.09 & 0.07 & 0.16 & 0.15 \\
\hline Num. obs. & 1388 & 1402 & 1375 & 1415 \\
\hline RMSE & 1.46 & 1.62 & 1.16 & 1.64 \\
\hline
\end{tabular}

Table D.3: GDP ARDL models. Note: ${ }^{* * *} p<0.001,{ }^{* *} p<0.01,{ }^{*} p<0.05$. 


\begin{tabular}{|c|c|c|c|c|}
\hline & $\Delta$ DoS U.S. $>$ 2012-02-13 (techno., 50\%) & $\Delta$ DoS U.S. $>2012-02-13$ (techno., $75 \%$ ) & $\Delta$ DoS E.U. $>$ 2012-01-31 (techno., 50\%) & $\Delta$ DoS E.U. $>$ 2012-01-31 (techno., 75\%) \\
\hline Sanction $(\mathrm{t}-1)$ & -0.12 & -0.30 & 0.56 & 0.77 \\
\hline & $(0.73)$ & $(1.15)$ & $(0.74)$ & (1.16) \\
\hline Sanction (t-2) & 0.15 & -0.24 & -1.27 & -2.21 \\
\hline & $(0.73)$ & $(1.15)$ & $(0.74)$ & (1.16) \\
\hline Sanction (t-3) & -0.25 & -0.98 & -0.11 & -1.33 \\
\hline & $(0.73)$ & (1.15) & $(0.74)$ & $(1.16)$ \\
\hline Sanction (t-4) & 0.62 & 1.37 & -1.42 & -2.06 \\
\hline & $(0.73)$ & (1.15) & $(0.74)$ & (1.16) \\
\hline Sanction (t-5) & 0.78 & 2.01 & $1.97^{* *}$ & 2.11 \\
\hline & $(0.73)$ & (1.15) & $(0.74)$ & (1.16) \\
\hline Sanction $(\mathrm{t}-6)$ & $\begin{array}{l}-0.16 \\
(0.73)\end{array}$ & $\begin{array}{c}1.44 \\
(1.15)\end{array}$ & & \\
\hline Sanction (t-7) & $\begin{array}{c}1.21 \\
(0.73)\end{array}$ & $\begin{array}{c}1.53 \\
(1.15)\end{array}$ & & \\
\hline Sanction (t-8) & $\begin{array}{c}0.97 \\
(0.73)\end{array}$ & $\begin{array}{c}0.98 \\
(1.15)\end{array}$ & & \\
\hline Sanction (t-9) & $\begin{array}{c}0.63 \\
(0.74)\end{array}$ & $\begin{array}{c}1.49 \\
(1.15)\end{array}$ & & \\
\hline Sanction (t-10) & $\begin{array}{l}2.22^{* *} \\
(0.73)\end{array}$ & $\begin{array}{c}2.73^{*} \\
(1.15)\end{array}$ & & \\
\hline Sanction $(\mathrm{t}-11)$ & $\begin{array}{c}1.39 \\
(0.73)\end{array}$ & $\begin{array}{l}2.78^{*} \\
(1.15)\end{array}$ & & \\
\hline Sanction (t-12) & $\begin{array}{l}-0.68 \\
(0.73)\end{array}$ & $\begin{array}{c}-2.52^{*} \\
(1.15)\end{array}$ & & \\
\hline Sanction $(\mathrm{t}-13)$ & $\begin{array}{c}0.06 \\
(0.73)\end{array}$ & $\begin{array}{l}-0.42 \\
(1.15)\end{array}$ & & \\
\hline Sanction $(\mathrm{t}-14)$ & $\begin{array}{c}0.46 \\
(0.73)\end{array}$ & $\begin{array}{c}1.75 \\
(1.15)\end{array}$ & & \\
\hline Sanction threat & $\begin{array}{l}-0.48 \\
(0.68)\end{array}$ & $\begin{array}{c}1.39 \\
(1.15)\end{array}$ & $\begin{array}{l}-0.11 \\
(0.73)\end{array}$ & $\begin{array}{l}-0.24 \\
(0.72)\end{array}$ \\
\hline$\Delta \operatorname{DoS}(\mathrm{t}-1)$ & $\begin{array}{c}-0.21^{* * *} \\
(0.03)\end{array}$ & $\begin{array}{c}-0.22^{* * *} \\
(0.03)\end{array}$ & $\begin{array}{c}-0.38^{* * *} \\
(0.03)\end{array}$ & $\begin{array}{c}-0.39^{* * *} \\
(0.03)\end{array}$ \\
\hline$\Delta \operatorname{DoS}(\mathrm{t}-2)$ & $\begin{array}{c}-0.16^{* * *} \\
(0.03)\end{array}$ & $\begin{array}{c}-0.15^{* * *} \\
(0.03)\end{array}$ & $\begin{array}{c}-0.22^{* * *} \\
(0.03)\end{array}$ & $\begin{array}{c}-0.22^{* * *} \\
(0.03)\end{array}$ \\
\hline$\Delta \operatorname{DoS}(\mathrm{t}-3)$ & $\begin{array}{c}-0.16^{* * *} \\
(0.03)\end{array}$ & $\begin{array}{c}-0.16^{* * *} \\
(0.03)\end{array}$ & $\begin{array}{c}-0.21^{* * *} \\
(0.03)\end{array}$ & $\begin{array}{c}-0.20^{* * *} \\
(0.03)\end{array}$ \\
\hline$\Delta \operatorname{DoS}(\mathrm{t}-4)$ & & & $\begin{array}{c}-0.09^{* *} \\
(0.03)\end{array}$ & $\begin{array}{c}-0.08^{* *} \\
(0.03)\end{array}$ \\
\hline$\Delta \operatorname{DoS}(\mathrm{t}-5)$ & & & $\begin{array}{c}-0.08^{* *} \\
(0.03)\end{array}$ & $\begin{array}{c}-0.08^{* *} \\
(0.03)\end{array}$ \\
\hline$\Delta \operatorname{DoS}(\mathrm{t}-6)$ & & & $\begin{array}{c}-0.10^{* *} \\
(0.03)\end{array}$ & $\begin{array}{c}-0.10^{* *} \\
(0.03)\end{array}$ \\
\hline$\Delta \operatorname{DoS}(\mathrm{t}-7)$ & & & $\begin{array}{l}-0.04 \\
(0.03)\end{array}$ & $\begin{array}{l}-0.04 \\
(0.03)\end{array}$ \\
\hline$\Delta \operatorname{DoS}(\mathrm{t}-8)$ & & & $\begin{array}{l}-0.00 \\
(0.03)\end{array}$ & $\begin{array}{l}-0.01 \\
(0.03)\end{array}$ \\
\hline$\Delta \operatorname{DoS}(\mathrm{t}-9)$ & & & $\begin{array}{l}-0.04 \\
(0.03)\end{array}$ & $\begin{array}{l}-0.03 \\
(0.03)\end{array}$ \\
\hline$\Delta \operatorname{DoS}(\mathrm{t}-10)$ & & & $\begin{array}{l}-0.01 \\
(0.03)\end{array}$ & $\begin{array}{l}-0.02 \\
(0.03)\end{array}$ \\
\hline$\Delta \operatorname{DoS}(\mathrm{t}-11)$ & & & $\begin{array}{l}-0.04 \\
(0.03)\end{array}$ & $\begin{array}{l}-0.04 \\
(0.03)\end{array}$ \\
\hline$\Delta \operatorname{DoS}(\mathrm{t}-12)$ & & & $\begin{array}{l}-0.03 \\
(0.03)\end{array}$ & $\begin{array}{l}-0.03 \\
(0.03)\end{array}$ \\
\hline$\Delta \operatorname{DoS}(\mathrm{t}-13)$ & & & $\begin{array}{c}0.02 \\
(0.03)\end{array}$ & $\begin{array}{c}0.02 \\
(0.03)\end{array}$ \\
\hline$\Delta \operatorname{DoS}(\mathrm{t}-14)$ & & & $0.07^{* *}$ & $\begin{array}{c}0.08^{* *} \\
(0.03)\end{array}$ \\
\hline $\mathrm{R}^{2}$ & 0.08 & 0.09 & $\frac{(0.03)}{0.16}$ & $\frac{(0.03)}{0.16}$ \\
\hline Adj. $R^{2}$ & 0.07 & 0.07 & 0.15 & 0.15 \\
\hline Num. obs. & 1402 & 1402 & 1415 & 1415 \\
\hline RMSE & 1.63 & 1.62 & 1.64 & 1.64 \\
\hline
\end{tabular}

Table D.4: Different Thresholds ARDL models. Note: ${ }^{* * *} p<0.001,{ }^{* *} p<0.01,{ }^{*} p<0.05$. 


\begin{tabular}{|c|c|c|c|c|}
\hline & $\Delta \operatorname{DoS}($ world $)<=2012-01-27$ & $\Delta \operatorname{DoS}($ world $)>2012-01-27$ & $\Delta$ DoS (world) $<=2012-01-27$ (techno.) & $\Delta$ DoS (world) $>2012-01-27$ (techno. $)$ \\
\hline \multirow[t]{2}{*}{ Sanction } & 0.41 & 0.08 & -0.05 & 0.06 \\
\hline & & $(0.37)$ & $(0.43)$ & $(0.54)$ \\
\hline Sanction ( $\mathrm{t}-1)$ & & & $\begin{array}{c}0.70 \\
(0.43)\end{array}$ & \\
\hline \multirow[t]{2}{*}{ Sanction (t-2) } & & & -0.41 & \\
\hline & & & $(0.43)$ & \\
\hline \multirow[t]{2}{*}{ Sanction (t-3) } & & & $1.14^{* *}$ & \\
\hline & & & $(0.43)$ & \\
\hline \multirow[t]{2}{*}{ Sanction (t-4) } & & & 0.37 & \\
\hline & & & $(0.43)$ & \\
\hline \multirow[t]{2}{*}{ Sanction (t-5) } & & & $1.11^{* *}$ & \\
\hline & & & $(0.43)$ & \\
\hline \multirow[t]{2}{*}{ Sanction (t-6) } & & & -0.02 & \\
\hline & & & $(0.43)$ & \\
\hline \multirow{2}{*}{ Sanction (t-7) } & & & -0.02 & \\
\hline & & & $(0.43)$ & \\
\hline \multirow[t]{2}{*}{ Sanction (t-8) } & & & -0.78 & \\
\hline & & & $(0.43)$ & \\
\hline \multirow[t]{2}{*}{ Sanction (t-9) } & & & -0.42 & \\
\hline & & & $(0.43)$ & \\
\hline Sanction $(\mathrm{t}-10)$ & & & $(0.43)$ & \\
\hline \multirow[t]{2}{*}{ Sanction (t-11) } & & & $-1.20^{* *}$ & \\
\hline & & & $(0.43)$ & \\
\hline \multirow[t]{2}{*}{ Sanction (t-12) } & & & -0.04 & \\
\hline & & & $(0.43)$ & \\
\hline \multirow[t]{2}{*}{ Sanction (t-13) } & & & 0.41 & \\
\hline & & & $(0.43)$ & \\
\hline Sanction (t-14) & & & -0.05 & \\
\hline & & & $(0.43)$ & \\
\hline Sanction threat & 0.19 & -0.08 & -0.03 & -0.02 \\
\hline & $(0.27)$ & $(0.35)$ & $(0.32)$ & $(0.47)$ \\
\hline Sanction threat $(\mathrm{t}-1)$ & & & -0.53 & \\
\hline & & & $(0.32)$ & \\
\hline$\Delta \operatorname{DoS}(\mathrm{t}-1)$ & $-0.36^{* * *}$ & $-0.30^{* * *}$ & $-0.36^{* * *}$ & $-0.30^{* * *}$ \\
\hline & $(0.03)$ & $(0.03)$ & $(0.03)$ & $(0.03)$ \\
\hline$\Delta \operatorname{DoS}(\mathrm{t}-2)$ & $-0.34^{* * *}$ & $-0.20^{* * *}$ & $-0.34^{* * *}$ & $-0.20^{* * *}$ \\
\hline & $(0.03)$ & $(0.03)$ & $(0.03)$ & $(0.03)$ \\
\hline$\Delta \operatorname{DoS}(\mathrm{t}-3)$ & $-0.24^{* * *}$ & $-0.21^{* * *}$ & $-0.23^{* * *}$ & $-0.21^{* * *}$ \\
\hline & $(0.03)$ & $(0.03)$ & $(0.03)$ & $(0.03)$ \\
\hline$\Delta \operatorname{DoS}(\mathrm{t}-4)$ & $-0.17^{* * *}$ & $-0.08^{* *}$ & $-0.16^{* * *}$ & $-0.09^{* *}$ \\
\hline & $(0.03)$ & $(0.03)$ & $(0.03)$ & $(0.03)$ \\
\hline$\Delta \operatorname{DoS}(\mathrm{t}-5)$ & $-0.15^{* * *}$ & $-0.09^{* *}$ & $-0.13^{* * *}$ & $-0.10^{* * *}$ \\
\hline & $(0.03)$ & $(0.03)$ & $(0.03)$ & $(0.03)$ \\
\hline$\Delta \operatorname{DoS}(\mathrm{t}-6)$ & $-0.10^{* *}$ & $-0.06^{*}$ & $-0.08^{* *}$ & $-0.07^{*}$ \\
\hline & $(0.03)$ & $(0.03)$ & $(0.03)$ & $(0.03)$ \\
\hline$\Delta \operatorname{DoS}(\mathrm{t}-7)$ & -0.04 & $-0.06^{*}$ & & $-0.06^{*}$ \\
\hline & $(0.03)$ & $(0.03)$ & & $(0.03)$ \\
\hline$\Delta \operatorname{DoS}(\mathrm{t}-8)$ & -0.02 & -0.03 & & -0.03 \\
\hline & $(0.03)$ & $(0.03)$ & & $(0.03)$ \\
\hline$\Delta \operatorname{DoS}(\mathrm{t}-9)$ & $-0.07^{*}$ & $-0.06^{*}$ & & $-0.06^{*}$ \\
\hline & $(0.03)$ & $(0.03)$ & & $(0.03)$ \\
\hline$\Delta \operatorname{DoS}(\mathrm{t}-10)$ & $-0.07^{*}$ & -0.03 & & -0.04 \\
\hline & $(0.03)$ & $(0.03)$ & & $(0.03)$ \\
\hline$\Delta \operatorname{DoS}(\mathrm{t}-11)$ & $-0.07^{*}$ & -0.05 & & -0.05 \\
\hline & $(0.03)$ & $(0.03)$ & & $(0.03)$ \\
\hline$\Delta \operatorname{DoS}(\mathrm{t}-12)$ & -0.05 & -0.04 & & -0.04 \\
\hline & (0.03) & $(0.03)$ & & (0.03) \\
\hline$\Delta \operatorname{DoS}(\mathrm{t}-13)$ & -0.03 & -0.01 & & -0.01 \\
\hline & $(0.03)$ & $(0.03)$ & & $(0.03)$ \\
\hline$\Delta \operatorname{DoS}(\mathrm{t}-14)$ & 0.01 & 0.04 & & 0.04 \\
\hline & (0.03) & $(0.03)$ & & $(0.03)$ \\
\hline $\mathrm{R}^{2}$ & 0.16 & 0.12 & 0.17 & 0.11 \\
\hline Adj. $R^{2}$ & 0.15 & 0.11 & 0.16 & 0.10 \\
\hline Num. obs. & 1396 & 1394 & 1396 & 1394 \\
\hline RMSE & 0.96 & 1.32 & 0.95 & 1.32 \\
\hline
\end{tabular}

Table D.5: World ARDL models. Note: ${ }^{* * *} p<0.001,{ }^{* *} p<0.01,{ }^{*} p<0.05$. 


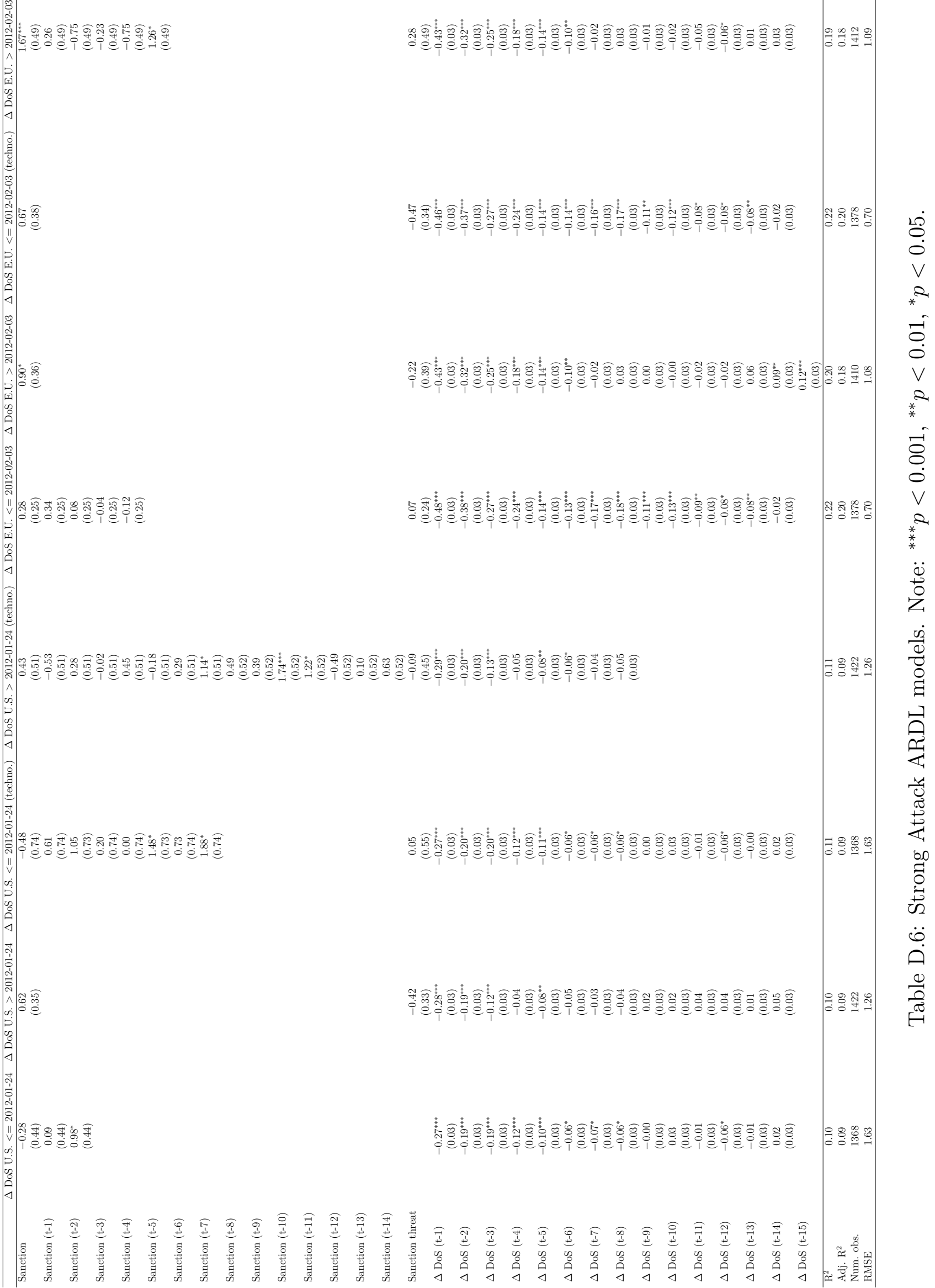




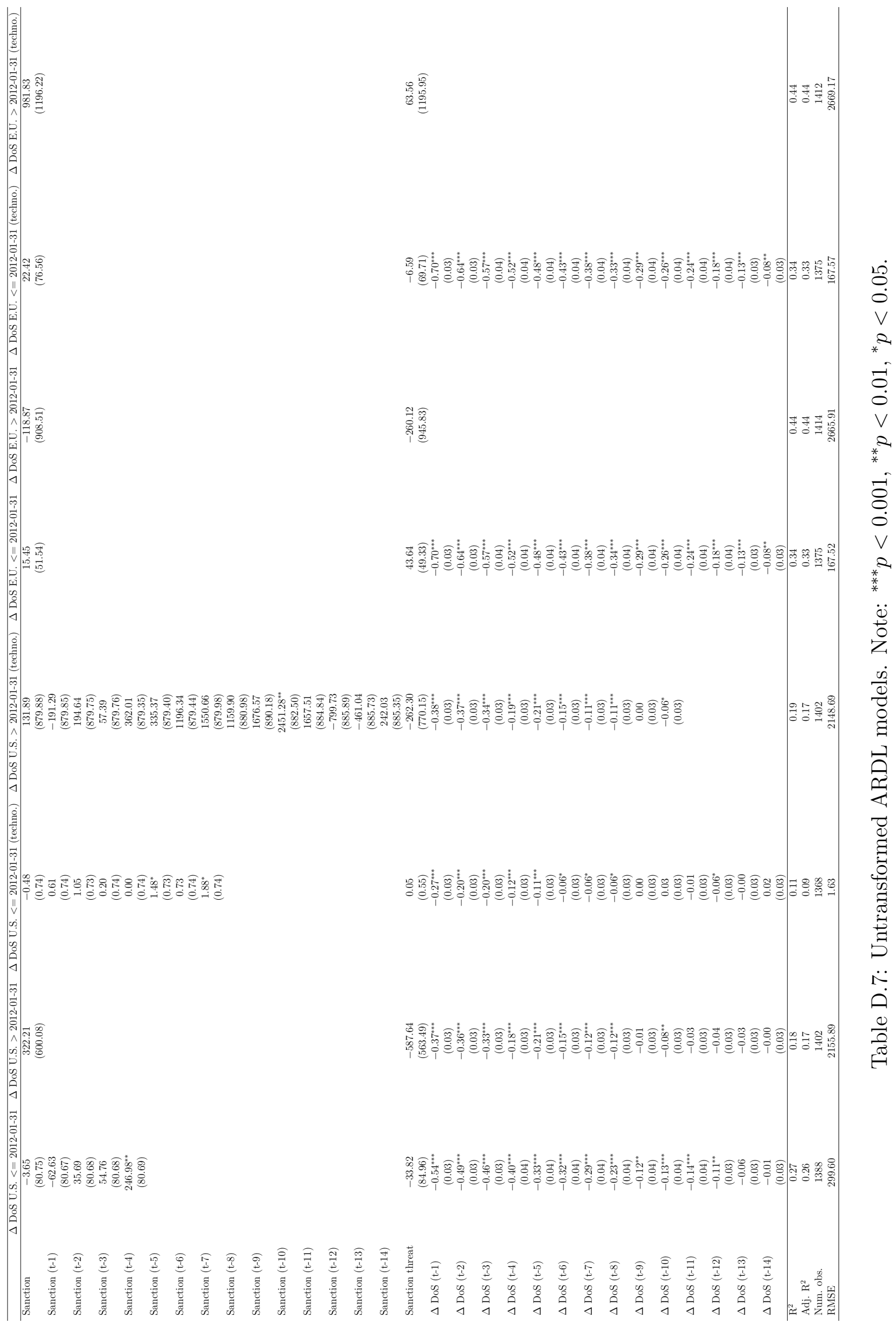




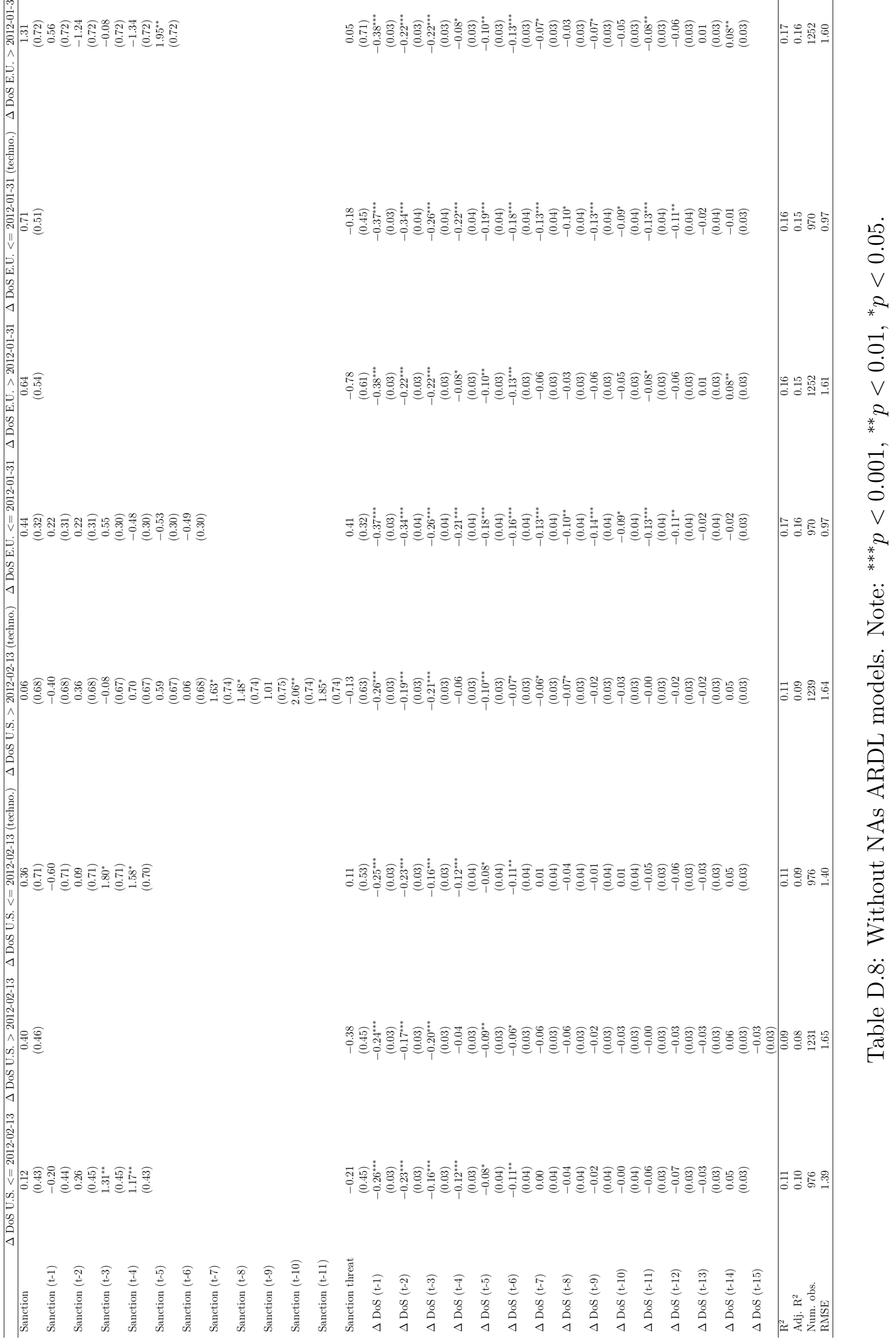




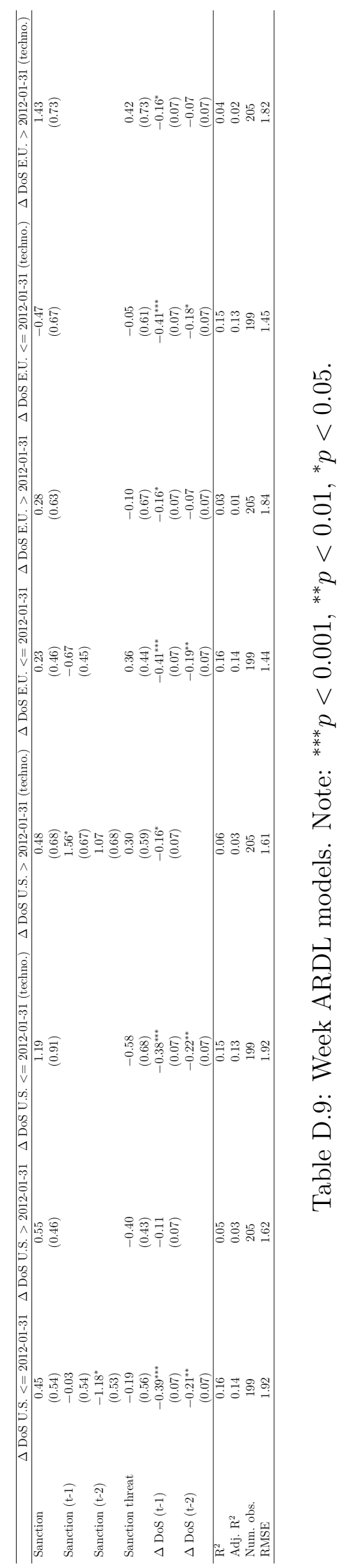




\begin{tabular}{llll}
\hline$\Delta$ DoS & Imposition & Threat & Model \\
\hline 21 & 4 & 0 & U.S. $<=2012-02-13$ \\
21 & 0 & 0 & U.S. $>2012-02-13$ \\
21 & 0 & 1 & U.S. (techno.) $<=2012-02-13$ \\
21 & 11 & 0 & U.S. (techno.) $>2012-02-13$ \\
21 & 6 & 0 & E.U. $<=2012-01-31$ \\
21 & 0 & 2 & E.U. $>2012-01-31$ \\
21 & 0 & 0 & E.U. (techno.) $<=2012-01-31$ \\
21 & 5 & 0 & E.U. (techno.) $>2012-01-31$ \\
\hline
\end{tabular}

Table D.10: Suggested lags when expanding maximal lag length to 21 days. Note: Models with best AIC values are chosen. 


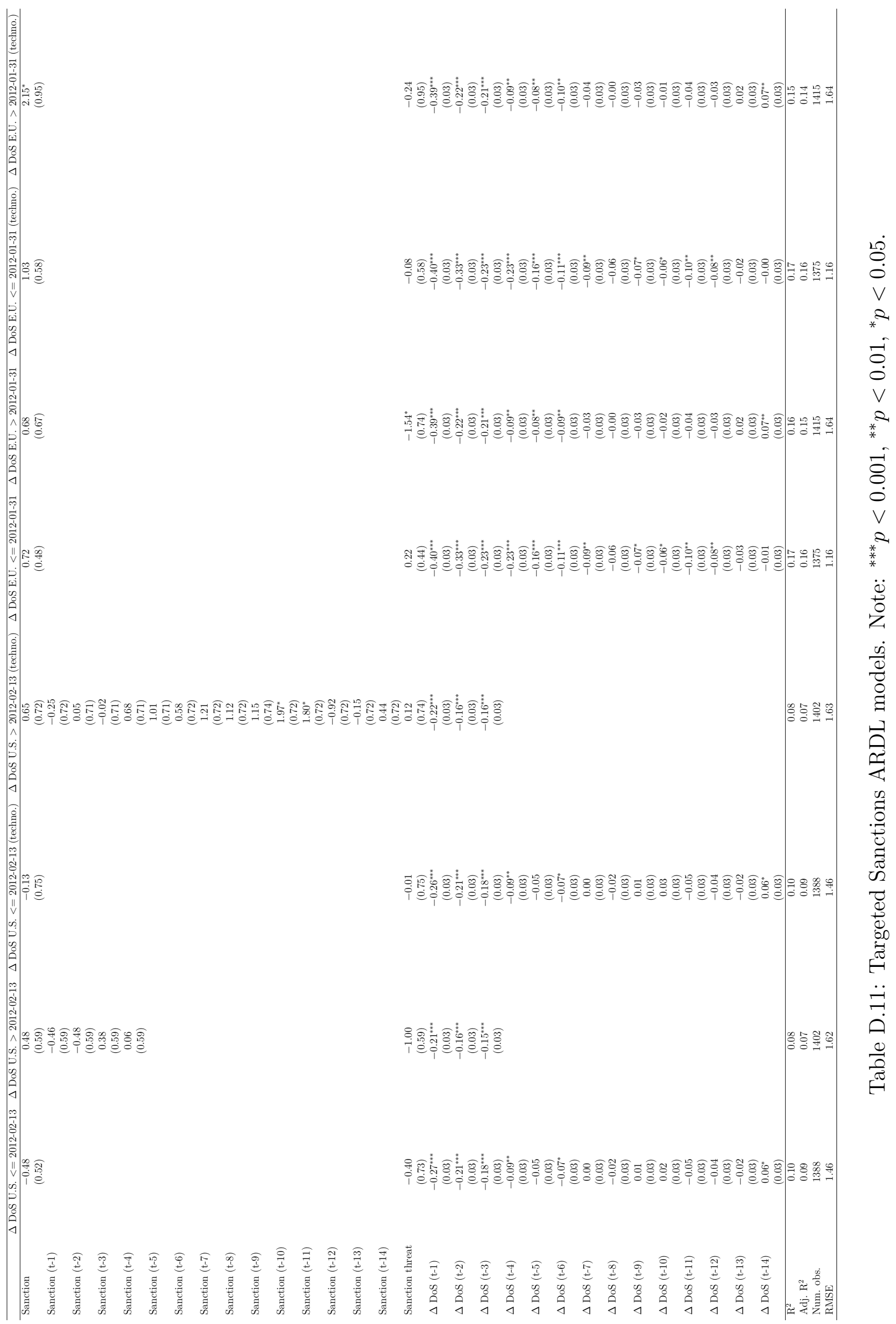




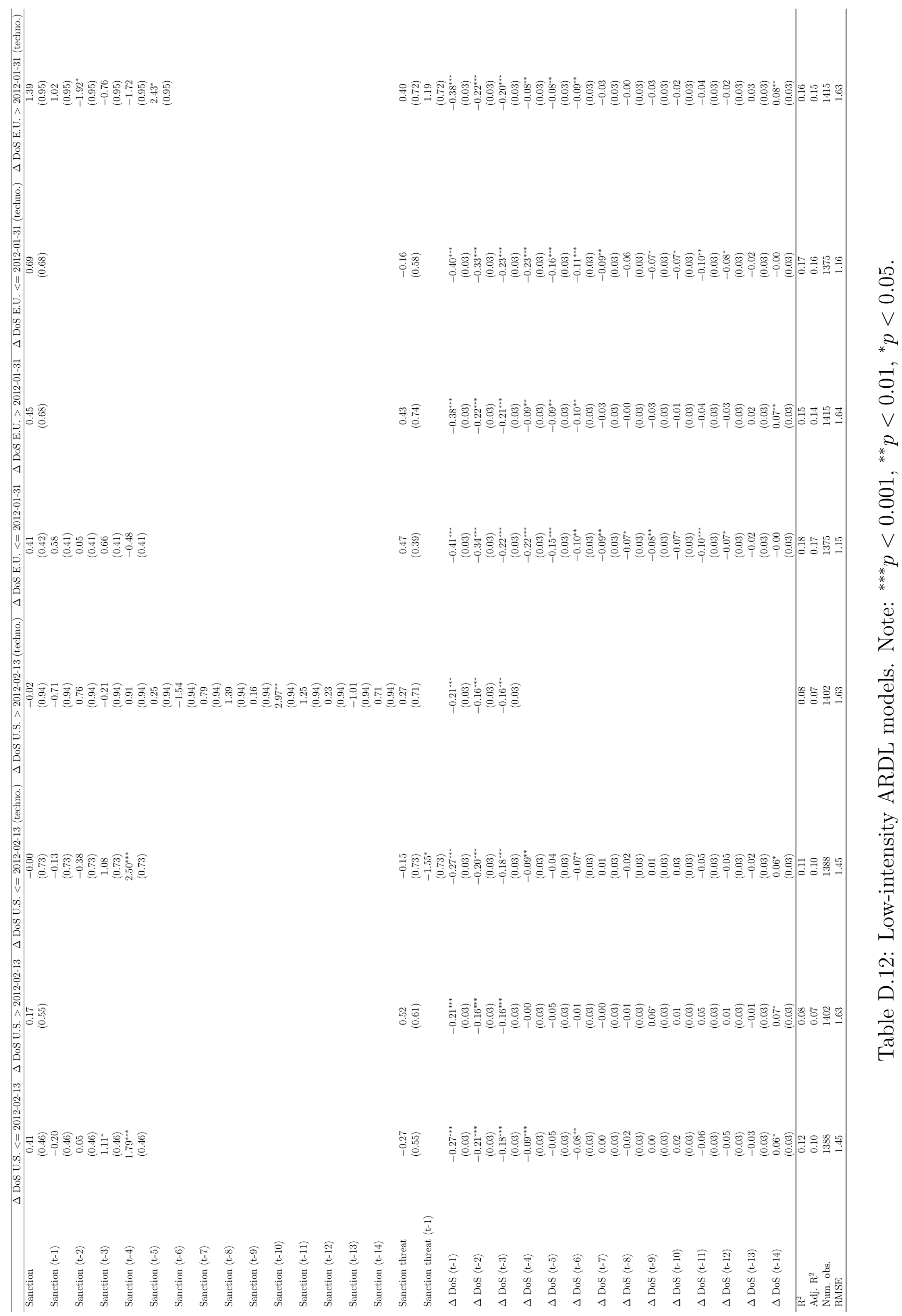




\begin{tabular}{|c|c|c|c|c|}
\hline & $\Delta$ DoS U.S. $<=2012-02-13$ & $\Delta$ DoS U.S. $>2012-02-13$ & $\Delta$ DoS E.U. $<=2012-01-31$ & $\Delta$ DoS E.U. $>2012-01-31$ \\
\hline Sanction & $\begin{array}{l}-0.72 \\
(1.45)\end{array}$ & $\begin{array}{c}2.03 \\
(1.62)\end{array}$ & $\begin{array}{c}2.01 \\
(1.16)\end{array}$ & $\begin{array}{c}4.06^{*} \\
(1.65)\end{array}$ \\
\hline Sanction (t-1) & $\begin{array}{c}0.74 \\
(1.45)\end{array}$ & $\begin{array}{l}-0.07 \\
(1.62)\end{array}$ & & $\begin{array}{c}0.05 \\
(1.65)\end{array}$ \\
\hline Sanction (t-2) & $\begin{array}{l}-0.69 \\
(1.45)\end{array}$ & $\begin{array}{c}0.21 \\
(1.62)\end{array}$ & & $\begin{array}{l}-3.78^{*} \\
(1.65)\end{array}$ \\
\hline Sanction $(\mathrm{t}-3)$ & $\begin{array}{c}1.53 \\
(1.45)\end{array}$ & $\begin{array}{l}-0.45 \\
(1.62)\end{array}$ & & $\begin{array}{l}-0.77 \\
(1.65)\end{array}$ \\
\hline Sanction $(\mathrm{t}-4)$ & $\begin{array}{l}3.14^{*} \\
(1.45)\end{array}$ & $\begin{array}{c}0.74 \\
(1.62)\end{array}$ & & $\begin{array}{l}-3.71^{*} \\
(1.65)\end{array}$ \\
\hline Sanction (t-5) & $\begin{array}{l}3.16^{*} \\
(1.45)\end{array}$ & $\begin{array}{l}1.48 \\
(1.62)\end{array}$ & & \\
\hline Sanction (t-6) & $\begin{array}{l}4.10^{* *} \\
(1.45)\end{array}$ & $\begin{array}{l}-2.08 \\
(1.62)\end{array}$ & & \\
\hline Sanction (t-7) & $\begin{array}{l}5.56^{* * *} \\
(1.46)\end{array}$ & $\begin{array}{l}-1.62 \\
(1.62)\end{array}$ & & \\
\hline Sanction (t-8) & $\begin{array}{l}-1.54 \\
(1.46)\end{array}$ & $\begin{array}{c}1.64 \\
(1.62)\end{array}$ & & \\
\hline Sanction (t-9) & $\begin{array}{l}-1.75 \\
(1.46)\end{array}$ & $\begin{array}{l}3.71^{*} \\
(1.62)\end{array}$ & & \\
\hline Sanction (t-10) & $\begin{array}{l}-3.31^{*} \\
(1.46)\end{array}$ & $\begin{array}{l}4.51^{* *} \\
(1.63)\end{array}$ & & \\
\hline Sanction (t-11) & $\begin{array}{c}0.31 \\
(1.47)\end{array}$ & $\begin{array}{c}3.67^{*} \\
(1.63)\end{array}$ & & \\
\hline Sanction (t-12) & $\begin{array}{l}-3.00^{*} \\
(1.47)\end{array}$ & $\begin{array}{l}-0.72 \\
(1.63)\end{array}$ & & \\
\hline Sanction (t-13) & $\begin{array}{l}-2.46 \\
(1.47)\end{array}$ & $\begin{array}{l}-3.95^{*} \\
(1.63)\end{array}$ & & \\
\hline Sanction (t-14) & & $\begin{array}{c}0.06 \\
(1.63)\end{array}$ & & \\
\hline$\Delta \operatorname{DoS}(\mathrm{t}-1)$ & $\begin{array}{c}-0.28^{* * *} \\
(0.03)\end{array}$ & $\begin{array}{c}-0.22^{* * *} \\
(0.03)\end{array}$ & $\begin{array}{c}-0.40^{* * *} \\
(0.03)\end{array}$ & $\begin{array}{c}-0.39^{* * *} \\
(0.03)\end{array}$ \\
\hline$\Delta \operatorname{DoS}(\mathrm{t}-2)$ & $\begin{array}{c}-0.22^{* * *} \\
(0.03)\end{array}$ & $\begin{array}{c}-0.16^{* * *} \\
(0.03)\end{array}$ & $\begin{array}{c}-0.34^{* * *} \\
(0.03)\end{array}$ & $\begin{array}{c}-0.22^{* * *} \\
(0.03)\end{array}$ \\
\hline$\Delta \operatorname{DoS}(\mathrm{t}-3)$ & $\begin{array}{c}-0.19^{* * *} \\
(0.03)\end{array}$ & $\begin{array}{c}-0.15^{* * *} \\
(0.03)\end{array}$ & $\begin{array}{c}-0.23^{* * *} \\
(0.03)\end{array}$ & $\begin{array}{c}-0.21^{* * *} \\
(0.03)\end{array}$ \\
\hline$\Delta \operatorname{DoS}(\mathrm{t}-4)$ & $\begin{array}{c}-0.10^{* * *} \\
(0.03)\end{array}$ & & $\begin{array}{c}-0.23^{* * *} \\
(0.03)\end{array}$ & $\begin{array}{c}-0.08^{* *} \\
(0.03)\end{array}$ \\
\hline$\Delta \operatorname{DoS}(\mathrm{t}-5)$ & $\begin{array}{l}-0.04 \\
(0.03)\end{array}$ & & $\begin{array}{c}-0.16^{* * *} \\
(0.03)\end{array}$ & $\begin{array}{l}-0.07^{*} \\
(0.03)\end{array}$ \\
\hline$\Delta \operatorname{DoS}(\mathrm{t}-6)$ & $\begin{array}{l}-0.06^{*} \\
(0.03)\end{array}$ & & $\begin{array}{c}-0.11^{* * *} \\
(0.03)\end{array}$ & $\begin{array}{l}-0.09^{* *} \\
(0.03)\end{array}$ \\
\hline$\Delta \operatorname{DoS}(\mathrm{t}-7)$ & $\begin{array}{c}0.02 \\
(0.03)\end{array}$ & & $\begin{array}{c}-0.09^{* *} \\
(0.03)\end{array}$ & $\begin{array}{l}-0.03 \\
(0.03)\end{array}$ \\
\hline$\Delta \operatorname{DoS}(\mathrm{t}-8)$ & $\begin{array}{l}-0.01 \\
(0.03)\end{array}$ & & $\begin{array}{l}-0.06 \\
(0.03)\end{array}$ & $\begin{array}{l}-0.00 \\
(0.03)\end{array}$ \\
\hline$\Delta \operatorname{DoS}(\mathrm{t}-9)$ & $\begin{array}{c}0.02 \\
(0.03)\end{array}$ & & $\begin{array}{l}-0.07^{*} \\
(0.03)\end{array}$ & $\begin{array}{l}-0.03 \\
(0.03)\end{array}$ \\
\hline$\Delta \operatorname{DoS}(\mathrm{t}-10)$ & $\begin{array}{c}0.04 \\
(0.03)\end{array}$ & & $\begin{array}{l}-0.07^{*} \\
(0.03)\end{array}$ & $\begin{array}{l}-0.02 \\
(0.03)\end{array}$ \\
\hline$\Delta \operatorname{DoS}(\mathrm{t}-11)$ & $\begin{array}{l}-0.04 \\
(0.03)\end{array}$ & & $\begin{array}{c}-0.10^{* * *} \\
(0.03)\end{array}$ & $\begin{array}{l}-0.04 \\
(0.03)\end{array}$ \\
\hline$\Delta \operatorname{DoS}(\mathrm{t}-12)$ & $\begin{array}{l}-0.03 \\
(0.03)\end{array}$ & & $\begin{array}{c}-0.08^{* *} \\
(0.03)\end{array}$ & $\begin{array}{l}-0.03 \\
(0.03)\end{array}$ \\
\hline$\Delta \operatorname{DoS}(\mathrm{t}-13)$ & $\begin{array}{l}-0.01 \\
(0.03)\end{array}$ & & $\begin{array}{l}-0.02 \\
(0.03)\end{array}$ & $\begin{array}{c}0.02 \\
(0.03)\end{array}$ \\
\hline$\Delta \operatorname{DoS}(\mathrm{t}-14)$ & $\begin{array}{l}0.05^{*} \\
(0.03)\end{array}$ & & $\begin{array}{l}-0.00 \\
(0.03)\end{array}$ & $\begin{array}{l}0.07^{* *} \\
(0.03)\end{array}$ \\
\hline Sanction threat & & & $\begin{array}{c}0.06 \\
(1.17)\end{array}$ & \\
\hline $\mathrm{R}^{2}$ & 0.13 & 0.09 & 0.17 & 0.16 \\
\hline Adj. $R^{2}$ & 0.12 & 0.07 & 0.16 & 0.15 \\
\hline Num. obs. & 1388 & 1402 & 1375 & 1415 \\
\hline RMSE & 1.44 & 1.62 & 1.16 & 1.64 \\
\hline
\end{tabular}

Table D.13: High-intensity sanctions ARDL models. Note: ${ }^{* * *} p<0.001,{ }^{* *} p<0.01$, ${ }^{*} p<0.05$. 


\begin{tabular}{|c|c|}
\hline & $\Delta$ DoS U.S. $>$ 2012-02-13 (techno.) - without Russia \\
\hline \multirow[t]{2}{*}{ Sanction } & -0.31 \\
\hline & $(0.73)$ \\
\hline \multirow[t]{2}{*}{ Sanction (t-1) } & -0.65 \\
\hline & $(0.73)$ \\
\hline \multirow[t]{2}{*}{ Sanction (t-2) } & 0.47 \\
\hline & $(0.73)$ \\
\hline \multirow[t]{2}{*}{ Sanction (t-3) } & 0.03 \\
\hline & $(0.73)$ \\
\hline \multirow[t]{2}{*}{ Sanction (t-4) } & 0.79 \\
\hline & $(0.73)$ \\
\hline \multirow[t]{2}{*}{ Sanction (t-5) } & 0.37 \\
\hline & $(0.73)$ \\
\hline \multirow[t]{2}{*}{ Sanction (t-6) } & 0.37 \\
\hline & $(0.73)$ \\
\hline \multirow[t]{2}{*}{ Sanction (t-7) } & $2.14^{* *}$ \\
\hline & $(0.73)$ \\
\hline \multirow[t]{2}{*}{ Sanction (t-8) } & 1.06 \\
\hline & $(0.73)$ \\
\hline \multirow[t]{2}{*}{ Sanction (t-9) } & -0.39 \\
\hline & $(0.74)$ \\
\hline \multirow[t]{2}{*}{ Sanction (t-10) } & $1.57^{*}$ \\
\hline & $(0.73)$ \\
\hline \multirow[t]{2}{*}{ Sanction (t-11) } & 0.72 \\
\hline & $(0.73)$ \\
\hline \multirow[t]{2}{*}{ Sanction (t-12) } & -0.29 \\
\hline & $(0.73)$ \\
\hline \multirow{2}{*}{ Sanction (t-13) } & 0.74 \\
\hline & $(0.73)$ \\
\hline \multirow[t]{2}{*}{ Sanction (t-14) } & 0.70 \\
\hline & $(0.73)$ \\
\hline \multirow[t]{2}{*}{ Sanction threat } & -0.18 \\
\hline & $(0.58)$ \\
\hline \multirow[t]{2}{*}{$\Delta \operatorname{DoS}(\mathrm{t}-1)$} & $-0.21^{* * *}$ \\
\hline & $(0.03)$ \\
\hline \multirow[t]{2}{*}{$\Delta \operatorname{DoS}(\mathrm{t}-2)$} & $-0.16^{* * *}$ \\
\hline & $(0.03)$ \\
\hline \multirow[t]{2}{*}{$\Delta \operatorname{DoS}(\mathrm{t}-3)$} & $-0.16^{* * *}$ \\
\hline & $(0.03)$ \\
\hline $\mathrm{R}^{2}$ & 0.08 \\
\hline Adj. $R^{2}$ & 0.07 \\
\hline Num. obs. & 1402 \\
\hline RMSE & 1.63 \\
\hline
\end{tabular}

Table D.14: Sanctions on techno. countries without Russia ARDL models. Note: ${ }^{* * *} p<$ $0.001,{ }^{* *} p<0.01,{ }^{*} p<0.05$. 


\section{References}

Burnham, Kenneth P and David R Anderson. 2004. "Multimodel Inference: Understanding AIC and BIC in Model Selection." Sociological Methods 85 Research 33(2):261-304.

Fisher, Max and Jared Keller. 2011. "Syria's Digital Counter-Revolutionaries." The Atlantic. https://www.theatlantic.com/international/archive/2011/08/syriasdigital-counter-revolutionaries/244382/ (accessed 29-07-2019).

Gardner, G, Andrew C Harvey and Garry DA Phillips. 1980. "Algorithm AS 154: An Algorithm for Exact Maximum Likelihood Estimation of Autoregressive-moving Average Models by Means of Kalman Filtering." Journal of the Royal Statistical Society. Series C (Applied Statistics) 29(3):311-322.

Hawkins, DM and S Weisberg. 2017. "Combining the Box-cox Power and Generalised Log Transformations to Accommodate Nonpositive Responses in Linear and Mixed-effects Linear Models." South African Statistical Journal 51(2):317-328.

Hellmeier, Sebastian. 2020. "How Foreign Pressure Affects Mass Mobilization in Favor of Authoritarian Regimes." European Journal of International Relations Online First:128.

HP Security Research. 2014. "Threat Intelligence Briefing Episode 11.". https://docplayer.net/48764481-Threat-intelligence-briefing-episode11-february-2014.html (accessed 10-14-2020).

ITU, International Communication Union. 2017. "The ICT Development Index (IDI): Conceptual Framework and Methodology.". https://www.itu.int/en/ITU-D/ Statistics/Pages/publications/mis2017/methodology.aspx.

Moritz, Steffen and Thomas Bartz-Beielstein. 2017. "imputeTS: Time Series Missing Value Imputation in R." The R Journal 9(1):207-218.

Pettitt, AN. 1979. "A Non-parametric Approach to the Change-point Problem." Journal of the Royal Statistical Society: Series C (Applied Statistics) 28(2):126-135. 
Philips, Andrew Q. 2018. "Have Your Cake and Eat It Too? Cointegration and Dynamic Inference from Autoregressive Distributed Lag Models." American Journal of Political Science 62(1):230-244.

Valeriano, Brandon, Benjamin M Jensen and Ryan C Maness. 2018. Cyber Strategy: The Evolving Character of Power and Coercion. Oxford: Oxford University Press.

Verstraeten, Gert, Jean Poesen, Gaston Demarée and Christian Salles. 2006. "Long-term (105 years) Variability in Rain Erosivity as Derived From 10-min Rainfall Depth Data for Ukkel (Brussels, Belgium): Implications for Assessing Soil Erosion Rates." Journal of Geophysical Research: Atmospheres 111(D22).

Volz, Dustin. 2018. "U.S. Charges, Sanctions Iranians for Global Cyber Attacks on Behalf of Tehran." Reuters, March 23. https://www.reuters.com/article/us-usacyber-iran/u-s-charges-sanctions-iranians-for-global-cyber-attacks-onbehalf-of-tehran-idUSKBN1GZ22K (accessed 07-30-2019).

Wooldridge, Jeffrey M. 2015. Introductory Econometrics: A Modern Approach. Toronto: Nelson Education.

World Bank. 2019. World Development Indicators. World Bank. 